Portland State University

PDXScholar

$5-22-2020$

\title{
In Search of a Third Place on Campus: an Exploration of the Effects of Built Space on Students' Sense of Belonging
}

Kimberly S. Stave

Portland State University

Follow this and additional works at: https://pdxscholar.library.pdx.edu/open_access_etds

Part of the Educational Sociology Commons, Higher Education Administration Commons, and the Urban Studies and Planning Commons

Let us know how access to this document benefits you.

\section{Recommended Citation}

Stave, Kimberly S., "In Search of a Third Place on Campus: an Exploration of the Effects of Built Space on Students' Sense of Belonging" (2020). Dissertations and Theses. Paper 5467.

https://doi.org/10.15760/etd.7339

This Dissertation is brought to you for free and open access. It has been accepted for inclusion in Dissertations and Theses by an authorized administrator of PDXScholar. Please contact us if we can make this document more accessible: pdxscholar@pdx.edu. 


\title{
In Search of a Third Place on Campus:
}

An Exploration of the Effects of Built Space on Students' Sense of Belonging

by

Kimberly S. Stave

A dissertation submitted in partial fulfillment of the requirements for the degree of

\section{Doctor of Education}

in

Educational Leadership: Postsecondary Education

\author{
Dissertation Committee: \\ Karen Haley, Chair \\ Andy Job \\ Christopher Miller \\ Lynn Santelmann
}

Portland State University 2020 


\begin{abstract}
Despite decades of environmental behavior research demonstrating the impact physical space has on human behavior, the American university has been slow to adopt this data into campus design and renovation plans. Campus ecology literature has demonstrated that the physical environment of the university campus communicates messages that influence students' feelings of well-being, mattering, and inclusion within the campus community, all significant contributors to student learning and retention.

Campus spaces designed for community building are essential to cultivate a sense of belonging for university students, however, locations dedicated to this type of social interaction, such as third places, are an often-underestimated consideration within built campus design. Therefore, the purposes of this study were to explore the effects of built space on students' sense of belonging as fostered through the identification and utilization of third places on campus, and to assess if the built campus environment is important for supporting an institutional commitment to a vibrant campus community.

The data for this exploratory study was collected through a qualitative embedded case study including student and employee interviews and campus observation at a small, rural, residential, private university in the Pacific Northwest of the United States whose institutional values identify a commitment to nurturing a robust student community. The five key findings of the study were: the impact of campus topography on student engagement, the social importance of campus pathways, the effect of location on building use, the influence of place-based campus traditions on students' sense of belonging, and the correlation between sense of belonging and campus third places.
\end{abstract}




\section{DEDICATION}

I dedicate this dissertation to my children,

Ieva Kirstine

Isak Andrius

Greta Louise

You are my sunshine and my greatest joy!

While producing this dissertation is something I'm extremely proud of,

it is nothing compared to how proud I am to be your mom.

I've done this work with the prayer that through it, you would see the value of dedication to a goal, of accomplishing what you might think impossible, and the amazing benefits of being a life-long learner. I'm the first of my family line to achieve a doctorate, and 20 years ago I never would have imagined it true.

I can't wait to see what dreams you accomplish and all the firsts you achieve! You will each go far in your own unique ways. And wherever you go, I'll be there in spirit cheering you on. 


\section{ACKNOWLEDGMENTS}

This dissertation journey has been possible due to the many strong shoulders I have stood upon well before and throughout this endeavor. As someone who hardly thought she was smart enough to get a bachelor's degree, the achievement of a doctorate feels nothing short of an act of God. Which, indeed, it sincerely has been. To Him who has gone before and behind, who has placed every person and situation in my life for reasons beyond my understanding, and who has provided through every step...to Him be all the glory for this amazing accomplishment.

A depth of gratitude to the village who has surrounded me in encouragement and grace:

To the incredible network of women in academia who have mentored, modeled, challenged, bolstered, and reminded me of countless timely truths along the way: I thank you. You have paved the path to demonstrate that I could, indeed, one day join your ranks. And now here I am, in large part due to you. Dr. Sarah Baldwin, my earliest professional inspiration and dear friend from the day you modeled the crucial balance of grace and justice at Spring Arbor; Dr. Eileen Hulme, who challenged me to think bigger professionally during my first year as an $\mathrm{RD}$ and again 22 years later following my last year as a Dean; Dr. Mel Humphreys, who gave me my first opportunity to speak into floor plan designs, prompting this entire project and passion; Dr. Shirley Hoogstra, for balancing professional savvy with personal care while tirelessly advocating for women's leadership development, shaping me tremendously; Dr. Becky Josberger, who made herself available at a crucible moment to look me in the eye and tell me what mattered most for my education; and Dr. Edee Schulze, Dr. Karen Longman, Dr. Amy 
VanDerWerf Carroll, and so many others who have given incredible educational and professional advice, and have demonstrated true superpowers of encouragement.

To the ACSD community, as an association you are what fuels my strength of connectedness. I can't imagine a professional life without such a phenomenal network of colleagues and friends. Through employment transitions, you provided consistency for service, for support, and for professional development. Thank you for the research grant! My role on the Executive Committee these past four years have been a gift to my soul.

To the Corban University community and particularly my campus liaison, Dean Nathan Geer, I am grateful for your hospitably allowing me to spend significant time on your campus, essentially putting it under a microscope for the sake of my research. It is my sincere hope that this study benefits the Corban campus as it continues to emphasize a commitment to students' social engagement in a vibrant, Christ-centered community.

To Dr. Christopher Miller, providential mentor and content specialist. When I first heard you present at the CCCU International Forum in early 2018, you gave language to concepts I sensed but didn't know, sparking a passion which aligned so strongly with my research interest that I couldn't help but seek every opportunity to learn from you. Thank you for making time to teach and guide me in this endeavor, for joining my committee, and for introducing me to third place, new urbanism, the hospitality of architecture, the Inhabit Conference, and so much more.

To our incredible EdD cohort: I can't imagine having done this with a more inspiring group of colleagues. When I chose a cohort-based program, I had high hopes for 
a cohort I would enjoy and feel supported by, and you've far exceeded my hopes with your grit, your thoughtfulness, and your laughter. I am so grateful for each one of you!

To my extraordinary advisor-turned-friend, Dr. Karen Haley. The personal investment you've made in me and my research still boggles my mind. From our first coffee meeting about the program, to the classes you taught, to the group study sessions in year 3, to the coaching you've given for my research and my career, you've provided the perfect amount of challenge and support, always embedded in care. God knew you were exactly who I needed to walk me through this life-changing journey. Thank you doesn't begin to cover the extent of my gratitude.

To my parents, Buz \& Barb Cliffe, the embodiment of selfless support and neverending encouragement. Thank you for always believing in me and my capabilities, for pointing me to my true source of strength, and for consistently reminding me who I belong to. I love you!

And to my steady \& supportive husband Andrew, the stabilizing force behind all my crazy ideas who has never stopped believing in me; and to our amazing kids: Ieva, Isak \& Greta. You four have sacrificed so much for me to pursue this calling, and I am so thankful to each one of you! You are what has kept me going; your hugs, encouraging words, and hand-written notes are what motivated me to get up at 4:00 am and have helped me through the long days. You four are my rock. You have my heart forever. 


\section{Table of Contents}

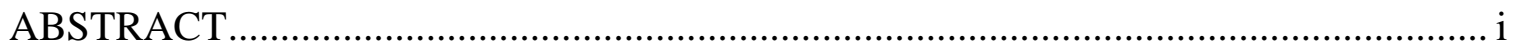

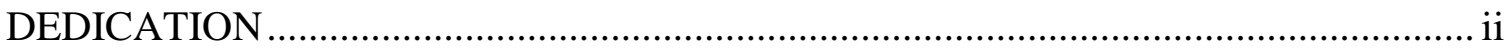

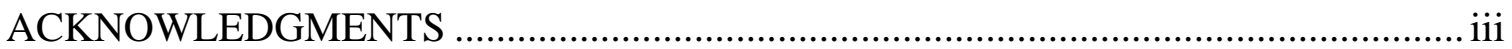

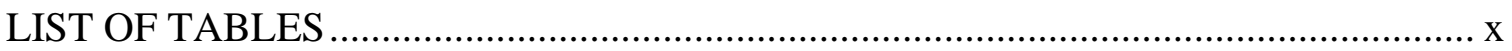

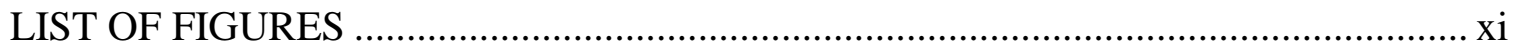

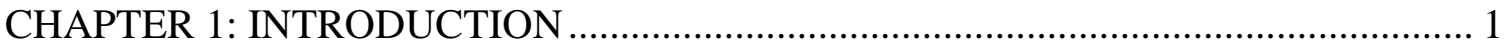

Background of the Problem ...................................................................................... 3

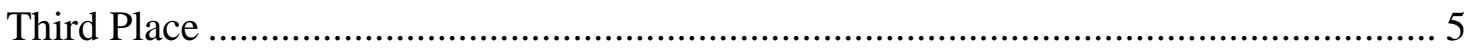

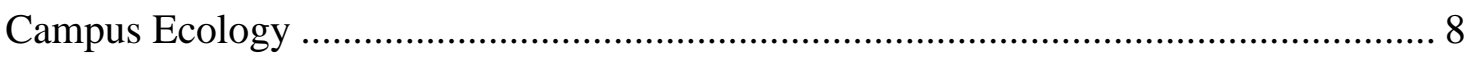

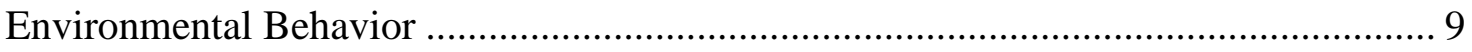

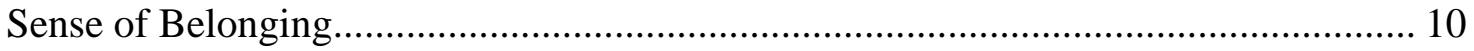

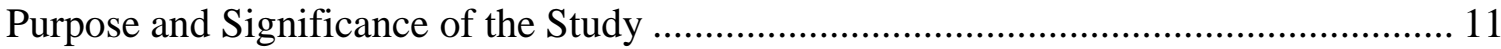

Conceptual Framework and Research Questions ............................................................. 12

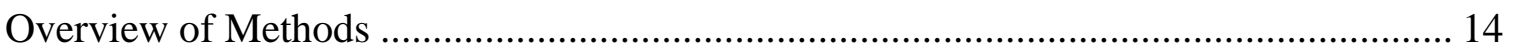

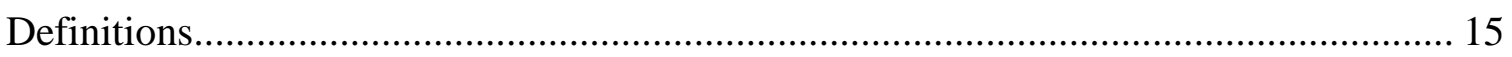

Small Colleges/Universities ............................................................................ 15

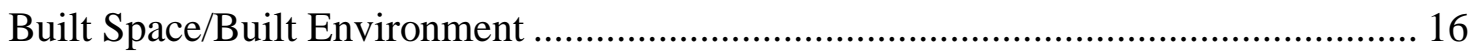

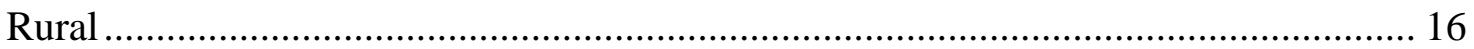

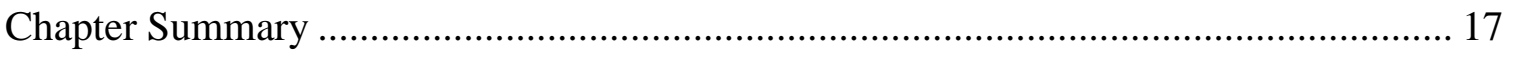

CHAPTER 2: REVIEW OF THE LITERATURE ………........................................ 19

The Ecological Perspective of Student Development..................................................... 20

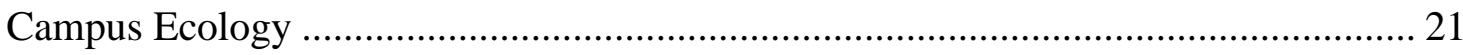

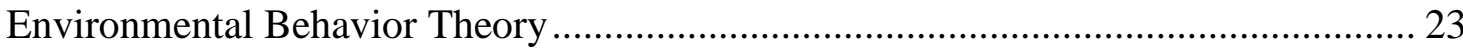

Proxemic Behavior Theory ………………………………………………….... 25

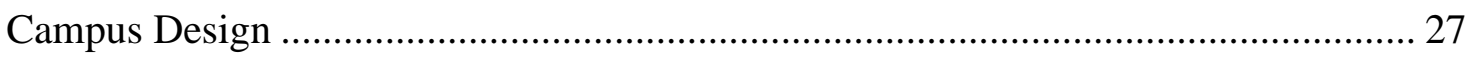

College Student Sense of Belonging and Campus Space .............................................. 33

Pedagogy and Sense of Belonging ............................................................................ 34

Inclusion and Sense of Belonging ....................................................................... 35

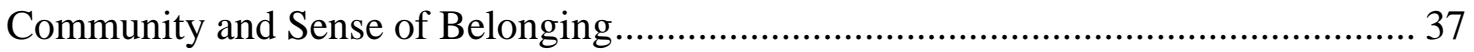

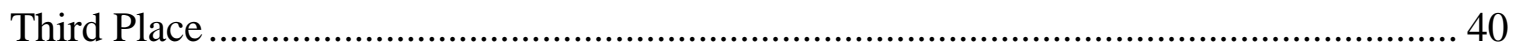




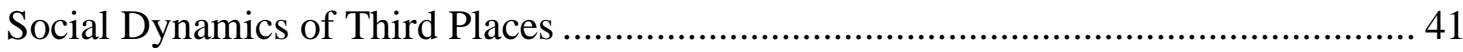

Physical Characteristics of Third Places .................................................................... 45

Third Places on the College Campus ....................................................................... 47

The Council for Christian Colleges and Universities (CCCU)......................................... 50

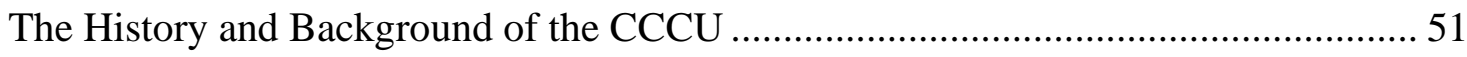

Common Commitment to Campus Community Development ...................................... 52

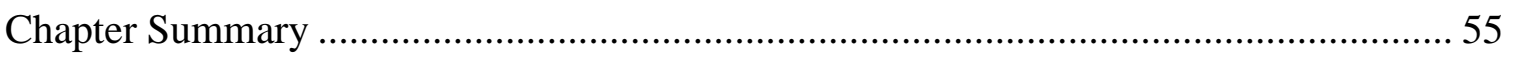

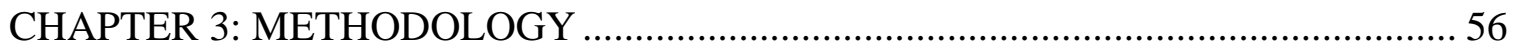

Research Problem, Questions and Qualitative Methodology ………………………....... 57

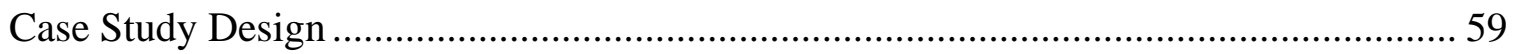

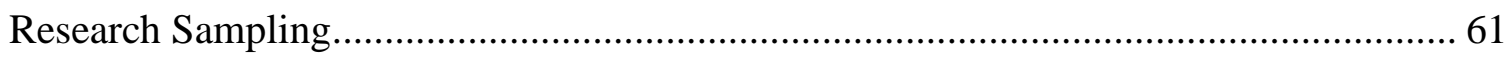

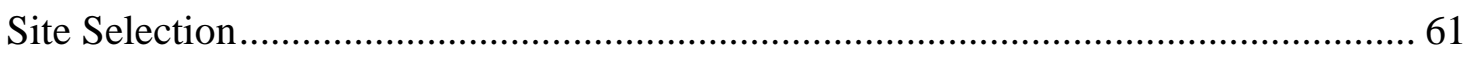

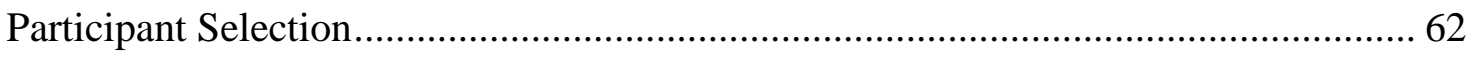

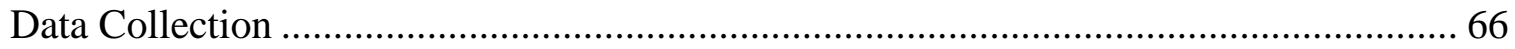

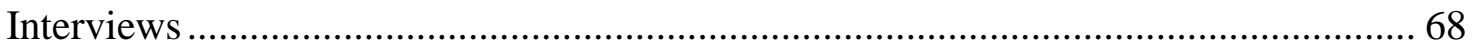

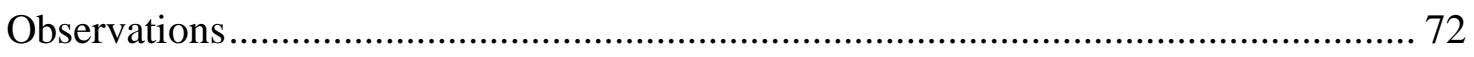

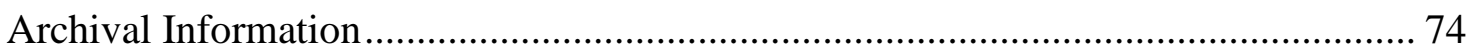

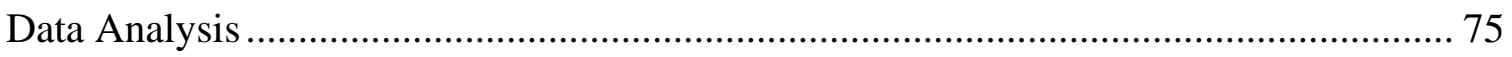

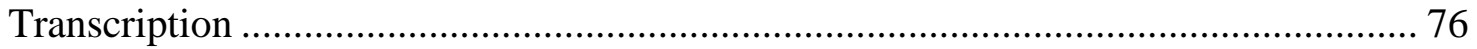

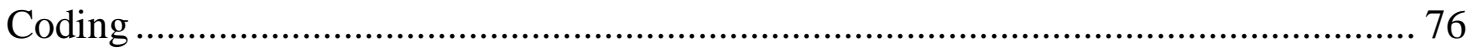

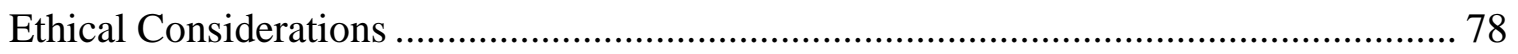

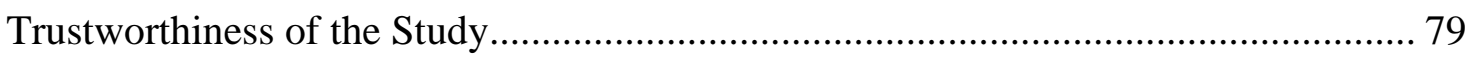

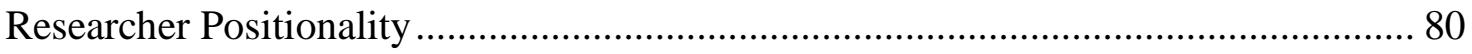

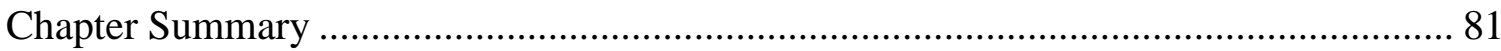

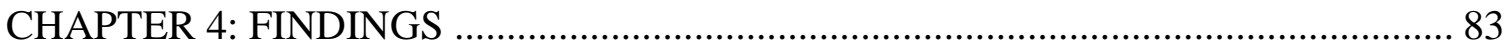

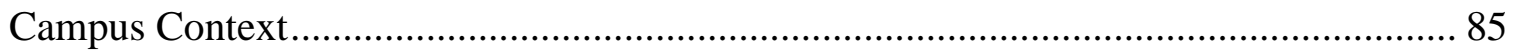

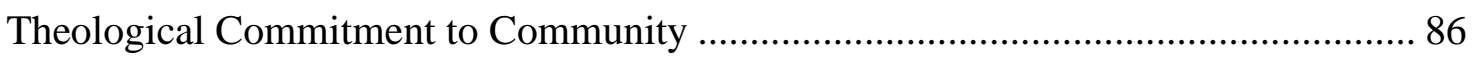

University Administration's Commitment to Community............................................. 87

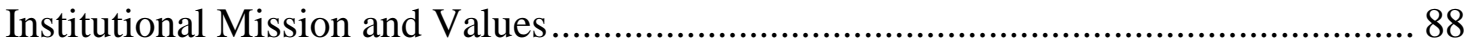

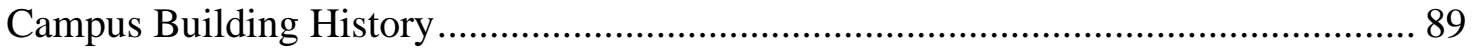

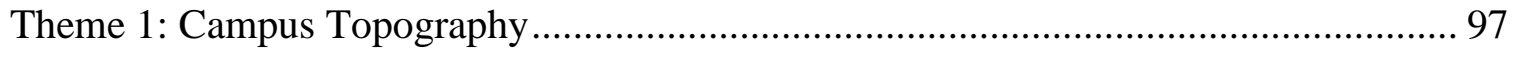




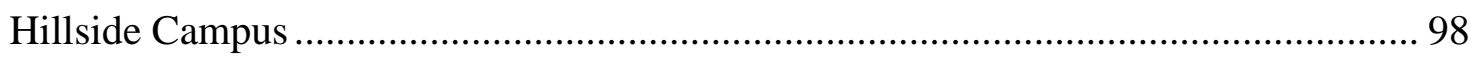

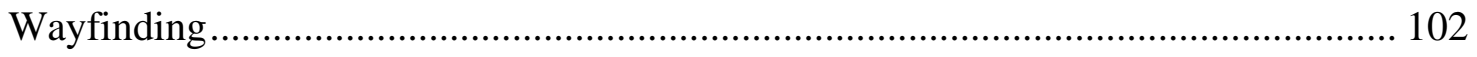

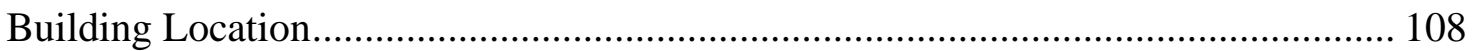

Theme 2: Campus Infrastructure ……………………...................................... 114

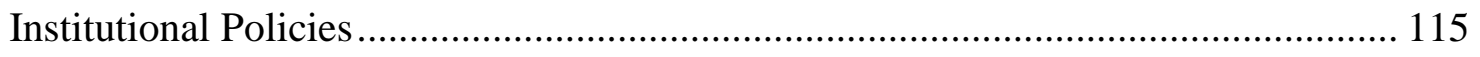

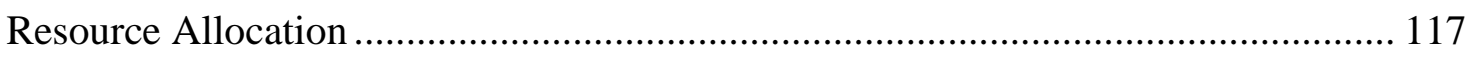

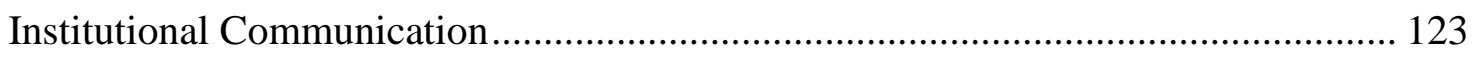

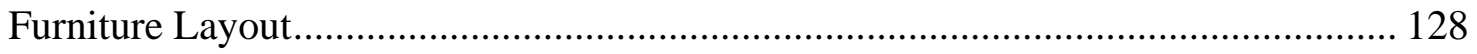

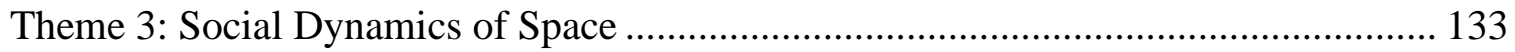

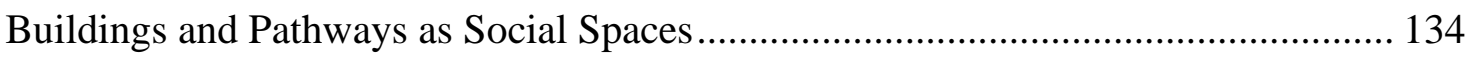

Affinity Groups Formed through Campus Spaces ................................................. 136

Campus Traditions Shaped by Campus Spaces ........................................................ 140

Residence Hall Lobbies as Social Spaces ................................................................ 144

Campus Coffee Shop as Social Space .................................................................. 148

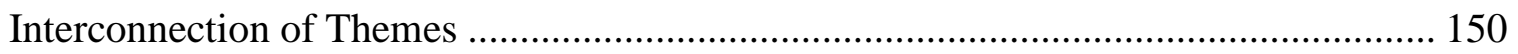

CHAPTER 5: DISCUSSION AND IMPLICATIONS ………………………........... 152

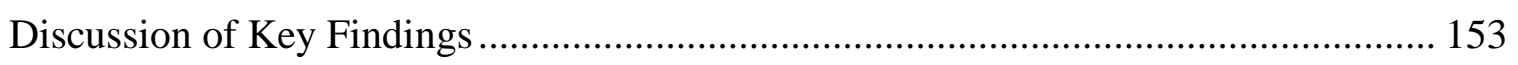

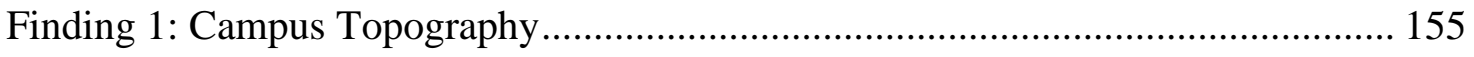

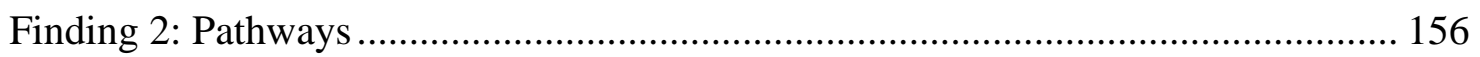

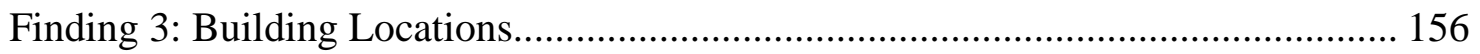

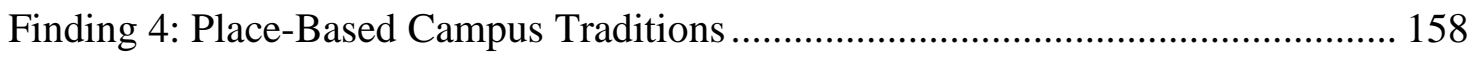

Finding 5: Sense of Belonging in Campus Third Places............................................. 159

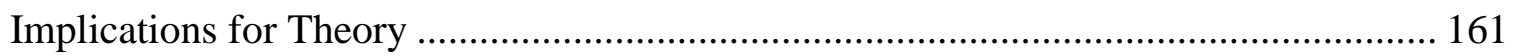

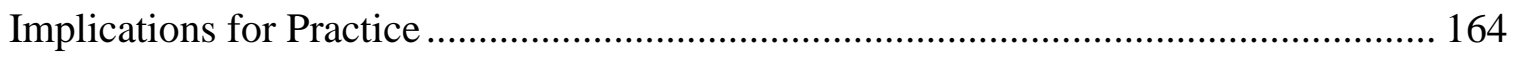

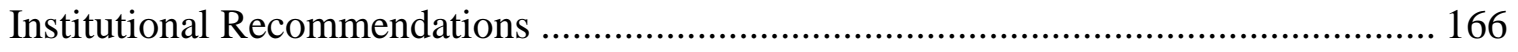

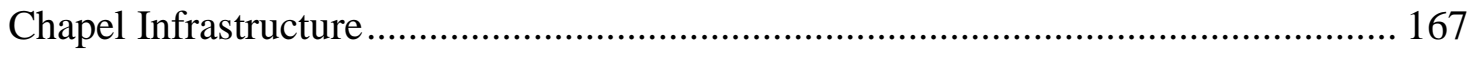

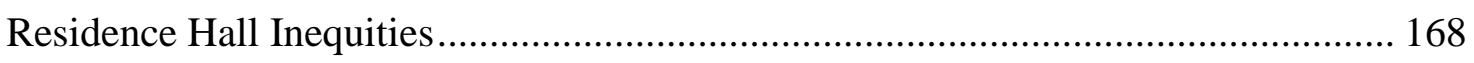

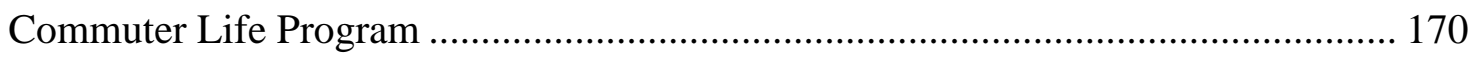

Limitations and Further Research ...................................................................... 170

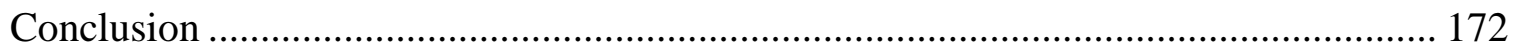

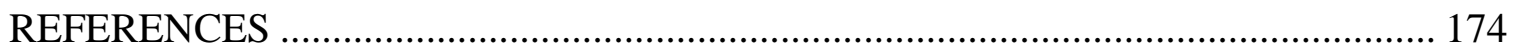


APPENDIX A: PARTICIPANT EMAIL INVITATIONS....................................... 189

APPENDIX B: CONSENT TO PARTICIPATE IN RESEARCH ….......................... 191

APPENDIX C: PARTICIPANT INTERVIEW QUESTIONS .................................... 194

APPENDIX D: PRE- AND POST- INTERVIEW FIELDNOTE FRAMEWORK ....... 197

APPENDIX E: ANTICIPATED PROVISIONAL CODES …..................................... 199

APPENDIX F: CORBAN UNIVERSITY CAMPUS MAP ....................................... 202 


\section{LIST OF TABLES}

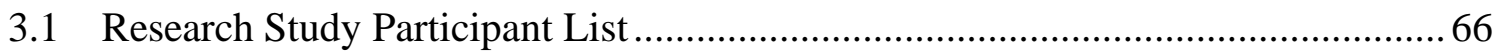

4.1 Emergent Themes and Supporting Subthemes .............................................. 83

5.1 Intersections of the Study's Research Questions, Data Themes,

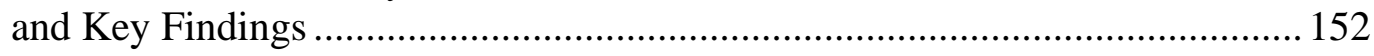

5.2 Characteristic Comparison of Home, Neighborhood Third Places,

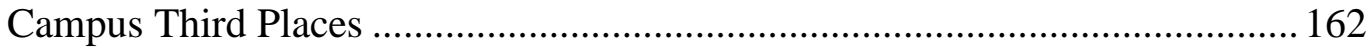




\section{LIST OF FIGURES}

2.1 Sociofugal (A) and Sociopetal (B) Classroom Designs ..........................................2 25

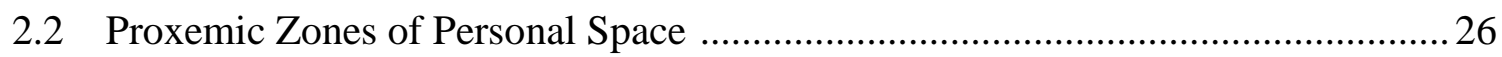

2.3 Continuum of User-Centered Theories of the Built Environment ..........................30

2.4 Lecture Hall Seat Spacing ................................................................................. 32

3.1 A Single, Embedded Case Study Design Diagram ………………………….........60

4.1 Schimmel Hall, Oregon Deaf-Mute School circa 1895, and Current Day ............. 91

4.2 Corban University Campus Care Facility; Originally a Horse Stable 1897 ........... 92

4.3 1912 Milk Barn and Engine Room Turned Current Day Maker Space...................93

4.4 Open-Air Sleeping Pavilion for Patients, Tuberculosis Hospital, 1920 ................. 94

4.5 Corban University's Pavilion Built in 1923, Photo from 2020 .............................. 94

4.6 1932 Tuberculosis Hospital; Corban Univ. Current Academic Center ...................95

4.7 Farrar Hall: Oldest Residence Hall on Corban's Campus, Built 1934 _.................. 96

4.8 Aagard Hall: Hospital's Last Construction Project remaining at Corban................97

4.9 Topographic Map Demonstrating Hillside Incline on Corban's Campus ...............98

4.10 Satellite Map Showing Forest Density on Corban University's Campus............... 99

4.11 Corban University Campus Map with Legend ...................................................... 100

4.12 The Pavilion Sign Identifies the Student Center and Classrooms ......................... 107

4.13 Campus Map with Central Building Cluster Circled in Blue .............................. 110

4.14 The Klatch: Outdoor Gathering Space with a Fireplace for Student Use ............. 120

4.15 Landscaping on Corban's Campus Accentuates Natural Green Space ……….... 121 


\section{CHAPTER 1: INTRODUCTION}

"The university environment is part of the learning experience, and buildings need to be silent teachers...the principle of academic mission being expressed or explored through the estate of buildings is an important one" (Edwards, 2014, p. 1).

For decades, environmental behavior theorists have argued that physical space impacts behavior (Altman, 1970, 1975; Hall, 1966), and yet this has been largely neglected in campus design. Since Banning (1978) coined the terminology of campus ecology in the 1970s, the literature has demonstrated that the physical environment of the university campus communicates messages that influence students' feelings of wellbeing, belonging, and identity, all which aid in the learning process (Kuh, Kinzie, Schuh, \& Whitt, 2005; Moos, 1979; Renn \& Patton, 2010; Scott-Webber, 2004, 2017; Strange \& Banning, 2001, 2015). However, despite the vast recognition that universities exist for the holistic development and education of students, a mere collection of buildings and spaces on a campus does not, on its own accord, create a sense of belonging or an environment of intellectual challenge (Edwards, 2014). "Knowing how people occupy and interact with campus environments — and how those environments influence people — is an important element in understanding contexts for leadership, organizational change, and student learning” (Renn \& Patton, 2010, p. 260). To cultivate a sense of belonging for university students through the built environment, spaces designed for community building are an essential contributor to the discovery of common interests (Strange \& Banning, 2015). Locations dedicated to this type of social interaction are an oftenunderestimated consideration within built campus design, despite the data demonstrating the need to place greater emphasis on such areas to increase student satisfaction (Miller, 
Bender and Schuh, 2005). This study explores the interconnection between built campus spaces designed for social engagement and students' sense of belonging to the university.

As the researcher, my interest in this topic grew from the opportunities I was given to contribute to the design of built campus environments, and the positive social impact I witnessed on the students who functioned within those spaces. It began in the early 2000s when I managed the residence life program at an international university in the former Soviet Republic of Lithuania, where more than 20 nationalities were represented within the 600-person student body. The majority of these students lived in a residence hall leased by the university, which also happened to be a former soviet army barrack. Most students hailed from post-soviet countries, and predominantly chose to occupy their 4-person residence hall rooms with peers from their own ethnic background. The university did not provide institutional food service, so students prepared their own meals in private kitchenettes within each residence hall room. Due to broad cultural biases often perpetuated in their home countries promoting negative stereotypes of other cultures, many students had no interest in exploring relationships beyond their own ethnic groups. The characteristic soviet-style low trust social environment combined with a traditionally designed austere dormitory building resulted in long, dark corridors of closed doors and minimal student interaction cross-culturally.

I had the opportunity to contribute to the design of a new residence hall building project and promoted a building design with floor pods consisting of 5 small bedrooms without kitchenettes surrounding a large shared kitchen \& lounge. When students moved in, they still predominately chose to live with roommates from similar cultures, and many 
initially complained that the rooms were too small for cooking. Eventually, however, the common kitchens were filled with students from multiple nationalities observing the variety of ways they each cooked potatoes (among other dishes), which led to discussions about their families, which led to humanizing one another as more than just the cultural stereotype they had been taught, which led to multicultural friendships. Within an academic year, the student body was significantly more culturally unified and socially integrated. The design of the built environment influenced students' behaviors, broke down social barriers, and created a rich multicultural community.

\section{Background of the Problem}

Over recent decades, campus ecology research done by Banning (1978), Moos (1979), Strange \& Banning (2001), Kuh et al. (2005), and Scott-Webber (2017) has demonstrated that the physical environment of the university campus has a significant influence on students' sense of belonging and well-being. Research by Hurtado (2012), Schlossberg, Lassalle, \& Golec (1990), Strayhorn (2012) and others identify a direct link between students' psychological sense of belonging within the university community to academic achievement, satisfaction, and retention. And while the belonging research has prompted many educators to evaluate student involvement models, residential communities, and other programmatic initiatives, institutions are largely not considering the influence of built campus space on students' sense of belonging. As Winston Churchill said in a speech to the House of Commons in 1943, "We shape our buildings, and afterwards our buildings shape us" (Hightower, 2017, para.7). Strange and Banning (2015) translated Churchill's frequently-utilized observation into the context of the 
university campus to demonstrate the influence buildings and space design have on college students as they experience the daily rhythm of campus life.

The built campus space can bring students together and encourage exploration, collaboration, growth, and connection, or it can carry a message of silence and disconnectedness (Oblinger, 2006). Unfortunately, American higher education has been slow to update built campus designs, despite the needs and expectations of current-day students being significantly different from that of their predecessors (Strange \& Banning, 2015). Most university facilities were designed with a combination of utilitarian and elitist assumptions about the purpose and function of a campus that are now obsolete, and subsequently students and faculty have developed a belief that college life consists of sterile spaces lacking in creativity, unable to accommodate modern pedagogical approaches, and uncomfortable for supporting a wide variety of adult bodies (Chism \& Bickford, 2002). While this is not an ideal reality, institutional lack of regard for the research, conflicting priorities within organizational leadership, high demand on limited institutional resources, and disputes with local civic agencies can prevent institutions from developing updated campus plans with student learning and engagement at the center (Strange \& Banning, 2015). Following is an introduction to the sociological concept of third place, an overview of the study's conceptual framework of campus ecology including environmental behavior theory, the theoretical framework of sense of belonging, and the two problem statements undergirding the study. 


\section{Third Place}

Hurtado (2012) asserts that a student's ability to "fit" within a campus community has as much as do with the student themselves as it does with the educational environment and affirms that it is the responsibility of the university to create social niches where students can establish a sense of community based on common affinity (as cited in Strayhorn 2012, p. ix). Sociologist Oldenburg (1989) defines a similar social niche as a "third place" — a social environment or physical space outside of home (the first place) and work (the second place), that lends itself to frequent interpersonal connections and is important for establishing a sense of place, engaging with civic responsibility, and developing community. In neighborhoods, third places are often unassuming local businesses like coffee shops, bookstores, or bars where people gather for leisure, social connection, and engaging in important conversation; in these spaces friends unite, and new friends are introduced to the community (Oldenburg, 1989). Sociological research regarding the impact of third places on neighborhood community building has only recently been conducted within the university environment. When transferring third place descriptors from a neighborhood to a residential post-secondary educational context, the definition of a first place for college students would be their campus living environment (e.g., residence hall room or campus apartment) with academic environments (e.g., classrooms or laboratories) serving as their second places (Waxman et al., 2007). One value of intentionally developing third places on colleges campuses is that they promote informal learning through the social discourse occurring 
within them and foster the formation of student community (Banning \& Bryner, 2001; Oldenburg, 1989; Santasiero, 2002).

A vibrant student community provides individual students a shared purpose, as well as a sense of meaning, belonging, and mattering (Boyer, 1987; Schlossberg, 1989; Taub, 2008). As the student body of today's universities continue to diversify, the desire for a community that connects individual students around common purposes continues to be an expressed priority of the traditionally aged college student (Cheng, 2004). Institutional prioritization of the development of this type of community demonstrates a value for each member, as a healthy student community encourages individuals to see beyond themselves and to foster a sense of responsibility and commitment to one another (Taub, 2008). Intentionally developed campus third places contribute to the development of a vibrant student community, as they provide a stronger sense of belonging for students and an increased desire for involvement in the life of the institution (Banning et al., 2006).

For small, rural, residential campuses where students don't have walkable access to off-campus third places for social activities, there is an increased need for intentionally developed on-campus spaces and programs which can positively contribute to meeting students' needs for inclusion and belonging (Banning, Clemons, McKelfresh, \& Gibbs, 2010). A university's location and proximity to off-campus resources are significant contributors to the degree students choose to be engaged and involved in the campus community (Strange \& Banning, 2015). However, every campus location, regardless if it is geographically isolated or within the center of a metropolis, can be capitalized on for 
the benefit of student learning and engagement (Kuh, et al., 2005; Kuh, Schuh, \& Whitt, 1991). Particularly for rural residential institutions who articulate a missional value of cultivating a vibrant student community, a lack of built campus spaces for student engagement could be detrimental to achieving their stated institutional goals.

A 2006 study asking college students to locate the space on campus which best fit the description of a third place found that nearly $80 \%$ of the students identified their third place off campus (Banning et al., 2010). This data should cause concern for rural institutions who place high value on social connection and sense of belonging within their student community as third places are significant contributors to both. The literature also suggests that the presence of intentionally designed third places on campus are linked to higher retention rates, increased alumni giving, and making the campus look more attractive to prospective students (Banning et al., 2010; Reeve and Kassabaum, 1997).

A study by Waxman (2006) found that the more often people frequent a third place, the stronger their feelings of attachment to the place becomes, as well as to the community within it. "The underlying concept of this research was that a university is a community unto itself and the design of spaces within the university can greatly impact the student's experience and attitude toward college life" (Waxman et al., 2007). Any campus space designed for students to engage socially, from dining services to recreation centers, can generally play an important role in the development of healthy community on a college campus, as they provide students a safe haven to interact and relax outside of their home or work environment (Butts, Beltramini, Bourassa, Connelly, Meyer, 
Mitchell, Smith, \& Willis, 2012). It follows that campus spaces specifically designed for community building would attract students, connecting them more deeply with their peers and with their campus environment, preventing them from feeling they must go off-site in order to build community in a third place location off campus. Campus planning teams have opportunities when evaluating built environments to consider what the space communicates to those who function within it. From representing the mission of the institution to establishing a culture of learning, from communicating a commitment to traditions to providing a sense of belonging, built spaces influence the people who inhabit them (JISC, 2006).

\section{Campus Ecology}

In 1978, Banning developed the theory of campus ecology, focusing on the transactional relationship between students and their campus environment. In his scholarly personal narrative Campus Ecology and University Affairs: History, Applications and Future (Banning, 2016), he describes the foundation of the campus ecology framework growing out of the significant legal and societal changes occurring within the United States in the 1960s in response to unjust environmental conditions. This growing understanding of person-environment interaction laid the foundation for the research of several behavioral theorists' work, which were then applied within the context of the university campus (Walsh, 1978). This began Banning's development of campus ecology theory, which brings human ecology, the study of the relationship between people and their environment (Marten, 2001), to the natural, social, and built elements of the college campus (Banning, 2016). Banning edited the first monograph 
compiling the research of several ecological/environmental psychologists to focus on the interactions between students and their campus environments in the 1978 National Student Personnel Association (NASPA) journal (Blocher). The research on the interaction between the student and the campus environment has increased significantly since the publication of the monograph, and yet too little consideration continues to be given to impact of the built space within which the work of higher education occurs (Temple, 2008).

\section{Environmental Behavior}

The construct of environmental behavior defines an environment as anything surrounding an individual, both built and natural, at both macro and micro levels (ScottWebber, 2004). Environmental behavior defines the human response to a building's physical characteristics (including symbols, furniture design, landscaping, etc.), as well as to the social interactions occurring within the setting of a built space (Altman, 1975). According to the theory of proxemic behavior, the structure of one's spatial environment directly impacts their social interactions (Hall, 1971).

A significant component of environmental behavior is the study of proxemics, which defines how individuals negotiate personal and communal space through a synthesis of sensory inputs, territorial response, and personal boundaries (Scott-Webber, 2004). Hall first defined the concept of personal space in 1959 as "an invisible threedimensional zone surrounding a person, which allows that person to regulate his interactions with the outside world" (as cited in Beaulieu, 2004, p. 794). As personal space and levels of emotional response are largely cultural, Hall's proxemic dimensions 
are used primarily as descriptors of Americans (Hall, 1971). Each of these proxemic zones impact users' communication and behaviors within built space. Hall (1971) asserts that structuring of space occurs at unconscious levels, and while the study of proxemics cannot inform an architect on how to design built space, it can provide important considerations for the process. Further, understanding this conjoined effect of space on behavior enables campus planners as well as educators to develop campuses that support institutional behavioral goals and produce holistically supportive university spaces (Scott-Webber, 2004).

\section{Sense of Belonging}

There is a strong link between built spaces on campus designed for the purpose of community building and increased educational outcomes (Spitzberg \& Thorndike, 1992; Tierney, 1993; Tinto, 2003). When built space is designed to serve as an active component of the educational experience, students have increased rates of learning and engagement (Banning \& Cunard, 1986; Strange \& Banning 2001, 2015). McMillan and Chavis (1986) identify the key components of a psychological sense of community including feelings of belonging, a perception of one's ability to have influence in the community, a shared belief that members' needs will be met by their commitment to be together, and a shared emotional connection. Strange and Banning (2015) identify the educational power of the concept of community, especially given the current "age of increasing social division and fragmentation, especially along lines of class and culture" (p. 214). One retention study found that loyalty to the university was largely determined by the quality of the student relationships formed on campus (Waxman, Clemons, 
Banning \& McKelfresh, 2007). Campus spaces designed to foster community promote unifying values, mutuality of care and responsibility, belonging, self-worth, and a synergy of participation, all which contribute to the elements of a dynamic learning environment (Strange \& Banning, 2015). Campus spaces designed for community building are essential to cultivate a sense of belonging for university students, however, locations dedicated to this type of social interaction, such as third places, are often overlooked within built campus design (Temple, 2009; Strange \& Banning, 2015). Therefore, the two problem statements prompting this study are:

PS1: A lack of dedicated campus space designed to serve the social purposes of third places may hinder students' ability to feel connected to the campus community, especially within geographically rural institutions without third place establishments within a walkable distance from campus.

PS2: A lack of intentionally designed community-building spaces on campus may hinder the development of an interconnected campus community and therefore be preventing the institution from fulfilling a significant component of its mission or values.

\section{Purpose and Significance of the Study}

Today's universities are under scrutiny by constituents ranging from accreditation bodies and government agencies to parents and students driving the institution to ensure it provides the support structures necessary for holistic student success (Reif, 2014). Yet in a study interviewing students on the methods they found most effective to cope with the stressors of college life, the majority reported that social support through talking with friends was preferred over seeking professional help through 
campus resource offices (Robbins \& Tanck, 1995). As such, the expansion of sociallyfocused built campus spaces can assist students in their development of healthy interdependence, leading to a stronger sense of belonging to the campus community (Mallon, 2015). In an era where recruitment and retention are integral to the sustainability of most institutions of higher education, a strong campus community can make the difference between retaining students or losing them to another environment where their need for belonging is met (Leslie \& Brinkman, 1988). Many small, residential colleges and universities with membership in the Council for Christian Colleges and Universities (CCCU) express an institutional value of community building, and yet research suggests that many of their facilities and campus spaces do not reflect that missional priority (Chism \& Bickford, 2002, Temple, 2008, Strange \& Banning, 2015). Therefore, due to the ecological connections between the sense of belonging literature and the sociological influence of third places, the purpose of this study was to explore the effects of built space on students' sense of belonging at a small, residential, rural university campus as fostered through the identification and utilization of third places. The study also explored how built campus space supported the expressed institutional value of developing a strong student community.

\section{Conceptual Framework and Research Questions}

Maxwell (2013) identified the conceptual framework for a research study as simply a "tentative theory of the phenomena" being investigated (p. 39), with a theory defined as "the linking of two concepts by a proposed relationship" (Maxwell, 2013, p. 49). The act of theorizing, therefore, is a cognitive method of identifying concepts and 
the relationships between those concepts (LeCompte \& Preissle, 1993). This research study was conceptually framed by the theory of campus ecology, which considers the interactive relationship between college students and the built campus environment (Banning, 2016). The theoretical frames for the study are theories constructed within the larger framework of campus ecology, namely college students' sense of belonging and the sociological concept of third place, both examined through the interrelated nature of college students and their built environment. The campus ecology literature demonstrated the influence of built space on students' university experience (Strange \& Banning, 2015; Scott-Webber, 2004), therefore, this theoretical approach sought to serve as a spotlight illuminating specific elements of the relationship (Maxwell, 2013) between students' sense of belonging and the built campus environment that might have otherwise been overlooked.

The research questions were formed through investigating and identifying the practical and intellectual goals for the study (Maxwell, 2013). Practical goals determine what is hoped to be accomplished with the result of the study, and since existing research considering third places on post-secondary campuses has only occurred at large, public institutions, the practical goal for this study was to produce data transferrable to small, residential, private universities who articulate an institutional value for the development of an interconnected student community. Intellectual research goals focus on the phenomenon the researcher hopes to understand, which for this study was assessing if students had locations on campus they perceived as contributing positively to their sense of belonging at their institution, and to determine if built campus environments were 
important for supporting an institutional commitment to a vibrant student community. Maxwell (2013) suggests framing the research questions so they lead the researcher to the information and understanding needed to accomplish the practical goals of the research. The researcher's intellectual goals, then, can be the link between the practical goals and the research questions by assessing what is needed to be understood in order to accomplish the established intellectual goals (Maxwell, 2013). With that premise, the following research questions were established for this study:

RQ1. What are students' experiences of community-focused built campus spaces as those spaces pertain to students' sense of belonging at a small, rural, residential institution? RQ2. To what extent do small, rural residential campuses intentionally design or emphasize community-centered third places within their built space?

\section{Overview of Methods}

These research questions were answered through a qualitative embedded case study utilizing semi-structured individual student and employee interviews as well as field observation on the campus of Corban University, a small, rural, residential, Christian, private university in the Pacific Northwest of the United States. Due to the articulated mission and values of most private Christian universities to foster a vibrant campus community, the study site was selected due to its membership in the Council for Christian Colleges and Universities (CCCU). The participants included 14 residential students who had lived on Corban's campus for a minimum of two semesters prior to the time of the study, and four Corban employees who were selected based on the relationship their position had to campus design and/or to student space utilization. 
During the interviews, participants were provided a description of Oldenburg's third place (1989) and were asked to identify one or two physical locations on campus meeting that description. Additionally, student interviewees were asked to describe the characteristics that attracted them to the place and the benefits they perceived the space provided, particularly if there was an influence on their sense of belonging within the university community. The employees were asked to reflect on their perceptions of how the institution demonstrated its stated value of student community through the built campus space.

General campus observations were made prior to the interviews, then following the interviews observations were made at locations participants identified as meeting their understanding of a third place, with field notes and photographs taken to note the physical qualities of the spaces as well as student behaviors and the social dynamics which occurred within them. The interview data was transcribed and coded utilizing a coding structure that began with a foundational set of provisional codes and was followed by the process of open coding, with the goal of answering the study's research questions.

\section{Definitions}

The following definitions provide context for the utilization of terms throughout this study, defining and operationalizing relevant concepts.

\section{Small Colleges/Universities}

According to College Data, an online college advisory website (College Data, n.d.), small colleges/universities are defined as having fewer than 5,000 undergraduate students. The Department of Education College Scorecard defines small 
colleges/universities as having fewer than 2,000 undergraduates (US Department of Education, n.d.). The average undergraduate population of member institutions within the Council for Christian Colleges and Universities is approximately 3,000 students (CCCU, 2017), so for the purpose of this study, small colleges/universities will be defined by using the average CCCU institution size.

\section{Built Space/Built Environment}

For the purpose of this study, the terms built space and built environment are used relatively interchangeably, both describing the human-constructed features of the elements within a bounded location or territory. Built space typically references physical spatial characteristics whereas built environment often extends beyond the physical to include conceptual, subjective, or non-tangible features of an area (Rapoport, 1990; Vischer, 2008; Scott-Webber, 2009; Mallon, 2015).

\section{Rural}

The US Census Bureau defines the terms rural and urban based on residential density metrics (Ratcliffe, Burd, Holder, \& Fields, 2016). One block must have a residential density of 1,000 people per square mile to be considered urban. A rural area is then defined as any square mile with a less-dense residential population than the urban areas (Ratcliffe, et al., 2016). While urban metrics are based primarily on residential density, higher-density areas also host more retail and businesses than rural areas (Frank, Sallis, Saelens, Leary, Cain, Conway, Hess, 2010) including third place establishments. Further, urban areas are often assigned levels of walkability based on a large combination of factors, which for this study included residential density, business and retail density, 
street and sidewalk design, and residence transportation mode choice (Frank, et al., 2010).

When considering universities and their geographic locations, residential campuses often have highly dense populations of students likely to utilize walking or bicycling as a primary mode of local transportation, with campus master plans often designed with a ten-minute walking route to accommodate for academic schedules (Kenney, Dumont, \& Kenney, 2005). The remaining walkability metric for urban areas not consistently present on a university campus is that of business or retail establishments. It follows then, that a residential university campus could meet the standards for an urban environment with high levels of walkability if retail and business spaces existed within one mile of the high-density residential areas of campus. Therefore, a university with a high residential density but without retail or business establishments within a mile of the campus perimeter was considered geographically rural for the purpose of this study.

\section{Chapter Summary}

The physical environment of a university campus has significant impact on how students engage socially with one another (Strange \& Banning, 2015), and social engagement is a critical element of psychological sense of belonging within a campus community (Strayhorn, 2012). A student's perception of their own belonging within an institution is a significant contributor to their decision to stay or leave that institution (Raisman, 2008). This study gives specific consideration to student-identified campus 
third places (Oldenburg, 1989) and the perceived influence those locations have on students' sense of belonging within the university community.

Chapter 2 presents a review of the literature related to campus ecology, student sense of belonging, third place theory, and the interconnectedness of the three areas. Chapter 3 outlines the study's methodology and research design utilized to conduct this qualitative study. Chapter 4 presents an analysis of the study's findings and Chapter 5 provides a discussion of the study's conclusions, including implications for practice, for theory, for future research, as well as recommendations for the study site. 


\section{CHAPTER 2: REVIEW OF THE LITERATURE}

Recruitment and retention are integral to the sustainability of most institutions of higher education and a strong student community can make the difference between retaining students or losing them to another environment where their need for belonging is met (Leslie \& Brinkman, 1988). Campus ecology research shows that the design of the built spaces within the university significantly influences a students' experience as it pertains to their sense of belonging to the university community, among other critical educational goals (Scott-Webber, 2004; Strange \& Banning, 2015). The design and layout of the physical, built elements of a campus can bring students together and encourage exploration, collaboration, growth, and connection, or it can carry a message of silence and disconnectedness (Oblinger, 2006). Campus spaces designed for students to engage socially, from dining services to recreation centers, can play an important role in the development of healthy community on a college campus, as they provide students a safe haven to interact and relax outside of their home or work environments (Butts et al., 2012). Sociologist Oldenburg (1989) defines a similar concept as a "third place"-a physical space that lends itself to frequent interpersonal connections and is important for establishing community and engaging in healthy social discourse. For rural residential universities without local third place locations within walking distance from campus, the intentional identification of such locations on campus can meet a critical need for the development of a robust student community.

Following is a review of the literature determined as critical to meet the goals of this study organized into four primary sections. First, the history and background of 
campus ecology is reviewed, including environmental behavior and proxemic zone theory, both critical to understanding the influence of built space on how people engage within a given setting. As the conceptual framework for this study, campus ecology is the lens through which each element of this study is viewed. Key research on user-centered design theories and campus design will also be presented. College student sense of belonging has been established as one of the theoretical frames for the study, and as such, this chapter will review the background of the concept and its reciprocal relationship to the development of a vibrant campus community. The second theoretical framework for the study is the sociological concept of third place, and this chapter specifically focuses on contributions of third places to the development of a robust community within a university campus environment. Lastly, the Council for Christian Colleges and Universities (CCCU), an organization providing membership to 140 American institutions of higher education who share an institutional value for the cultivation of a robust student community, will be introduced.

\section{The Ecological Perspective of Student Development}

The foundation of the campus ecology framework was birthed out of the significant legal and societal changes occurring within the United States in the 1960s as a response to unjust environmental conditions within institutions of higher education (Banning, 2016). Prior to the better-known Civil Rights Act of 1964, the Voting Rights Act of 1965, and the 1968 Fair Housing Act, President John F. Kennedy had signed the Community Mental Health Act in 1963 and the field of psychology granted credence to the viewpoint of behavior as a function of person-environment 
interaction. This provided a platform for the sub-discipline of environmental psychology to advance the concept of the reciprocal relationship between people and their surroundings (Banning, 2016). Concurrently, theories of college student development were emerging from the realm of developmental psychology with a nearly exclusive focus on the development of the individual, and with minimal emphasis on the role of the environment (Gonzalez, 1989). Outside of higher education, a growing understanding of person-environment interaction was laying the foundation for the research of several behavioral theorists' work which was then applied within the context of the university campus (Walsh, 1978). Banning was the first to broaden student development theories beyond their sole focus on the individual to include consideration of an environmental influence on college student development (Gonzalez, 1989). Following is an overview of the literature pertaining to the reciprocal relationship between people and built space, specifically considering interactions within a university context (campus ecology), an individual's psychological response to their surroundings (environmental behavior), the social dynamics of built space (proxemic behavior), and the pedagogical influence of space on learning (campus design).

\section{Campus Ecology}

As a clinical psychologist providing counseling services to students on a university campus in the 1960s and 1970s, James Banning had been reading the new environmental psychology literature and found particular interest in Walsh's 1973 monograph titled Theories of Person-Environment Interaction: Implications for the 
College Student. Given Banning's context, the following line resonated deeply with him, "to understand the behavior of a person, one must understand the environmental context or situation within which the behavior occurs" (p.6). This began Banning's development of campus ecology theory, which brings human ecology, the study of the relationship between people and their environment (Marten 2001), to the natural, social, and built elements of the college campus (Banning, 2016). The premise of the campus ecology framework is the recognition of how a campus environment influences college students' engagement with their space (Banning \& Bryner, 2001). Banning edited the first monograph compiling the research of several environmental psychologists to focus on the interactions between students and their campus environments and published it through the National Association of Student Personnel Administrators (NASPA) Journal in 1978 (Blocher). This foundational research provided new information for university administrators and campus architects to consider when designing campus buildings or planning facility renovations. In it, Banning (1978) concisely summarized the central distinctive of campus ecology as: "the focus of concern is not solely on student characteristics or environmental characteristics but on the transactional relationship between students and their environment" (p. 5). An aspiration of the development of the campus ecology movement was for student affairs practitioners to think beyond the holistic development of students and consider how changes to the campus environment might improve student learning and success (Banning \& Bryner, 2001). Yet despite the significant increase of data produced since the NASPA monograph (Blocher, 1978) demonstrating the influence campus 
environment has on the students' experience, too little consideration continues to be given to the space within which the work of higher education occurs (Temple, 2007). As Banning (1978) wrote: “Our campus environments are too rich and our students are too important, therefore, we must not bypass the simple notion of viewing them in a transactional relationship" (p. 6).

\section{Environmental Behavior Theory}

As thinking beings, humans engage with built space both cognitively as well as physically, demonstrating a mental and experiential congruence between people and their environment (Michelson, 1970). This congruence indicates how people feel they are supported by spatial patterns as well as how the space physically accommodates the functionality of those within it (Scott-Webber, 2004). When considering the principles of environmental psychology, an environment is defined as anything surrounding an individual, both built and natural, fixed or portable, at both macro and micro levels (Scott-Webber, 2004). Environmental behavior defines the human response to a building's physical characteristics, including social interactions within the setting of a built space (Altman, 1975). Due to the influence of the design elements of a space on its social use, early environmental psychologists developed the terms sociopetal and sociofugal to denote the psychological and social impact of specific built designs (Meagher \& Marsh, 2017). During a 1960s phenomenological study considering the influence of the building design of a Canadian mental institution on its patients, the clinical director and an architect used a psychedelic drug which increased their perceptions of the environment in order to experience the built space as their 
schizophrenic patients did as a form of "sympathetic embodiment" (Edginton, 2010, p. 88). In this groundbreaking study demonstrating the relationship between built space and behavior, the models of sociofugal design (space created to inhibit social interactions) and sociopetal design (spaces created to orient people toward each other) were introduced (Hall, 1966). These design models were later brought into pedagogical environments identifying the traditional classroom seating arrangement of forward-facing rows as a sociofugal design (see Figure 2.1A), and classrooms designed with clustered desks so students face each other identified as a sociopetal design (see Figure 2.1B) (Meagher \& Marsh, 2017). Further environmental behavior studies have demonstrated that despite negative social interaction even to the extent of ostracism, sociopetal environmental designs promoting social inclusion were found to be predominantly desired (Meagher \& Marsh, 2017). Due to the highly social nature of the residential college student experience, these studies provide post-secondary institutions data for further consideration of the influence of the built campus environment on students' social development. 
Figure 2.1

Sociofugal (A) and Sociopetal (B) Classroom Designs

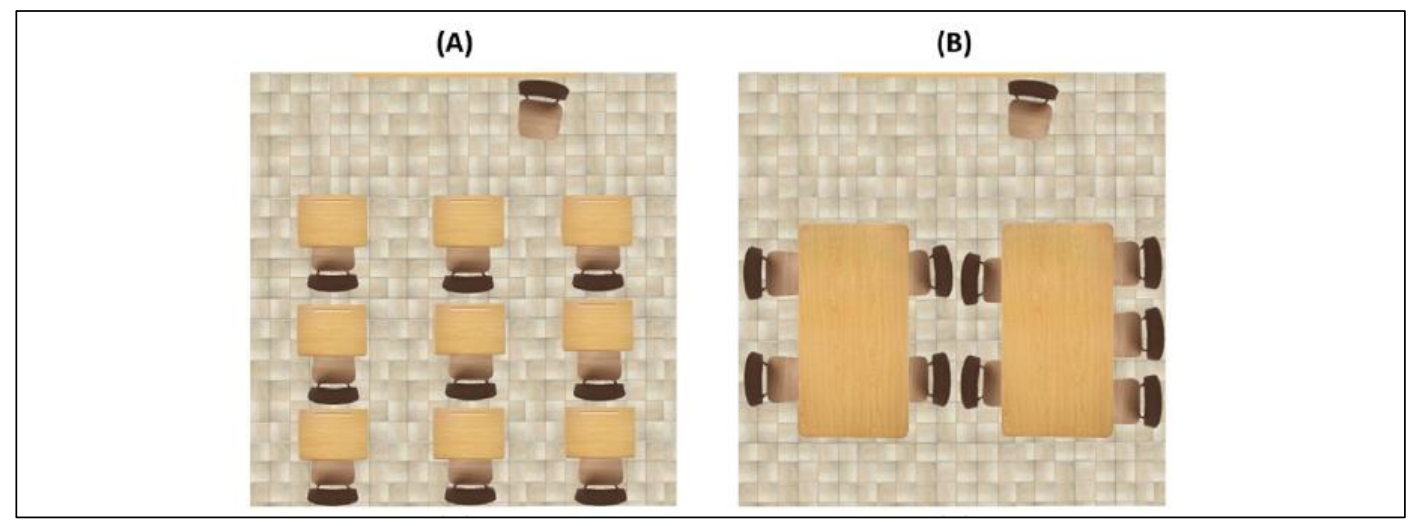

Note. Meagher \& Marsh (2017)

\section{Proxemic Behavior Theory}

Specifically considering the social dynamics within a space, the theory of proxemic behavior was developed to analyze how the structure of a person's spatial environment impacts their interactions with others (Hall, 1966). Hall first defined the concept of personal space as "an invisible three-dimensional zone surrounding a person, which allows that person to regulate his interactions with the outside world" (Beaulieu, 2004, p. 794). Each of these proxemic zones impact users' communication and behaviors within any given environment. The study of proxemic zones is illustrated as bubbles moving in concentric circles away from a person (see Figure 2.2), with each zone holding a subjective definition of acceptable and unacceptable behaviors by other people based on their proximity to the originator (Hall, 1966). As Figure 2.2 illustrates, each bubble is more elliptical rather than circular, representing the visual line of site for the individual determining appropriate social distance (Schmitz, 2012). The four proxemic zones of 
personal space are measured and defined as intimate distance ( 0 to 1.5 feet), personal distance ( 1.5 to 4 feet), social distance ( 4 to 12 feet), and public distance (beyond 12 feet) (Hall, Birdwhistell, Bock, Bohannan, Diebold, Jr., Durbin, Edmonson, Fischer, Hymes, Kimball, La Barre, Lynch, McClellan, Marshall, Milner, Sarles, Trager \& Vayda, 1968). However, these measurement approximations were developed through study of American social behavior with the acknowledgement that there is no "universal index of crowding" (Hall et al. 1968, p. 84). Culture plays a significant role in spatial experience, as different cultures normalize sensory experiences uniquely (Hall, 1966).

\section{Figure 2.2}

Proxemic Zones of Personal Space

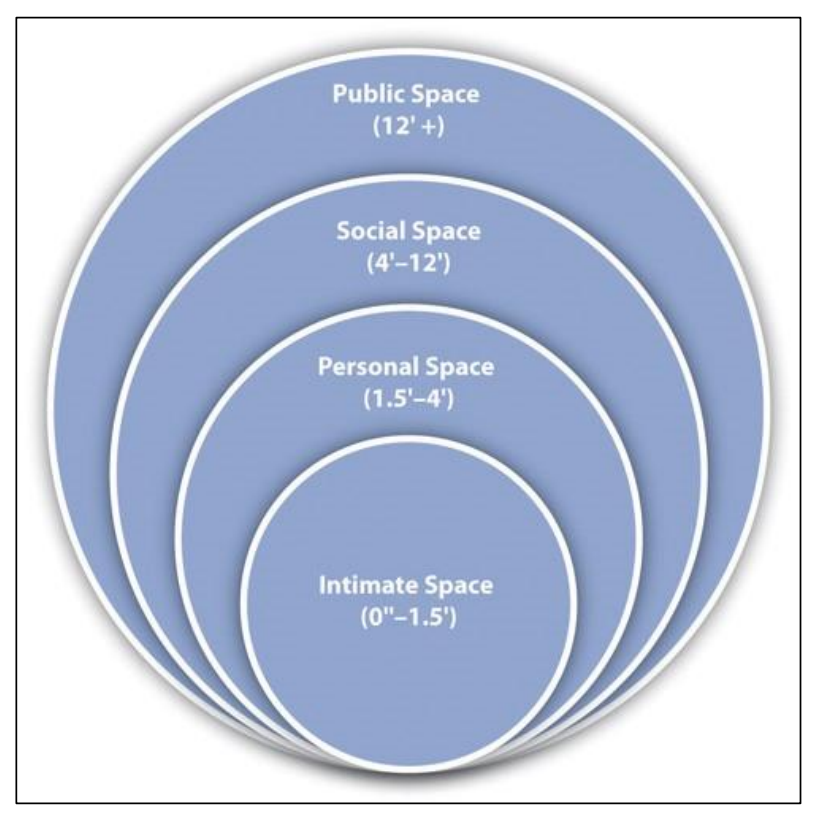

Note. Hall (1966)

Hall (1971) asserts that structuring of space occurs at unconscious levels, and while the study of proxemics cannot inform an architect how to design built space, it can 
provide important considerations for the process. Further, understanding this conjoined effect of space on behavior enables campus planners and educators to design campuses which will support institutional goals and produce holistically supportive university spaces (Scott-Webber, 2004). Due to the strong social implications of proxemic zone theories, universities who identify an institutional value of developing a strong student community could benefit from consideration of environmental behavior research when examining the necessary constructed elements for designing campus spaces.

\section{Campus Design}

As one of the earliest American campus architects in the late 1700s and early 1800s, Thomas Jefferson was a strong proponent of designing university campuses on a human scale for the purpose of enhancing social connection and academic collaboration, even stating that a well-designed campus should be more of a village than a building (Sensbach, 1997). Since the publication of Banning's $(1978,2001)$ research confirming the social and educational benefits of institutional adaptation of an ecological perspective on college campuses, it has had seemingly minimal impact on the university campus planning process (Strange \& Banning, 2015). The social influence of university architecture has been discussed for over 200 years and the specific study of campus ecology has been prevalent for decades, yet institutions still design buildings and campus landscape without student engagement or learning as a priority (Temple, 2009).

Campus buildings are designed to look impressive for the purposes of attracting new students, winning architectural awards, to appeal aesthetically to constituents (Jamieson, Fisher, Gilding, Taylor \& Trevitt, 2000), or as Dober (1992) articulated, to 
serve as a "cultural currency... charged with allegorical significance and perceptual connotations and meaning" (p. 5). Or worse, minimal intentional consideration is given because university administrators interact with campus buildings so frequently that the purpose behind for why they were built is simply overlooked. Dovey (2005) challenges university personnel to revive their reflexes and view campus architecture as an opportunity for discourse:

We experience architecture primarily in states of distraction; we live in it first and look at it second. Our contemplative gaze falls upon 'architecture' within a spatial world we have already silently imbibed and embodied. How do we reconcile this unreflexive embodiment...? (p. 283)

Similarly, an institution's lack of environmental reflexiveness can be demonstrated through ineffective campus wayfinding such as campus signage and other messaging that is only understood by members of the campus community, creating an "insider ecology" (Banning, 1996).

Effective wayfinding, demonstrated through both natural and built architectural features as well as clear signs, creates an ease of environmental navigation (Bell, Fisher, Baum, \& Green, 1996), and facilitates a welcoming campus experience (Banning, 1996). Many university campuses can be difficult to navigate due to complex layouts, similarlooking buildings, and visual access often blocked by buildings; all challenges which intentional wayfinding can solve, but too commonly is overlooked by university planners and administrators (Banning, 1996). Banning (1996) outlined the importance of effective campus wayfinding by encouraging campus planners to consider the following 
guidelines: locate wayfinding at the point where decisions are made, ensure signs are visible and legible, succinctly communicate for quick readability, keep sign content current and correct, and consider the sign's degree of accessibility for people of all abilities. As noted by Arthur and Passini (1992), "good wayfinding decreases frustration and stress, increases efficiency, accessibility, and safety" (as cited in Banning, 1996, p. 2). Providing navigational assistance through intentional wayfinding strategies can make a significant difference in a student's educational experience (Strange \& Banning, 2015). Despite the needs and expectations of current-day students being significantly different from that of their predecessors, American higher education has been slow to update built campus designs (Strange \& Banning, 2015). Most university facilities were designed with a combination of utilitarian and elitist assumptions about the purpose and function of a campus that are now obsolete, and subsequently students and faculty have developed a belief that college life consists of sterile spaces lacking in creativity, unable to accommodate modern pedagogical approaches, and uncomfortable for supporting a wide variety of adult bodies (Chism \& Bickford, 2002). While this is not the ideal, institutional lack of regard for the research, conflicting priorities within organizational leadership, high demand on limited institutional resources, and disputes with local civic agencies can prevent institutions from developing campus plans with student learning and engagement at the center (Strange \& Banning, 2015).

The sluggish rate of building design change in American higher education toward creating more student-centered campus facilities is not fully the fault of the educational institutions themselves (Temple, 2007). Theories of the built environment have differing 
foci regarding how a building is designed to be used and how the user experiences it, resulting in a practical macro-emphasis on building performance and serviceability (process-orientation) falling at one end of the debate and a micro-emphasis on the user's physiological or psychological response to the built space (product-orientation) at the opposite end of the discussion (Vischer, 2008). Due to this complexity in determining a focused approach to the purpose and influence of the built environment, user-centered theories fall along a continuum (see Figure 2.3) ranging between an environmental determinist view asserting that the built environment actually causes users' behavior, and a social constructivist view claiming that users' behavior is caused by social contexts, and the built environment has no impact (Vischer, 2008).

\section{Figure 2.3}

\section{Continuum of User-Centered Theories of the Built Environment}

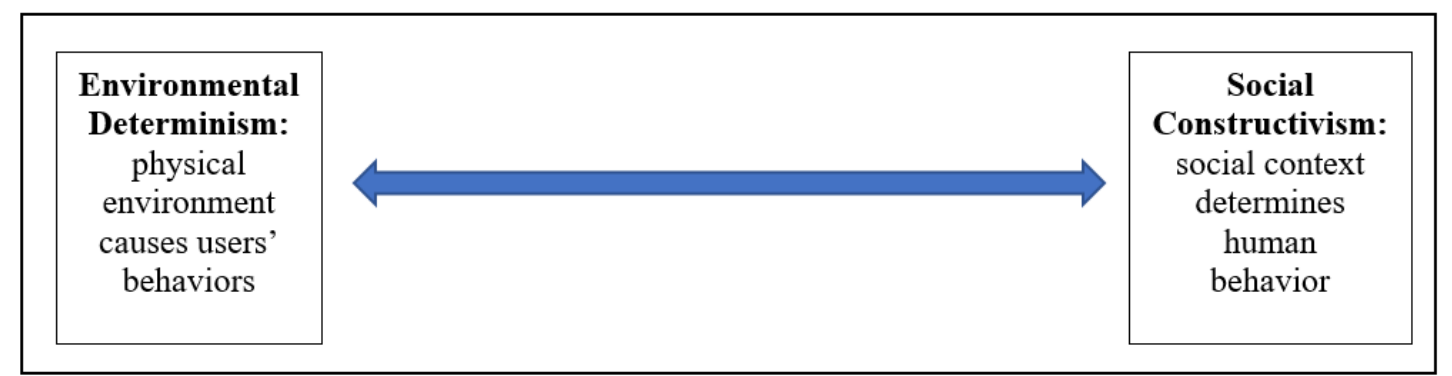

Note. Vischer (2008)

It is likely that most user-centered theories of built space will fall somewhere within the middle of these two extreme views, as neither are realistic positions given research on the influence of the built environment on human behavior and due to the breadth of factors that influence users' feelings and perceptions of a given space (Vischer, 2008). Strange and Banning (2001) offer the theory of architectural possibilism as a balanced center 
within the continuum, positing that while human behavior may not be predictable, physical features of the built environment still provide opportunity to influence behavior. Despite these theoretical complexities, performing consistent user assessment of current space and maintaining a user-centered approach to new building design are paramount to meeting the goals of the desired use of the built environment (Vischer, 2008).

While this study did not focus explicitly on academic space layouts, the influence of classroom design on pedagogy is an important consideration for effective student learning. The design of a traditional lecture hall usually includes fixed seats providing only 18 to 24 inches of horizontal space from one side of a chair's space to the other (Theatre Solutions, 2017), resulting in approximately 7.5 square feet of space per person seat (see Figure 2.4) (Scott-Weber, 2004). When full, this classroom design requires students to infringe on each other's intimate zones, which can result in increased levels of stress, potentially leading to lower attention and class engagement which can ultimately lead to a reduction of learning (Scott-Webber, 2017). As a defense mechanism against crowding and to prevent potential stress, students often respond to a lecture hall seating design by filling seats on either side of them with books or bags to expand their personal proxemic zone (Scott-Weber, 2017). 
Figure 2.4

Lecture Hall Seat Spacing

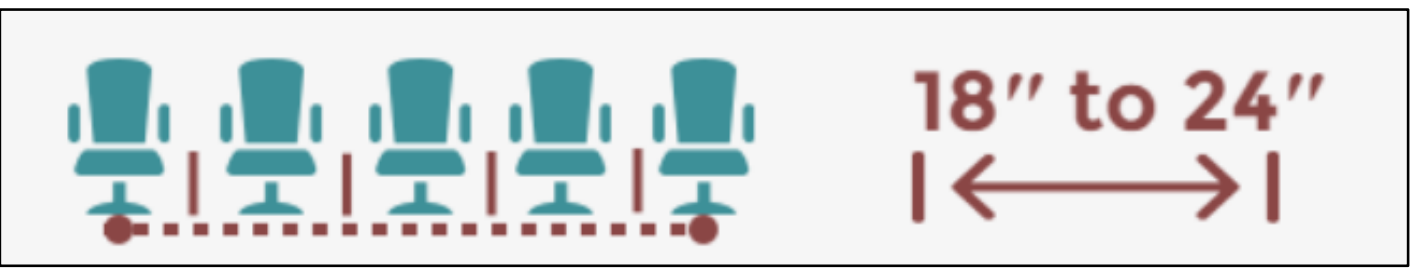

Note. Theatre Solutions (2017)

Stage, Muller, Kinzie, \& Simmons (1998) considered how classrooms could be made more learner-centered by looking at the implications of learning theory for college classrooms and recommended that social learning experiences that promote group construction of knowledge to be most effective. Considering the built campus space within a user-centered approach to higher education can produce a developmentally holistic student experience that not only increases student learning and opportunities for healthy social engagement, but can contribute positively toward decreasing student stress (Banning, Clemons, McKelfresh, \& Gibbs, 2010; Oblinger, 2006; Scott-Webber, et al., 2018; Strange \& Banning, 2015). "Just as words can be understood by the manner in which they are used, so buildings can be grasped by the manner in which they are perceived - the narratives of use in which they are inscribed" (Leach, 2005, p. 298).

Beyond a pedagogical impact, the literature also demonstrates the significant influence built campus design has on college students' sense of belonging. Following is a review of the literature regarding college students' psychological need for belonging and its contribution to student success and retention. Ecological connections between the built campus environment and students' sense of mattering are also highlighted. 


\section{College Student Sense of Belonging and Campus Space}

Built space is internalized psychologically as well as through all five physical senses, and over time and repeated use, an "archive of memorized sensory experiences" (Leach, 2005, p. 306) is developed. Through frequent use of the same space, narratives and "spatial stories" are formed as familiarity creates memories engrained deep within the psyche later to be recalled by connection to that particular built environment (Leach, 2005, p. 300). In these environments, patterns of behavior create normalized codes and rituals which lead to a psychological sense of belonging and attachment to that specific physical location (Bell, 1999). This sense of belonging is forged not through observing an environment and attempting to decipher the meaning it holds, but rather through engagement within the built space which results in the creation of unique and personalized meaning (Leach, 2005). "Architecture therefore offers a potential mechanism for inscribing the self into the environment" (Leach, 2005, p. 308). When considering the built environment of the university campus, the social context of the environment also has a significant influence on students' psychological sense of belonging and their perceptions of mattering, both of which are significant contributors to student attrition and retention (Strayhorn, 2012). Based in the understanding that a sense of belonging is one of the most fundamental human needs, failure to attain adequate sense of belonging can have a critically negative impact on a students' ability to succeed in college (Baumeister \& Leary, 1995). The student persistence literature reflects a strong connection to sense of belonging (Hausmann, Schofield \& Woods, 2007). Tinto's (1993) theory of student persistence states that a students' ability to integrate into the campus 
environment is a predictor of whether they will remain enrolled through graduation, and to the degree they are not integrated into the community they are more likely to withdraw from the university. To increase students' sense of belonging on campus, Strange \& Banning (2001) advocate for designing educational spaces that promote inclusion and safety, encourage involvement, and build community. The upcoming sections outline several components of the university experience that contribute to students' sense of belonging within the campus environment including learning styles, inclusion and mattering, and community integration.

\section{Pedagogy and Sense of Belonging}

While the purpose of the university has always been and will likely always be for learning, post-secondary institutions have realized in recent decades that the historical narrative of learning as occurring only from knowledge passed by faculty to students is a limited view (Strange \& Banning, 2015). Further, as universities struggle to meet the increasing societal demands to produce graduates with specialized expertise and technical skills, they can create a separation between academic and social life on campus, resulting in a disintegration of the campus community (Boyer, 1987, 1990; Cheng, 2004). It is now understood that teaching and learning are multidimensional experiences rather than a one-dimensional transferal of information (Strange \& Banning, 2015). Post-secondary pedagogical experts have made a strong case for universities to expand their perceptions of learning to include consideration of a diversity of learning styles, the influence of the educational environment, and most importantly, the human dimension of learning as a social endeavor (Fink, 2013; Kolb \& Kolb, 2012; Palmer, Zajonc \& Scribner, 2010). A 
socially collaborative approach to teaching and learning that emphasizes the value of the campus community has also been found to enhance a students' sense of belonging within the university (Cheng, 2004). Approaching pedagogy from this human perspective can lead institutions toward further consideration of the environmental factors influencing student learning.

\section{Inclusion and Sense of Belonging}

Environmental behavior theories posit that when people consider their ideal space in which to spend time, preference will be given to environments which meet the basic human needs for exploration and protection (Meagher \& Marsh, 2017). Similarly, Strange \& Banning (2015) proposed a hierarchy of environmental design based on Maslow's (1968) model of human needs. A foundational assumption of Maslow's (1968) model is that the basic needs of a psychological sense of belonging, love, and safety must be satisfied before higher-level cognitive and self-actualizing needs can be met. The environmental design hierarchy follows a similar assumptive pattern for a university student population, stating that the basic human needs for a safe and inclusive environment must be met before students will participate in higher levels of engagement and learning (Strange \& Banning, 2015). "Without a basic sense of belonging to the campus community, free from threat, fear, and anxiety, attempts at other more lasting goals will likely fail” (Strange \& Banning, 2015, p. 141).

For a student to experience psychological inclusion on a college campus, more is required than a simple absence of hostility or threat, but there must also be opportunities to feel validation (Rendon, 1994) and a sense of mattering. Similar to sense of belonging, 
a psychological sense of mattering comes from the belief that one matters to someone significant (Schlossberg, 1989). Schlossberg (1989) identified four aspects of mattering which include attention, importance, dependence, and ego-extension. Before a student can feel capable of academic or social involvement, they must feel noticed (attention), cared about (importance), needed (dependence), and that someone else cares about their achievements and sympathizes when they fail (ego-extension) (Chaves, 2006). Rosenberg \& McCullough (1981) succinctly define mattering as the "direct reciprocal of significance" (p. 163). Especially vital for students from diverse ethnic, racial, or cultural backgrounds to feel a sense of inclusion within campus life, Rendon (1994) articulated their need for personal confirmation and support, which can take many forms and be provided within many campus settings. And while critical for institutions to acknowledge the uniqueness and individuality of every student throughout the campus environment, it must be remembered that every student shares the common experience of feeling the need to matter and to belong (Schlossberg, 1989).

Hurtado (2012) asserts that a student's ability to "fit" within a campus community has as much to do with the educational environment itself as it does with the student themselves and affirms that it is the responsibility of the university to create social niches where students can find a sense of community based on common affinity. Similar to voluntary immigrant cluster communities in large cities, affinity environments (Friedmann, 2005) can be created on university campuses by students who come from similar cultures or discover social commonalities and gather within a specific space. By virtue of proximity and time spent within that space, material and emotional support can 
be provided to one another through deliberating and empathizing around experiences uniquely understood by those sharing their similar affinity (Friedmann, 2005). Through attaching a specific use to a built space, a cultural identity can become associated with the physical features of the architecture and the cultural artifacts within the place, connecting deep meaning to the location because of the activities taking place and memories created there (Leach, 2005).

\section{Community and Sense of Belonging}

As the student body of today's universities continue to diversify, the desire for a community that connects individual students around a common purpose continues to be an expressed priority of the traditionally aged college student (Cheng, 2004). This type of community demonstrates value for each member, as it encourages individuals to see beyond themselves and to foster a sense of responsibility and commitment to one another (Taub, 2008). Community provides a shared purpose, as well as a sense of meaning, belonging, and mattering (Boyer, 1987; Schlossberg, 1989; Taub, 2008). In Boyer's (1990) seminal work on the virtues of campus community, he developed six characteristics vital to the cultivation of a college students' holistic educational experience, articulating that every university should strive toward creating a community that is purposeful, open, just, disciplined, caring, and celebrative. Boyer's charge offered a significant expansion and new framework for how universities defined a healthy student community and contributed to the establishment of a common agenda for institutions aspiring to shift their institutional culture in this holistically development way (Cheng, 2004). Universities who emphasize and encourage student involvement in extracurricular 
activities further promote an institutional value of a vibrant campus community, which can result in an increase in students' sense of belonging to the institution (Kuh, et al., 1991, Cheng, 2004).

College student development literature has shown that students who are more involved in the community life of the campus report higher levels of satisfaction about their overall educational experience, feel more connected to the university community, and are more successful academically (Astin, 1984; Pascarella \& Terenzini, 2005; Schlossberg, 1989). Suggesting a strong correlation between student mattering and campus engagement in social or academic activities, Schlossberg (1989) states “...for whether [students] are traditional or nontraditional, gifted or average, male or female, all students are concerned about belonging and mattering" (pp. 6-7). High student involvement, defined as the "physical and psychological energy that a student devotes to the academic experience" (Astin, 1984, p. 518) has a direct connection to a student's perception of mattering to significant others and to the institution.

Participation in institutional traditions symbolizes a student's membership into the university's community of learners and cultivates both the recognition of one's need for interdependence as well as a sense of belonging within a healthy community. "Before a place can matter, people must matter" (Manning \& Kuh, 2005, p. 3). Institutional rituals and traditions designed to invite all students into a shared understanding of the university's mission and values play a significant role in a student's perception of their ability to belong within the institution and to succeed academically (Manning \& Kuh, 2005). When new students see upper division students and alumni participating in 
university traditions, it provides anticipation and allows them to envision themselves in those roles in the future, thereby creating opportunity for goal setting. Institutions who celebrate their unique heritage and culture through shared practices demonstrating respect for both past tradition and future innovation invite students into a rich community legacy (Cheng, 2004; Magolda, 2001; Schlossberg, 1989). Participation in the campus community cultivates opportunities for learning and provides the support needed to foster a sense of belonging within a given social group (Tinto, 2001).

Despite this deeply rooted psychological need for belonging, Smith (1992), found that the economic expansion in the modern era has resulted in the achievement of independence from larger communities, as the innate human desire for a westernized individualistic security has been attained. This anti-collectivist prosperity has, according to Smith (1992), contributed to a "growing atomization of American society and a withdrawal from public life of increasing numbers of citizens" (p. 2). In Putnam's 2000 Bowling Alone, the author reflects on a nation-wide epidemic of a decrease in healthy relationships within family, friends and neighbors, and suggests that this decline in community engagement poses a threat to society's civic and personal health (Putnam, 2000). Therefore, educational institutions must consider how their campus environments promote the theoretical and cognitive development necessary for recognizing the fundamental interdependence shared within a healthy community. Due to this continual decrease of social connectivity within local communities and neighborhoods, the importance of the environmental behavior literature pointing to a mutuality of influence between physical space and people (Banning, 2016) is even greater, and the need for 
places dedicated to cultivating relationships is paramount (Waxman, 2006). Such places are introduced in the upcoming section.

\section{Third Place}

Campus spaces designed for students to engage socially, from cafeterias to recreation centers, can generally play an important role in the development of healthy community on a college campus, as they provide students a safe haven to interact and relax outside of their home or work environments (Butts et al., 2012). Sociologist Oldenburg (1989) defines a similar concept as a "third place"-a social environment or physical space outside of home (the first place) and work (the second place), that lends itself to frequent interpersonal connections and is important for establishing a sense of place, engaging with civic responsibility, and practicing democracy. Diversification of relationships and ideas occur within these locations where a variety of people from different backgrounds can gather before or after spending the majority of their time with those who think and act similarly within their vocational or familial realms. Third places are often unassuming local businesses like coffee shops, bookstores, or bars where people gather for leisure, social connection, and engaging in important conversation.

(Oldenburg, 1989).

Third places have both social and physical descriptive characteristics, and while the physical characteristics could be similar enough to other local food and beverage establishments that it could be difficult to know the difference, the social dynamic of a third place is what truly sets it apart and gives it its unique identity (Chon \& Maier, 2009; Oldenburg, 1989; Rosenbaum, 2006; Waxman, 2006). 


\section{Social Dynamics of Third Places}

A significant characteristic used to describe the social nature of third places is as a "home away from home" (Oldenburg, 1989). Oldenburg states that one of the dictionary definitions of home is simply "a congenial environment" (p. 39), which he suggests is more likely to be a reality for the average third place than for the average home. In a 2006 study on how third places become meaningful in consumer's lives, the data showed that the more companionship and emotional support a patron experienced within a diner, coffee shop, or bar, there was a correlated increase in loyalty to that place as well as an increased feeling of "home" (Rosenbaum, 2006). In that same study, a third place diner owner even referred to his regular customers as family. This group created the base of the diner's clientele with consistent patronage at least five times per week and made up 50\%$60 \%$ of the diner's business. The owner said that this particular clientele was the group "we take care of," which turned his diner into a socially warm, home-like environment for those patrons (Rosenbaum, 2006, p. 63).

A mixed methods study by Waxman (2006) assessed the traits of coffee shops to consider which attributes contributed to patrons' perceptions of creating a third place environment and found a unique set of social characteristics consistently identified as critical to those who frequented third place establishments. The six key themes which emerged around the social dynamics of the coffee shop were opportunity to linger, feelings of ownership or territoriality, trust and anonymity, productivity, opportunity to socialize and social support. Many of the identified characteristics align with Oldenburg's 
(1989) descriptors of third places in The Great Good Place, his original introductory work on the topic.

Oldenburg (1989) aligns several third place descriptors alongside Seamon's $(1979,2015)$ five criteria for assessing the qualities of "home", identifying them as characteristics found to be true within the most effective third places. Seamon's first characteristic of home is a psychological sense of rootedness that connects a person to a place (1979, 2015). Oldenburg (1989) articulated how the participants in his third place studies often expressed how they felt integrated into the community of their local third place due to their consistency of presence and the familiarity of the other regular attenders. This feeling of rootedness came from more than merely long-standing attendance but was developed as an extension of the personal care shown through the common occurrence of people reaching out to make contact when the regulars were absent. Similarly, Waxman's (2006) study found the first critical social aspect identifying a coffee shop as a third place is the opportunity to linger, in contrast to the unspoken expectation that once a patron is handed a check, it's time to go. The regulars who come daily and linger have a strong influence on the social climate of the coffee shop (Waxman, 2006). Oldenburg (1989) agrees: "It is the regulars who give the place its character and who assure that on any given visit some of the gang will be there" (p. 33). This consistent time spent in the same place creates a psychological sense of mattering: the belief that one matters to someone else and the feeling of a reciprocated significance (Schlossberg, 1989; Rosenberg \& McCullough, 1981), which contributes significantly to the sense of rootedness that a third place can provide. 
The second characteristic of home according to Seaman $(1979,2015)$ is appropriation, which is a sense of possession or ownership that increases with familiarity. Oldenburg (1989) discusses the privileges and access rights consistent third place patrons might receive, such as access through doors not used by the public or use of a house phone that wouldn't necessarily be available to the occasional customer. Some third place establishments may even have a special section of seating reserved, formally or informally, for "friends of the house" (Oldenburg, 1989, p. 40). Waxman's (2006) study also found a sense of ownership or territoriality as a social identifier of a third place, as regular patrons reported claiming favorite seats or having permission to walk behind the counter when they wanted something. Third place owners reported the more negative side of the patrons' sense of ownership as having a sense of entitlement to speak on how the coffee shop was being run (Waxman, 2006).

Seamon's $(1979,2015)$ third psychological descriptor of a home is the sense of social or emotional renewal that occurs there, recognizing that there is a relief that comes from personalizing a place as ones' own. Oldenburg (1989) connects the environmental contributors of third places to these feelings of personal restoration to consider how a third place location can provide a similar sense of personal renewal as the home. Oldenburg (1989) identifies key social functions of a third place as bringing people together, providing a place for new neighbors to assimilate into a new community, a gathering place for the planning of community events, and simply for the fun and joy of association, also identified as "pure sociability" (Oldenburg \& Brissett, 1982, p. 270). Waxman's (2006) study also speaks to the roles of personal growth and productivity in 
contributing to a person's sense of personal renewal occurring within a third place. Retired patrons articulated the value of having a place to consistently go as a part of maintaining their regular routine, while teenage patrons expressed joy in the autonomy they experienced while spending time with friends in coffee shops as it made them feel "grown up" (Waxman, 2006, p. 48). Students and professionals expressed appreciation for the productivity they experienced in a third place, as it provided a place free of the distractions of school, work, or home to get things done (Waxman, 2006).

The fourth criteria describing a home is the feeling of freedom of self-expression and the ability to leave a mark even after physically departing the space (Seamon, 1979, 2015). Oldenburg (1989) discusses that while a private residence allows for a physical self-expression such as furniture selection and arrangement, third place self-expression is equally important in the social context of conversation and healthy banter. Further, due to the inclusive nature of a third place where no set criteria for admission or participation exists, there is an emotional safety to be oneself regardless of social status, religious or political views in the world outside, creating an acceptance and even expectation for a diversity of expression and ideas (Oldenburg, 1989). Waxman's (2006) study found third place patrons appreciated a relative anonymity, as they felt the freedom to take on a somewhat different persona in the coffee shop than the one they typically embody at home or at work. This created a climate of trust and mutual respect, where the feelings of safety for self-expression increased with more time spent in the community of the third place. 
Seamon's $(1979,2015)$ final description of home is a relational sense of warmth. When considering this warmth within third place locations, Oldenburg (1989) states that it grows out of "friendliness, support, mutual concern" and "radiates from the combination of cheerfulness and companionship, enhancing the sense of being alive" ( $p$. 41). While private residences can exist without this emotional warmth, it is the defining social characteristic of what differentiates a third place from any other commercialized food or beverage establishments (Oldenburg, 1989). Chon \& Maier (2009) affirm these critical emotional and social dynamics of third place establishments that are typically overlooked by commercially successful restaurants and bars with the primary goal of high patronage for high profit. This contrast in purpose is described in a textbook on the hospitality industry: “Oldenburg's concept of the third place provides a helpful perspective on the social and cultural dimensions of hospitality, often overlooked by those who see only its "business" aspects" (Chon \& Maier, 2009 p. 210). These nonconcrete, social characteristics of third places are the experiential elements that make them both special to their regular clientele, and important establishments for the strengthening of local communities.

\section{Physical Characteristics of Third Places}

While studies have identified the most compelling feature of third places is characterized largely through their social climates, there are several physical and environmental aspects which differentiate a third place from other local food and beverage establishments. The most common physical description of a third place is that its appearance is relatively plain, and it maintains a low visual profile. Oldenburg (1989) 
identifies several reasons for this non-impressive stature, primarily rooted in the type of clientele it desires to attract. Third places draw ordinary people who desire an ordinary place, free of social pretense and commercialism (Oldenburg, 1989). For regulars, this low profile contributes to the consistent and normalizing role a third place plays in their life as it becomes a "taken-for-granted part of their social existence" (Oldenburg \& Brissett, 1982, p. 270). The non-impressive physical dimensions of third places also discourage transient customers who don't find it notable or interesting, as its goal is not to impress and attract new clientele, but rather to provide a comfortable environment for members of the local community to gather (Oldenburg, 1989).

Other physical characteristics of third places are in regard to size and accessibility. Third places need to be of human scale, not expansive or institutional, as smaller spaces allow for greater intimacy and social connection (Banning, Clemons, McKelfresh \& Waxman, 2006). The location of a third place establishment is most ideal when it's accessible by foot for a large residential population, providing a location for local neighbors to connect (Oldenburg, 1989). "The need to drive to a third place begins to defeat the purpose" (Banning et al., 2006, p. 48). Oldenburg's (1997) research found that in some states, $80 \%$ of the patrons regularly accessing bars lived within a two-block radius on them, demonstrating a clear draw to the locals. Research study participants reported that they prefer third places with seating which have views to the outside in order to feel a sense of connection to and awareness of the neighborhood activities happening outside, as well as to feel closer to the elements of nature beyond the brick and mortar of where they're sitting (Waxman, 2006). 
Turning to the interior physical qualities of third places, a correlation exists between the amount of comfortable furniture and length of a patrons' stay (Waxman, 2006). Studies of coffee shops have found that comfortable furniture invites longer visits, while less comfortable furniture encourages high customer turnover (Waxman, 2006). Furniture design should be sociopetal in layout, allowing for flexibility in function and optimizing personal interaction (Banning et al., 2006). Environmental psychology studies have found an increase of "purposive, engaged social interaction" (Edginton, 2010, p. 94) within spaces designed with furniture which orients occupants toward each other (Meagher \& Marsh, 2017). Information-sharing is a social priority within third places and is achieved both through sitting with people and discussing personal and local happenings, as well as through physical features such as bulletin boards where announcements and needs can be posted (Waxman, 2006).

As much as third places exist for interpersonal human connection, there is space for intentionally designing sociofugal spaces which allow for individualized and nonsocial seating (Meagher \& Marsh, 2017). Many third place regulars have been found to consistently sit alone, while still reporting their experience as a pleasant "social outing" (Waxman, 2006, p. 50). The most ideal third place design will allow for a variety of fixed and movable seating, so patrons have the option for a social or an individualized experience (Banning et al., 2006).

\section{Third Places on the College Campus}

Previous sociological research on the impact of third places on neighborhood community building has only recently been considered within the university 
environment. Since the university is a unique community unto itself, the third place literature points to a correlation between students' attitudes toward their college experience and the design of the built campus space (Waxman, Clemons, Banning, \& McKelfresh, 2007). Although Oldenburg published an article in 1997 challenging campus planners to consider ways to shape the built campus environment for the purpose of "making college a great place to talk," he never referred to the social campus spaces he was promoting as "third places," despite the alignment of his descriptors of those environmental factors with their previously-defined third place characteristics (1989). It wasn't until 2006 that Banning, Clemons, McKelfresh \& Waxman conducted research studying third places on a university campus and found a strong sense of attachment between the physical locations and the social communities who regularly occupied them. When transferring third place descriptors from a neighborhood to a residential postsecondary educational context, the definition of a first place for college students would be their campus living environment (e.g., residence hall room or campus apartment) with academic environments (e.g., classrooms or laboratories) serving as their second places (Waxman et al., 2007). One of the many benefits of intentionally developing third places on college campuses is that they promote informal learning through the social discourse occurring within them and foster the formation of affinity-based student communities, strengthening students' sense of belonging to the campus community (Banning 2001; Oldenburg, 1989; Temple, 2007).

A study at a large public university asking college students to locate the space on campus which best fit the description of a third place found that nearly $80 \%$ of the 
students identified their third place off campus (Banning et al., 2010). This data is concerning for institutions who place high value on social connection and sense of belonging within their student community as third places are significant contributors to both. The data also suggest that the presence of intentionally designed third places are linked to higher student satisfaction and retention rates, making the campus look more attractive to prospective students, increased alumni giving, and institutional growth (Banning et al., 2010). Any campus space designed for students to engage socially, from dining services to recreation centers, can generally play an important role in the development of healthy community on a college campus, as they provide students a safe haven to interact and relax outside of their home or work environment (Butts et al., 2012). The research done regarding third places on college campuses found coffee shops to be the top-identified campus location for meeting the need of a social gathering location (Banning et al., 2006). While simplistic to state that the creation of third places on campus solves the problems related to social engagement and healthy community development at all post-secondary institutions, providing such locations could contribute to a stronger sense of belonging for students and an increased desire for involvement in the life of the institution (Banning et al., 2006). This development of a healthy community within the student body becomes more emphasized institutionally when the university states it as an overt priority in the mission or values statements; a practice of many of the member institutions discussed in the next section. 


\section{The Council for Christian Colleges and Universities (CCCU)}

Due to this study's focus on a students' sense of belonging within a university community, member institutions of the Council for Christian Colleges and Universities (CCCU) will be the sample group because of their shared institutional commitments which attract students with an interest in a campus community ethos. Whether it is explicitly articulated in an institutional mission statement or nuanced more implicitly, CCCU institutions share a high value for developing relational campus environments where cultivating an inclusive and supportive community within the student body is a priority. Member institutions within the CCCU fit what Benne (2001) refers to as churchrelated colleges and universities who utilize a "Christian vision as the organizing paradigm" (p. 49) which primarily attracts students interested in integrating a Christian philosophy into their post-secondary education. To assess the degree to which a particular church or theological belief system influences a college or university, Benne's (2001) typology organizes church-related colleges and universities into four categories: orthodox, critical mass, intentionally pluralist, and accidentally pluralistic. Within each category the following eight aspects of the institution's life is examined: the public relevance of its Christian vision, public rhetoric, membership requirements, the role of the religion/theology department and requirements of its courses, the nature of chapel programming, the overall ethos, the degree of support by a sponsoring church, and the role of a church in matters of governance (Glanzer, Carpenter \& Lantinga, 2010). According to Benne's (2001) typology, CCCU institutions fall within the orthodox or 
critical mass categories due to their overt Christian mission as seen throughout these eight aspects of their organizational structure.

\section{The History and Background of the CCCU}

The Council for Christian Colleges and Universities (CCCU) was founded in 1976 for the purpose of creating "a broad association of Christian colleges that would support promotion and leadership activities for member schools and provide a unifying voice for Christian higher education in the public square" (CCCU: About Our History, n.d., para.8). Some of the unique services provided for member institutions include public advocacy to offer a unified voice for all member schools, professional development and scholarship for staff and faculty, and experiential education for students in ten offcampus study programs domestically and abroad (CCCU, 2018). The CCCU serves 180 higher education institutions across the United States, Canada, and outside North America in Australia, Bolivia, Dominican Republic, Ghana, Haiti, Hungary, India, Indonesia, Israel, Japan, Kenya, Lithuania, Netherlands, New Zealand, South Korea, Taiwan, Uganda, and the United Kingdom (CCCU, 2018). According to the CCCU Annual Report (2018), member institutions employ 75,000 faculty and staff in the United States and have more than 466,000 students enrolled in US institutions with more than 520,000 students enrolled globally annually. Each CCCU institution affirms an alignment with the following foundational commitments: that integrated biblical spirituality is critical to every academic discipline and cocurricular program, that true learning cannot occur without "deepening the soul" and as such, prioritizes the moral and spiritual 
formation of students, and that CCCU institutions are developing alumni who can offer restoration to a broken world and "contribute to human flourishing" (CCCU, 2018, p. 2).

\section{Common Commitment to Campus Community Development}

CCCU institutions share a unique characteristic in their common commitment to the establishment of a vibrant campus community in large part due to their collective theological belief structure. These institutions hold to a shared value of the integration of biblical truth throughout the curricular and co-curricular arenas of higher education (CCCU: About: What is Christian Higher Education?, n.d.). Stemming from this value comes a commitment to the moral development of students, rooted in the biblical principles of loving others, acting justly, and living humbly (CCCU: About: What is Christian Higher Education?, n.d.). This commitment, coupled with the biblical narrative that God made humans to live in fellowship with one another and with him (1 John 1:6-7 New International Version), creates a communally centered organizational underpinning for colleges and universities who hold this belief structure. While every CCCU institution may not expressly articulate an emphasis on a robust campus community as an element of their mission statement or values, their commitment to biblical integration results in a campus culture encompassing an individually holistic and collectively altruistic framework for higher education, giving weight to the value of student community (CCCU: About: What is Christian Higher Education?, n.d.).

Following are segments from the "about us" pages of a cross-section of CCCU member institution websites who overtly articulate a commitment to fostering a vibrant student community: 
Azusa Pacific University is located in Azusa, California and has an undergraduate enrollment of 5,671 (US News and World Report, 2019). Two quotes referencing their institutional value of community found in the "Four Cornerstones" section of their website state:

Azusa Pacific University is an institution built on four cornerstones: Christ, Scholarship, Community, and Service. These four components define why APU exists (Azusa Pacific University: Four Cornerstones, n.d., para.2).

Community: We believe in community. We are a richly diverse people who value the worth of each individual. Our mission is to encourage, equip, and enable each student to fulfill his or her great potential, and in turn, encourage, equip, and enable others (Azusa Pacific University: Four Cornerstones, n.d., para.7).

Wheaton College is located in Wheaton, Illinois and has an undergraduate enrollment of 2,391 (US News and World Report, 2019). Within the Wheaton College website section entitled "The Value of a Wheaton Education," their institutional commitment to community is stated:

Wheaton College firmly believes that the primary intrinsic value of a liberal arts education comes from the formation and preparation of the whole person for all of life's vocations. To this end, we require our students to learn broadly while at the same time inviting them to study more deeply in the discipline(s) they love the most. We also encourage on-campus, residential learning because as the only first-tier evangelical liberal arts college, our goal is not only to teach students to think well, but to live well. This is achieved most effectively when learning 
happens in a vibrant community. (Wheaton College: The value of a Wheaton education, n.d., para.2)

John Brown University is located in Siloam Springs, Arkansas and has an undergraduate enrollment of 1,972 (US News and World Report, 2019). Under the "Mission, Vision, and Values" section of the John Brown University website, the $3^{\text {rd }}$ institutional value is entitled "People" and posits:

We make decisions that benefit students; we extend hospitality to strangers; we recognize the God-given gifts of our colleagues; we act and treat each other with integrity; we respectfully engage and encourage a variety of differences among people; we nourish relationships; and we study and learn in community because God has created people in His image. (John Brown University: Mission, Vision, and Values, n.d., para.6)

As demonstrated through these examples spanning a breadth in size and geographic location, $\mathrm{CCCU}$ institutions have a commitment to fostering a healthy student community on their campuses, whether they articulate that commitment through an overt mission or value statement or more subtly through a narrative description of those values. A similar pattern would be found in a search through the websites of the remaining member institutions, as the shared emphasis of viewing community as an integral part of the holistic educational experience grows from the common theological commitment required of Council membership. 


\section{Chapter Summary}

As demonstrated through the literature, a common thread exists between the topics of environmental behavior and design on college campuses, students' sense of belonging within the university community and the social theory of third places. Through the lens of campus ecology theory which postulates a transactional relationship between students and university spaces, it is clear that the design of built space influences how students engage with one another within campus settings. There is a strong reciprocal relationship between a students' sense of belonging within the university and a vibrant campus community which is exemplified through spaces on campus designed for the purpose of bringing people together. Third places are examples of such locations designed specifically for this unifying purpose of community building, and the literature demonstrates the many benefits of university design intentionally including third place locations on campus. 


\section{CHAPTER 3: METHODOLOGY}

This qualitative research study explored student perceptions of the influence of the built campus environment on their sense of belonging to their institution, as well as how the built spaces on small, rural, private, residential university campuses support their institutional value of developing a strong student community. This exploration occurred through an embedded case study consisting of semi-structured interviews, field observation, and archival research.

According to Creswell and Creswell (2018), conducting research includes both the identification of a philosophical approach as well as clearly articulated methods. The philosophical approach, also known as a worldview, paradigm, or epistemology, is the researcher's theoretical orientation about the world that shapes the direction of their research (Creswell \& Creswell, 2018), or simply put, "a basic set of beliefs that guide action" (Guba, 1990, p. 17). This research study was oriented around a constructivist philosophy rooted in the belief that individuals construct meaning about the world through their interactions with other people, with their environments, and through their experiences (Creswell \& Creswell, 2018). As a researcher, it is critical to seek further than simply the concrete actions and overt behaviors that present as data, and to look for the unique meanings and beliefs that participants use to make sense of these behaviors and actions in individualistic ways (Maxwell, 2013). This constructivist paradigm guided each step of the methodological approach utilized in this study. 


\section{Research Problem, Questions and Qualitative Methodology}

The study specifically explored the influence of the built campus environment on students' sense of belonging within spaces designed and/or utilized for the express purpose of student community building (meeting the criterion of a third place) on the campus of Corban University, a small, rural, residential, private, Christian university in the Pacific Northwest of the United States. A 2006 study at a large research institution asking students to locate the space on campus which best fit the description of a third place found that a large percentage of the participants identified their third place off campus (Banning et al., 2010). This data, in conjunction with the literature outlined in chapter two, guided the problem statements of this study:

PS1: A lack of dedicated campus space designed to serve the social purposes of third places may hinder students' ability to feel connected to the campus community, especially within geographically rural institutions without third place establishments within a walkable distance from campus.

PS2: A lack of intentionally designed community-building spaces on campus may hinder the development of an interconnected campus community and therefore be preventing the institution from fulfilling a significant component of its mission or values. Based on the identified problems, the following research questions have been established:

RQ1. What are students' experiences of community-focused built campus spaces as those spaces pertain to students' sense of belonging at a small, rural, residential, private institution? 
RQ2. To what extent do small, rural residential campuses intentionally design or emphasize community-centered third places within their built space?

These questions were answered through a qualitative embedded case study which utilized semi-structured individual student and employee interviews, campus observation, and archival research on a small, rural, residential, Christian university campus in the Pacific Northwest of the United States. Both research questions are particular, as they place this case study within a specific location and connect directly to the purpose of the study (Maxwell, 2013). The questions also reflect a realist approach, in that they considered the participants' feelings, beliefs, and intentions as actual data (Maxwell, 2013), which contributed to identifying the influence the built campus environment had on students' sense of belonging. Lastly, these research questions are framed as process questions (Maxwell, 2013) as they sought to explore how built campus spaces influenced student community building, what those built spaces meant to people, and the influence of the social context on students who engaged within those spaces.

Qualitative research emphasizes the process of how individual elements of the research influence one another (Maxwell, 2013), as seen in the purpose and research questions of this study as it explored the relationship between community-centered built campus spaces and institutional mission. Merriam and Tisdell (2016) describe qualitative research as seeking to understand "how people interpret their experiences, how they construct their worlds, and what meaning they attribute to their experiences" (p. 6). This constructivist approach is best accomplished through collecting rich, thick descriptive data (Maxwell, 2013), which in this study was used to examine how students experienced 
built space on campus and their perception of the influence of those spaces on their sense of belonging to the institution.

\section{Case Study Design}

The research design determined to provide the most effective data to answer this study's research questions was an embedded qualitative case study. As with several other forms of qualitative research, a case study identifies the researcher as the primary instrument for data collection and analysis, utilizes an inductive investigative strategy to find meaning and greater understanding, and has the goal of producing rich descriptions of those findings (Merriam \& Tisdell, 2016). The primary characteristic differentiating case study from other approaches is its focus of analysis on a bounded system (Merriam \& Tisdell, 2016; Miles, Huberman, \& Saldana, 2014; Yin, 2018). According to Schramm (1971): "The essence of a case study, the central tendency among all types of case study, is that it tries to illuminate a decision or set of decisions: why they were taken, how they were implemented, and with what result" (p. 6). Yin (2018) instructs that Schramm's use of the term "decisions" can be exchanged with "organizations," "programs," "processes," or even "institutions" (p. 14), as a case study shines a narrow beam of light onto one particular bounded entity: the case, looking deep within why and how it is what it is. Another key feature distinguishing case study from other methodologies is its focus on the unit of analysis more than on the topic of investigation (Yin, 2018). A case study design then becomes embedded when sub-units of analysis are determined necessary to expand the insights of the single case, as seen in Figure 3.1 (Yin, 2018). 


\section{Figure 3.1}

\section{A Single, Embedded Case Study Design Diagram}

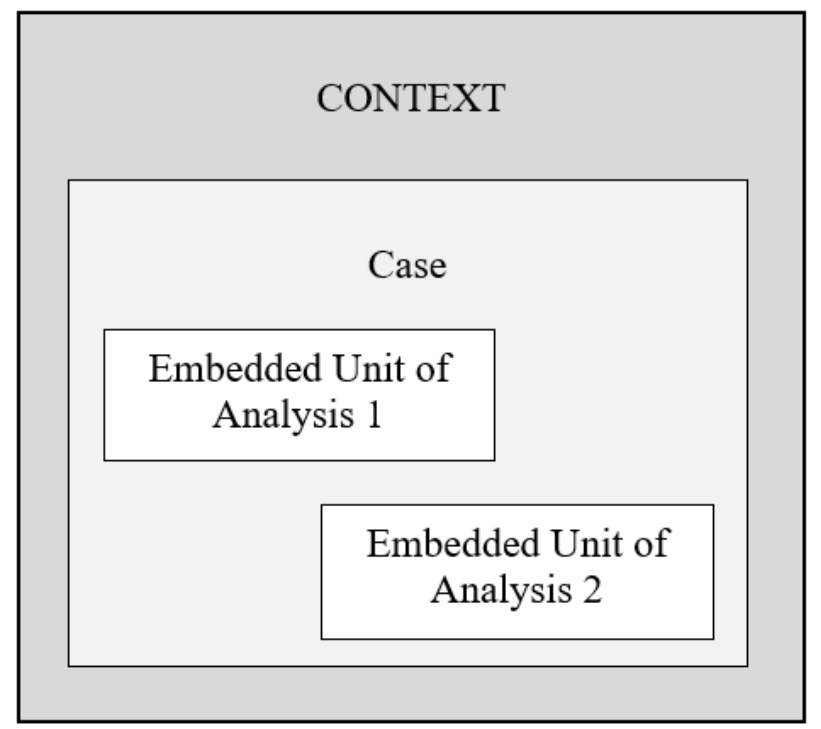

Note. Adapted from Yin (2018)

The primary unit of analysis for this case was the built environment of the university campus, and how students perceived they were influenced by that environment. As an embedded case study, this research design had two specific sub-units of analysis which allowed for a broadening of the study's focus, including the analysis of students' sense of belonging as influenced by the built campus environment (sub-unit 1), and the analysis of the campus's commitment to an institutional value of community as seen through their built environment (sub-unit 2).

This case sought to understand the influence of a particular environmental component (community-focused built spaces) on a particular type of campus (small, residential, Christian, private) with a particular institutional value (the cultivation of student community) in a particular geographic location (rural) on a particular 
psychological component (sense of belonging) of a particular type of students' (residential) college experience. Therefore, the explicit focus of this embedded case study analysis was the influence of the built environment (the bounded unit) on the students' perception of their sense of belonging (sub-unit 1) and on the institution's expressed commitment to student community (sub-unit 2).

\section{Research Sampling}

The rationale for participant selection was determined through two levels of purposeful sampling, beginning with justification for the selection of the case, followed by the grounds for which the people within the case were selected (Merriam \& Tisdell, 2016). Maximum variation sampling strategies for site and participant selection for this study were based on their respective representation of the broader institutional and student demographic populations with the goal of acquiring transferrable interview data for applicability beyond the single institution studied (Seidman, 2013).

\section{Site Selection}

Due to the strong connection identified in the literature between students' sense of belonging and a robust student community on a college campus (Hurtado, 2012; Strange \& Banning, 2015), the criteria for the site selection of this study was narrowed to small, residential, private colleges and universities who cited a high value for developing student community as a component of their institutional mission or value statements. This criterion fit the majority of the member institutions of the Council for Christian Colleges and Universities (CCCU), due to their shared educational approach encompassing an individually holistic and collectively altruistic framework for higher education (CCCU: 
About: What is Christian Higher Education?, n.d.). As such, this exploratory case study was conducted at one CCCU-member institution's campus who fit the above-mentioned criteria for their stated mission or values, as well as who met the additional criteria established through the research question of institutions in a geographically rural location. This site selection criteria assisted in providing data for the second research question, which explored the degree to which the built environment on such campuses upheld their stated institutional values of a robust student community.

Regarding site access for data collection, a site representative who managed the IRB process for the institution was contacted, and the necessary requirements for satisfying IRB stipulations for both the study site, Corban University, and for Portland State University were fulfilled.

\section{Participant Selection}

The criteria for individual participant selection in this study was based on a maximum variation sampling strategy with the goal of interviewing a selection of students who broadly represent the larger population of the site (Seidman, 2013). To support the goal of exploring the study's theoretical orientation toward defining the value of a campus community space as a third place, the participant selection process considered that the defined intent of third places were to develop community within locations outside of home (first place) and outside of work (second place) (Oldenburg, 1989). With consideration to the specificity of a residential university campus as the selected sample site and rooted in the literature (Banning et al., 2006; Waxman et al., 2007; Banning et al., 2010), the assertion was made that residential students engaged with 
and perceived the campus as their first place (home), due to their residential status in a campus residence for approximately eight months of the year. Therefore, for consistency in the data collected for this study, participant selection drew from only the residential student population of the identified site, so that all participants shared the same geographic identification of their campus "home" as consistent with the third place literature. These participant selection criteria provided the most accurate data to answer the first research question, which is: "What are students' experiences of communityfocused built campus spaces as those spaces pertain to students' sense of belonging at a small, rural, residential institution?" In order to collect richer data for answering the second research question of "To what extent do small, rural residential campuses intentionally design or emphasize community-centered third places within their built space?" a select group of institutional employees was also interviewed. The employees were chosen based on their role within the university and the relationship their position had to campus design and/or student space utilization.

Lastly, to ensure the interview data would broadly transferable (Seidman, 2013), student participants were selected from those who had lived on campus for a minimum of one academic year prior to the time of the interviews, and who identified academically as holding sophomore, junior, or senior status at the time of the study. For students to speak to their lived experience on the campus and specifically to their perceptions of the influences of the built environment on their sense of belonging to the institution, a minimum residential requirement of one academic year was identified as the least amount of time necessary to interactively experience the campus environment. The rationale for 
narrowing the scope of participant selection in this way was also due to the timing of the data collection process, which occurred in late September and early October. This aligned with the beginning of the new academic year for the selected study institution, which would have only permitted minimal time spent on campus for first-year students by the time of data collection. These participant selection criteria assisted in providing data for the first research question which explores how students experience community-focused built campus spaces (identified as third places) as they pertain to the students' sense of belonging at the institution.

Due to the goals of reaching appropriate data saturation as well as determining a sufficient sample representation (Seidman, 2013), this study aimed to have $10-15$ students and $3-5$ employees participate through individual interviews. An administrator from the Student Life department at the study site served as a campus liaison and preselected a group of 45 students and 15 employees who met the study's participant criteria. He sent me the full list of students and employees, including their names, email addresses, and for employees, their position titles. Based on the current student makeup of the residential population at the sample institution at the time of data collection, key demographics within the student body (i.e., gender, ethnicity, age, religious affiliation/denomination) were requested to be represented within the student participant group. At the time of the study, $42 \%$ of Corban University's student body lived on campus, as beds for 500 students were available in traditional residence halls (Corban University: Residence Life, n.d., paras.7-17) out of the 1196 total students enrolled on the Salem campus (Corban University: About Corban, n.d., para.2). The campus liaison sent 
an email to all students and employees on the potential participant list, informing them that they would be receiving an invitation from me requesting study participation, and encouraged their involvement. I then sent an email to every study participant (see Appendix A), inviting their participation in the study and requesting a response within one week. The email included basic information about the research study, and participant compensation information stating that students and employees who agreed to participate would be compensated with a $\$ 20.00$ gift card to the campus coffee shop. The email also provided a stated timeline for communication and contact information. Following the distribution of the study invitation, 14 email confirmations were received from student participants and 5 email confirmations from employee participants. Throughout the communication process, 3 students and 1 employee dropped out, leaving a total of 11 student participants and 4 employees as the final participants who engaged in the study. The student participants ranged in the length of time they had lived on campus prior to the time of the study, with 7 living in the residence halls for 4 or more semesters and the remaining 4 living on campus for only 2 semesters. The employee participants ranged in length of employment at Corban from 3 to 15 years, with 2 holding faculty positions and 2 in full time staff roles. Each participant reviewed and signed an informed consent (see Appendix B) and was assigned a pseudonym. See Table 3.1 for a complete list of study participants, pseudonyms, employee/student status, and the number of semesters living on campus (students) or number of years employed by the institution (employees). 
Table 3.1

Research Study Participant List

\begin{tabular}{|c|c|c|}
\hline Participant Pseudonym & Institutional Status & $\begin{array}{c}\text { Semesters lived on } \\
\text { campus/ Years employed } \\
\text { at Corban }\end{array}$ \\
\hline Annie & Student & 6 semesters \\
\hline Ben & Student & 2 semesters \\
\hline Chris & Student & 4 semesters \\
\hline Dan & Student & 2 semesters \\
\hline Eric & Student & 4 semesters \\
\hline Fiona & Student & 4 semesters \\
\hline Grace & Student & 4 semesters \\
\hline Heidi & Student & 2 semesters \\
\hline Isla & Student & 6 semesters \\
\hline Joy & Student & 2 semesters \\
\hline Kevin & Student & 4 semesters \\
\hline Lukas & Employee & 9 years \\
\hline Maggie & Employee & 3 years \\
\hline Nancy & Employee & 4 years \\
\hline Oliver & Employee & 15 years \\
\hline
\end{tabular}

\section{Data Collection}

Considering the focus of the study on the environment in which students engage socially, data was collected in the natural setting of the participants, rather than 
requesting them to leave their context to contribute to the study (Creswell \& Creswell, 2018). Both interviews and environmental observations occurred on the university campus where the participants reside or are employed, which was critical for the full scope of the student experience to be witnessed as participants sought to communicate the influence the built campus space has had on the student experience.

The study developed a holistic account of the issues being researched and identified how multiple factors and perspectives influenced the larger picture which emerged from the data collection and analysis. As with all qualitative research studies, I, as the researcher, served as the primary instrument for data collection and gathered, organized and interpreted the data (Creswell \& Creswell, 2018). However, despite my significant role in data collection, the analysis process provided opportunity to construct meaning from the data as the participants intended, rather than assigning meaning from my perceptions or from the research literature. Therefore, throughout this process, there was an acknowledged and identified reflexivity recognizing the role my positionality and biases could have in influencing how the data was interpreted and ultimately constructed (Creswell \& Creswell, 2018).

Multiple types of data were collected in the form of audio-recordings of the interviews, researcher memos, observation notes, archival information, and digital photographs from campus observations to illustrate relevant themes. These provided breadth to the scope of the study, allowing for a view of the same topic from multiple angles rather than interpreting the data through a singular perspective. These varied data forms were also compared to one another to assess the level of support they offer toward 
reaching similar conclusions (triangulation), which enriched the study's validity (Maxwell, 2013).

The specific data collection approaches used in this embedded case study included student interviews, environmental observation (including digital photography), and archival research. These approaches were selected due to their methodological fit and alignment with the stated research questions. Interviews are one of the most important sources of evidence for case studies because of their ability to provide data on why and how things occur through the lens of the participant, which is a key element of qualitative research (Yin, 2018). Direct observations added significant dimensionality to the data collected during interviews, as viewing people actively engaged within an environment brought new understandings of their behaviors and decisions (Yin, 2018). And due to the environmental nature of the study considering the campus topography and buildings, historical archive data added context and a perspective of the campus development over time.

\section{Interviews}

Seidman (2013) stated that interviewing is an effective method of inquiry if the goal of the research is to understand the meaning people make from their experiences. "At the very heart of what it means to be human is the ability of people to symbolize their experience through language" (Seidman, 2013, p. 8). However, in order to effectively understand another person's communicated experiences and to appropriately interpret the meaning the participant is expressing, recognition of the unique perspectives of the participant is critical to the process of qualitative interviewing (Warren, 2001). This 
recognition requires a foundational shift from the historic view that interviewing operates on the premise of neutrality, and to adopt a more human and empathetic approach where the interviewer becomes an advocate who "takes an ethical stance in favor of the individual or group being studied" (Fontana \& Frey, 2005, p. 696).

Interview protocol for the Corban study included emailing the individual participants an outline of the requirements for involvement and inviting them to participate (see Appendix A). The email also included an attached consent form which outlined the potential risks of involvement and communicated that they would be given the opportunity to sign the consent form prior to their interview (see Appendix B) should they commit to participation. Finally, the email informed them that a $\$ 20$ gift card to the campus coffee shop would be given to each participant following their interview as compensation for involvement.

As qualitative interviews are rooted in the premise of constructing meaning from participants, the interview structure reflected an interactional philosophy, recognizing that "the nature of the social dynamic of the interview can shape the nature of the knowledge generated" (Fontana \& Frey, 2005, p. 699). Beyond strategically developed interview questions, establishing the most operative location and times for interviews were the other key contributors utilized for effective data collection (Glesne \& Peshkin, 1992). Due to my geographic distance from Corban University, a total of five full or partial days were spent on the campus. Multiple interviews were scheduled within the same day, based on participant availability. Regarding interview location selection, Fontana and Frey (2005) discussed the critical importance of appropriately gaining access 
to participants' space by considering how the appearance and language of the researcher should, to some extent, reflect that of the participant's environment. Due to this, consultation with the campus liaison occurred prior to my first campus visit to gain insight on any informative environmental factors that might hinder or benefit the interview process as well as recommendations for appropriate campus locations to hold interviews. Each participant was asked for an interview location preference during email correspondence following their agreement to engage in the study. Nine of the eleven student participants requested to hold interviews in the campus coffee shop, while the remaining three students requested to meet in a residence hall lobby, the Psalm Center lobby, and a study room in the library, respectively. Of the four employees interviewed, three requested meeting in their respective offices, while the fourth offered to let me select an area of campus I hadn't yet observed, so we held our interview in The Barn, following a tour of the space. Each of the selected interview locations provided insightful perspective on the campus environment, as well as the participants' views on the space itself.

Interviews were scheduled to last one hour in length, as Glesne \& Peshkin (1992) noted that one hour of steady conversation is a maximum time for effective and fluid communication. Most interviews took the full hour, with a few less-talkative participants utilizing only 45 minutes. Each interview began by providing a brief introduction to the study consisting of its purpose and goals, the two research questions, definitions of key concepts (including third place, community, and sense of belonging), a review of the interview format (including types of interview questions, interview length, and number of 
participants), and data collection methodology (including variety of ways data was being collected, how interview transcription would occur, how pseudonyms would be assigned, and the timeline for study completion), concluding with the opportunity for the participant to ask questions.

Interview questions were partially modeled after two previous research studies by Banning which asked college students to identify their third places on the campuses of two large public institutions in 2006 and 2010, respectively. The 2010 study found that nearly $80 \%$ of those interviewed identified their third places off campus and concluded with an implication that universities should put more emphasis on establishing third place locations on campus. This previous data drove the current study to assess if similar findings would be true of a small, rural residential university campus. Therefore, the interview questions of this study were modeled after Banning's two previous research studies and included questions such as: how would you describe your third place? What attracts you to your third place? How often do you frequent your third place (Banning, et al., 2010)? Pre-established prompts (see Appendix C) to gain more insights on the research questions were also utilized.

Therefore, this qualitative case study used semi-structured interview questions which were broad and open, providing the participants a breadth of space to discuss their personal experiences and feelings (see Appendix C). Because the interviews focused on students' observations of built campus space and the influence they perceived the space had on them, the questions were divided into three categories: demographic questions (name, major, academic standing, etc.), experiential/behavior questions (inquiring about 
their reflections on and use of built campus space), and perception/feeling questions (inquiring about how the spaces influence them). This structure for interview questions fit the personalized, experiential nature of the data necessary to answer the first research question, which asked: "What are students' experiences of community-focused built campus spaces as those spaces pertain to students' sense of belonging at a small, rural, residential institution?"

Similarly-structured but slightly modified interview questions were designed for employee interviews (see Appendix C), which also provided both experiential/behavior data as well as perception/feeling data, contributing to answering the second research question of: "To what extent do small, rural residential campuses intentionally design or emphasize community-centered third places within their built space?"

Each participant was asked if they were aware of specific times when students more frequently used the locations identified as meeting the qualification of campus third places. Effort was then made to engage in field observation at those identified locations during the specified high-use times identified by participants. The observation rationale and structure are outlined in further detail in the coming section.

\section{Observations}

Jorgensen (2015) states that participant observation is the ideal methodology for projects such as case studies where the goal is to gain practical and theoretical information about human life rooted in daily realities. Observation provided me a firsthand view of patterns of behavior and the opportunity to experience what was expected, as well as what was unexpected (Glesne \& Peshkin, 1992). Since the focus of 
this study was on students' perceptions of how they were influenced by communityfocused built spaces on campus, observing how students utilized and engaged within those spaces communicated valuable information about their environmental realities.

As such, along with interviews, observation was the other primary method for collecting data to answer the research questions. Experiential data from the observations made of the specific built campus spaces or the participant-identified third places assisted in answering the first research question: "What are students' experiences of communityfocused built campus spaces as those spaces pertain to students' sense of belonging at a small, rural, residential institution?" General campus observations provided more applicable data to inform the second research question: "To what extent do small, rural residential campuses intentionally design or emphasize community-centered third places within their built space?" Concentrated time viewing the third places on campus identified from participant interviews, and patterns of student use within them provided insightful data on the overall campus design, as well as the institution's emphasis on community-centered spaces.

Two phases of campus observations were held. The first occurred prior to participant interviews, for the purpose of familiarizing myself with the selected site and making initial observations regarding the student community spaces within the built campus environment. Utilizing a campus map, I observed campus locations perceived for the use of student community building. Field notes and photographs were taken during the 20-45 minutes spent in each space. Participant interviews followed the general campus observations, then the second observation phase of the study occurred in the 
locations student participants identified during the interviews as meeting the criteria for third places on campus. Based on the literature, I anticipated that the identified third place locations would be the campus coffee shop, library, or student lounges. The second phase of campus observations were attempted to occur at times similar to those the student participants articulated as being high-use times, and field notes and photographs were taken during the 20-45 minutes spent in each identified site.

During observations, field notes and photographs were utilized to document both environmental aspects of the built campus spaces as well as how students engage socially within those spaces. The first phase of observations (pre-interview) focused generally on the overall built structure of the campus and broad student usage patterns. Of interest will be observation of perceived "community" happening in a daily, patterned context. Postinterview observations occurred specifically within sites student participants identified as campus locations focused on community building, which they interpreted as meeting the definition of a third place. In those locations, field notes and photographs were taken, paying special attention to how students engaged socially as well as how individual students interacted with the elements of the built space itself. See Appendix D for a field note observation framework.

\section{Archival Information}

Due to the environmental nature of the study considering the campus topography and buildings, historical archive data was the last necessary step of data collection to provide context and understanding of the development and use of the campus over time. Online searches for archival records of the campus property provided both historic 
photographs of original buildings prior to the university's acquisition, and documentation regarding the development and prior uses of the property. These documents were instructional in understanding the current campus topography and building utilization, providing background and context to support the interview and observation data.

\section{Data Analysis}

The process of data analysis can be summed up as simply creating a structure to organize what has been read, observed, and heard in order to make sense of what has been learned (Glesne \& Peshkin, 1992). The process has been compared to peeling back the layers of an onion as it involves organizing the data into segments and taking it apart, looking deeply at every piece inside (Creswell \& Creswell (2018). The analysis for the data in this study focused on the bounded nature of the case and consisted of following the steps of analysis allowing for the creation of a holistic description of the case (Merriam \& Tisdell, 2016). This process included preparing the data for analysis by transcribing interviews, scanning non-digital materials, typing field notes and researcher memos, and cataloging and arranging data by source type. The next step involved reading and reflecting on the data, while taking notes on the overall depth, credibility, and potential usefulness of the information (Creswell \& Creswell, 2018). Data coding followed and was done utilizing QDA Miner Lite digital software to organize the data into chunks represented by a key word or phrase. This study organized the data utilizing provisional codes pre-selected for their alignment with the conceptual and theoretical frameworks of the research, followed by a process of open coding while analyzing the 
data. The codes were then organized into descriptive and analytic themes and represented through a qualitative narrative overview of the data.

\section{Transcription}

The best database for qualitative data analysis is produced when recorded interviews are transcribed verbatim (Merriam \& Tisdell, 2016). Initial transcription occurred during each interview through the web-based Otter.AI program which automatically created transcription while also audio-recording. Following the completion of all interviews, I listened to the audio recordings while reading the transcriptions to ensure accuracy and correct the content captured. Formatting the transcription was critical for comprehension and ease of reading, therefore each line of text was single spaced with double spaces between speakers, with an interview time stamp automatically produced by the program at each new speaker.

Participant risk was minimized through the transcription process by providing pseudonyms and asking participant permission to use any additional personally identifying information, such as student leadership position held. Participants were informed that identifying photographs would only be included in the study with the permission of those visible.

\section{Coding}

Due to the constructivist paradigm of this study which considered how each participant constructed meaning from their environment, the coding structure began with a foundational set of provisional codes, followed by the creation of additional codes based on key concepts identified by participants culled through the process of open 
coding. This coding structure began first with the creation of anticipated categories, or provisional codes (Saldana, 2016) prior to participant interviews. These codes were generated from the study's conceptual framework and research questions, literature related to the study, and from my prior knowledge and experience on the topics of the study (Saldana, 2016) (see Appendix E). The provisional codes were then organized by the study's conceptual framework (campus ecology), theoretical frameworks (third place and sense of belonging), and a site characteristics category (institutions with value of student community; namely the Council for Christian Colleges and Universities). Not all provisional codes were utilized, as some anticipated codes did not align with participants' experiences or with the shared language participants utilized to describe institutional or cultural anomalies specific to the study site.

Once the interviews were complete and transcripts edited, an open coding process was utilized to categorize additional themes from the data within the structure based on the study's conceptual and theoretical frames. Open coding involves a broad analysis of the data to find the maximum number of relevant concepts to be categorized, or "coding all the data in every possible way" (Glaser, 2016, p. 108). In the open coding process, several themes emerged from the same code, creating sub-codes. For example, the code “design" categorized within the campus ecology grouping had five differentiated variations identified by participants, resulting in each variable subtheme receiving its own code. Similarly, while a provisional code may have been anticipated to fall primarily under one framework, during the open coding process some codes (such as "activity engagement") were repeated by participants, but within the context of differing 
frameworks (e.g., fitting under both the sense of belonging and third place theoretical frames), and were therefore organized as two separate codes.

A codebook was created utilizing QDA Miner Lite software to identify, organize, and track the categories of code structures as well as the code descriptions (both provisional and open codes). The coded transcription data was next analyzed using a funneled order of categorization, considering the entire list of individual codes and grouping them together into narrower categories, and then clustered into larger themes. The three themes which emerged from the coded data funnel were campus topography, campus infrastructure, and social dynamics of space. Each theme was then organized and analyzed alongside the study's two research questions to assess the degree to which they satisfied the questions the research had posed, resulting in the basis for the presentation of data.

\section{Ethical Considerations}

Engaging in ethical qualitative research practices obligates the researcher to consider more than simply following the policies established by institutional review boards or other organizational standards, but to also give ethical consideration to the unique situations and the individual people involved in the study (Merriam \& Tisdsell, 2016).

As a research approach used widely within the applied fields of the social sciences, qualitative research predominately involves the study of people (Merriam \& Tisdsell, 2016). As such, developing trust between the researcher and those being studied is critical, as participants are more likely to provide straightforward, honest and more 
detailed feedback when they believe the researcher has their interests in mind (Glesne \& Peshkin, 1992). For the study to gain external credibility as research, trustworthiness of the data collection and analysis processes must be established.

\section{Trustworthiness of the Study}

Due to the socially constructed nature of qualitative research, the reality of the phenomenon being studied is subjective and multidimensional rather than objective and fixed (Merriam \& Tisdell, 2016) and can only reflect a snapshot of the context and situation surrounding the time of the study. The data cannot be replicated as the understandings gained are only reflective of a bounded period of time in the life of the participants and will have shifted due to life change and growth as times goes on (Tracy, 2012). Therefore, the validity of a study becomes relative and "has to be assessed in relationship to the purposes and circumstances of the research, rather than being a context-independent property of methods or conclusions" (Maxwell, 2013, p. 121). To ensure validity, creating methodology which demonstrates the existence of evidence reduces validity threats (Maxwell, 2013). This study employed practices of data triangulation, adequate time spent in data collection, and identified my positionality as the researcher to highlight the evidence necessary to reduce threats to the validity of the study (Merriam \& Tisdell, 2016). Triangulation of the data occurred when data from interviews were checked against data from observations, affirming that the content aligned with the data collected from field notes which ensured convergence. Lastly, my positionality and assumptions as the researcher were assessed and identified, as 
articulated in the upcoming section. All methods led to improved trustworthiness of the study.

\section{Researcher Positionality}

While efforts should be taken to account for and reduce researcher bias, Tracy (1995) asserts that it is impossible for anyone to perform completely objective research, free of any personal bias. Further, researcher subjectivity allows for personal experiences and perspectives to become the premise upon which the researcher shapes and tells the story of the study (Glesne \& Peshkin, 1992). This study grew out of my professional and personal experiences as the researcher, which cultivated a passion around the research topic developed within it.

As the researcher, my positionality is very connected to why I chose to focus the scope of my study on member institutions within the Council for Christian Colleges and Universities (CCCU). My personal experience with these predominately small, private, residential, liberal arts, Christian institutions is significant to my own academic and professional development as I have been deeply involved with these schools since I first left home to attend college at a CCCU member institution in 1992. Since that time, I have been employed by four CCCU institutions and received my Master of Education degree from another. Since 1997 I have participated with and served in several leadership capacities for a professional Student Affairs organization called the Association for Christians in Student Development (ACSD) that includes these institutions in their membership. Through this involvement, I have annually visited member campuses for conference participation, resulting in familiarity with the people, places, and institutional 
philosophies of many of the CCCU campuses. I also personally resonate with the CCCU's governing belief in the historic Christian faith and find deep value in the Council's shared missional commitment to holistically developing students in mind, spirit, and body, integrating Biblical principles with academic scholarship rooted in the arts and sciences (CCCU, 2018).

The significant familiarity and alignment I hold with member institutions of the Council for Christian Colleges and Universities allows for greater access to my selected study site, as well as acceptance within a CCCU institution for data collection. My understanding of how these institutions function served as a beneficial framework for how I collected and interpreted the data. However, based on my previous experiences with these campuses, that same familiarity has the potential to increase my assumptions of how CCCU institutions should work; a potentially negative bias I remained mindful of eliminating throughout the research process. Clearly identifying my position and the potential for personal bias, along with data triangulation were all critical methods for eliminating validity threats to this study.

\section{Chapter Summary}

This study explored the influence of the built campus environment on college students' sense of belonging within spaces perceived to foster a robust student community that met the criterion of third places on a small, rural, residential, private university campus in the Pacific Northwest. The third place context within a university campus environment considered campus residences as a first place with the classroom serving as the second place (Banning et al., 2006; Banning et al., 2010; Waxman et al., 
2007;), which left a gap for the campus third place location to be defined. Explored through participant interviews and campus observation, the data accumulated through this embedded case study analysis sought to answer the study's two research questions surrounding students' perceptions of the influence of the built campus environment on their sense of belonging and the degree to which the institution commits to creating or enhancing built space for the explicit purpose of developing a vibrant student community. 


\section{CHAPTER 4: FINDINGS}

The purpose of this case study was to explore student perceptions of the influence of the built campus environment on their sense of belonging to their institution, as well as how the built spaces on small, rural, residential, private university campuses support the institutional value of fostering a strong student community. As described in earlier chapters, the study was framed by the theories of campus ecology (Banning, 1978), college students' sense of belonging (Strayhorn, 2012), and the sociological concept of third place (Oldenburg, 1989).

The study was conducted on the campus of Corban University, a small, rural, residential private, Christian institution in the Pacific Northwest of the United States, where data was collected from fourteen semi-structured interviews with students and employees, field observations, and archival research. Through data analysis, three primary themes emerged, each with supporting subthemes, as seen in Table 1 . When framed through the lens of campus ecology, each main theme was discovered as an influencing factor in students' sense of belonging to their institution. The three dominant themes were: campus topography, campus infrastructure, and social dynamics of space.

\section{Table 4.1}

Emergent Themes and Supporting Subthemes

\begin{tabular}{|l|l|}
\hline Theme & Subtheme \\
\hline Campus Topography & $\begin{array}{l}\text { Hillside Campus } \\
\text { Pathways/Wayfinding } \\
\text { Building Location }\end{array}$ \\
\hline
\end{tabular}




\begin{tabular}{|l|l|}
\hline Campus Infrastructure & Policies \\
Resource Allocation/Prioritization \\
Institutional Communication \\
Space Design/Furniture Layout
\end{tabular}

The themes created a funnel for presenting the data, looking first at the macro view of campus as a whole, then moving toward smaller structures and personalized perspectives. The first theme, and widest part of the funnel, is the physical nature of the university: campus topography. It considered the data which demonstrated the influence of the natural or built structural elements of campus on how students experience community. The second theme is campus infrastructure, which is rooted in administrative frameworks and decision-making and analyzed how policies and practices influenced students' ability to feel a sense of belonging on campus. And the last emergent theme is the student experience, considering the social dynamics occurring within campus spaces and how those lived experiences contribute to a students' sense of belonging. While one of the study's research goals is to produce data transferable to other institutions for the purpose of furthering both theory and practice, the unique characteristics of this study's research site provides context for framing the data themes and understanding their broader application. 


\section{Campus Context}

Ecologically, the unique topographical as well as missional contexts of the campus where data was collected proved to have a significant influence on key factors that shape the university's student community. The study site was selected for its overt articulation of an institutional value of a robust student community. For the purpose of this study, community was defined as a psychological sense of belonging to a group and a perception of one's ability to have influence within that group, a shared belief that members' needs will be met by their commitment to be together, and a shared emotional connection (McMillan \& Chavis,1986). Every student interviewed reported some level of connection to the campus community, and every employee interviewed affirmed the perception that the institution places value on students feeling connected to one another in a committed way. This relational commitment to community identified by students and employees shared the following combination of factors: community is shaped within a space which allows access to a variety of students and allows versatility for engagement in a variety of activities. It was further identified that the shared emotional connections developed within these identified campus spaces increased the students' sense of belonging when the peers they engaged with shared a similar affinity. Due to the institution's theological identity, one of the broadest common affinities among students and employees alike was a shared articulation recognizing, if not a personal alignment with, the Christian faith. 


\section{Theological Commitment to Community}

The spiritual climate on campus was frequently identified as a contributor to students' relational commitments influencing their feelings of belonging. One student, Heidi, said: "we're already a family in Christ's dynamic and that gives you more of a fluidity and a grace for infringing on other people's spaces without it feeling like infringement." She gave the following example: “...in your house, there are spots where people typically gravitate toward, but if my brother sits on the couch where I usually sit, he's my brother, so I don't even think about it. I just move to a different space, because we're family. That's how it is, naturally." From Heidi's perspective, the collective spiritual commitment of the community contributed to a willingness to graciously share space. Another student, Dan, reported that after participating in campus worship night events with other students, his individual faith was strengthened because of the spiritual experience he shared within the context of the campus community.

Employees agreed that strong student community is a natural outpouring of the theological commitment of the university. Lukas (employee) discussed how "spiritual formation isn't usually... an individual endeavor. With terms like discipleship, there is more of a community, a plurality." Spiritually focused events were identified as having some of the largest participation from the campus community. One employee reported over 600 people in attendance at a worship service held at the campus outdoor amphitheater. The chapel program, which, unlike most Christian universities, does not have mandatory attendance, was also identified as a contributor to relational commitments specifically because students are not required to attend. As Eric identified: 
Everyone in there [chapel], we're all there for the same purpose. And that's because we're choosing to go, almost like a sacrifice in some way. We're coming to hear a message... and in one way or another you're giving up something that may be more meaningful.

This shared sacrifice, as Eric identified it, contributed to his sense of belonging within the student group who regularly attends chapel.

\section{University Administration's Commitment to Community}

University administrators at the institution were identified as placing a priority on community, as witnessed through their individual investments. An employee named Nancy recalled hearing students talk about how impactful it was when the university president demonstrated his commitment to the student community by spending the night in a men's residence hall to gain student perspective. Another employee, Oliver, discussed how the Vice President for Student Life had a vision for students to engage their curiosity in community, so she proposed, developed, and facilitated the transformation of a large storage area into a student maker space. A student leader referenced his confidence in the administration's commitment to student community because of their involvement leading a session on the importance of community during leadership training at the beginning of the year. These examples from employees and students alike communicated that this institution does more than simply talk about their value of community; they put action behind their words, showing up and making institutional decisions demonstrating their commitment. 


\section{Institutional Mission and Values}

The research site, Corban University, is located in Salem, Oregon, and has an undergraduate enrollment of 1,048 (College Tuition Compare, 2020). Under the "Mission and Values" section of the Corban University website, the second subpoint beneath the mission statement posits: "To build a vibrant Christian community that promotes worship, creative expression, and activities reflecting God's character" (Corban University: Mission and Values, n.d., para.1).

One employee discussed how the three C's of the university's "Vision for Our Students" statement (Character, Competence, and Christ) could easily include a fourth C of "Community" due to its prominence in institutional culture. When this employee was asked how he has seen community expressed as a university value, he attributed longstanding policies like small class sizes and on-campus residency requirements to the university's prioritization of student community building. He also referenced the subtle ways faculty and staff are encouraged to invest personally in the lives of students: "unspoken goals to create faculty and student connections...creates community," he said. This goal of employee-student relationships may be unspoken, but according to another employee, it is certainly modeled from the top down. "Lots of our upper management have personal connections to students...staff and even some administrators will write encouragement cards and put them in mailboxes, and a lot of [students] even get invited to their homes," she said. For employees to treat students with this type of care, hospitality, and kindness certainly embodies the element of the institutional mission: "To 
build a vibrant Christian community that promotes...activities reflecting God's character."

The context of Corban University as a small, Christian, rural institution contributes to its collective value of a strong student community. The small student body size provides a natural intimacy where student report feeling seen and known by many peers and employees alike. The institution's theological framework reinforces the belief that caring for one another is a Christian calling which supports and strengthens the community-centered emphasis. And the institution's rural location creates a relative geographic separation from the nearest urban center while also allowing for the agrarian topography to contribute to the social dynamics of campus life.

\section{Campus Building History}

Corban University acquired its current campus property as recently as 1969, and the unique history of the land, the institutions previously functioning there, and their buildings all provide context for some of the current structural limitations the university experiences. When discussing campus topography with participants, I consistently heard references to the impact of being built on a hillside, being outside of the city of Salem in a valley surrounded by farmland, and comments about the old buildings that "weren't intended for this" (Oliver, employee). Despite significant campus modernization in the 50 years since repurposing the land for an institution of higher education, these geographic realities of the property and original buildings create limitations for student function.

The current Corban campus property was acquired by the university in 1969 when the university relocated from El Cerrito, California (Corban University: Our History, n.d., 
para.9) into the space formerly inhabited by the Oregon tuberculosis hospital and prior to that, a school for the deaf. The property was first developed by the Oregon State DeafMute School in 1894 (Oregon Health and Sciences University, 2005), then abandoned in 1897 when the deaf school relocated closer into Salem due to difficulty transporting supplies to such a remote and nearly roadless location (Oregon Health and Sciences University, 2005). In 1910 the Oregon State Tuberculosis Hospital acquired the property as the state was in search of a facility which would provide ample space for pastures, gardening, and lots of fresh air, which was deemed medically necessary for recovery from tuberculosis (Oregon Health and Sciences University, 2005). The property included four buildings at the time of the hospital acquisition, with two of the four original buildings (Willamette Heritage Center, 2012), the academic building and the horse stable, still in use at Corban University today.

Schimmel Hall is the property's original building, built in 1895 as the Oregon State Deaf-Mute School (see Figure 4.1), and now serves as the university's primary administrative building housing several offices including the president, admissions and student services, as well as the campus dining hall (GoogleMaps: Corban University Campus Map, n.d.). Schimmel Hall is one of the most prominent landmarks on campus due to its central and visible location on a bluff overlooking the road that borders the west side of the campus. 


\section{Figure 4.1}

Schimmel Hall when Oregon Deaf-Mute School circa 1895, and Current Day
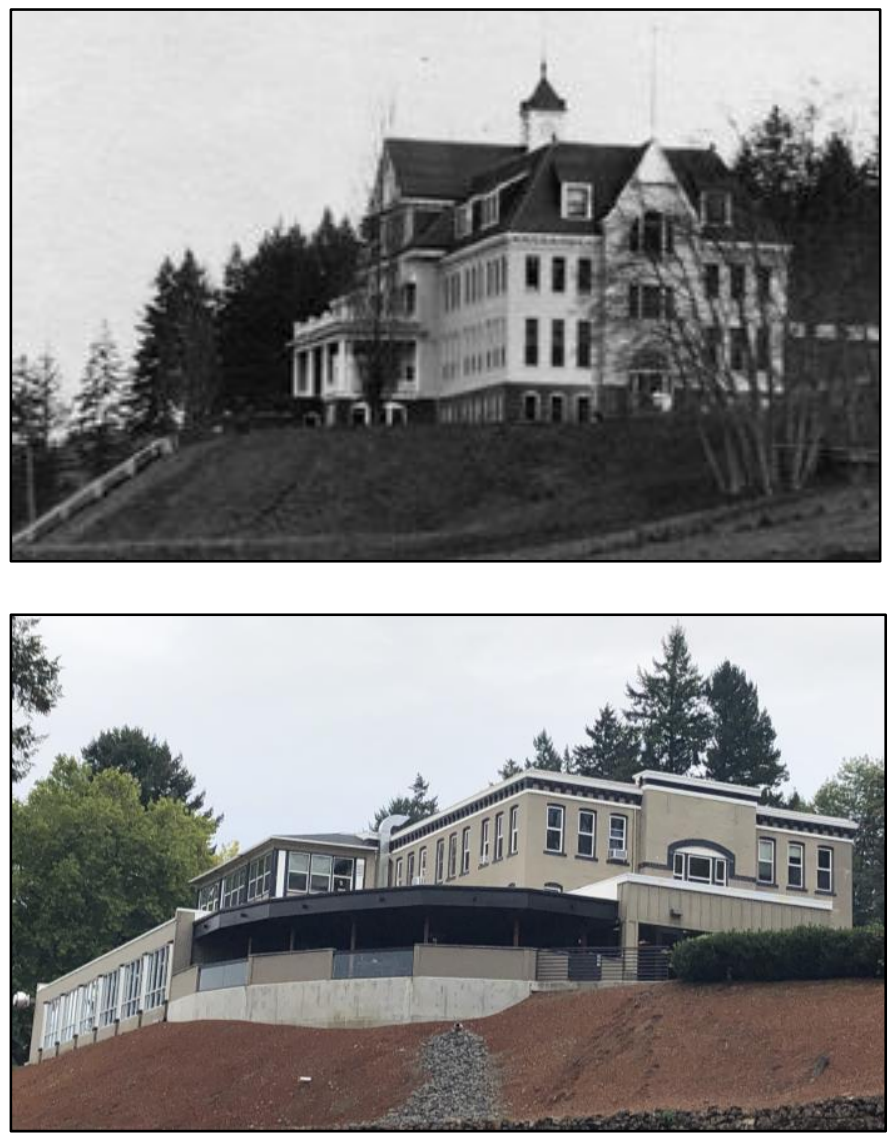

Note. Upper panel photo credit: Oregon Health and Sciences University Archives; Lower panel photo credit: K. Stave

The all-brick Campus Care building (see Figure 4.2) is the other facility built before the turn of the century for the Deaf-Mute School and still in use by Corban University today. In 1897 it was constructed as a horse stable for commuter students of the deaf-mute school, and later housed the property's boiler. One of Corban University's oldest historic buildings, it now houses the campus maintenance, housekeeping, and ground crew offices. 


\section{Figure 4.2}

The Corban University Campus Care Facility; Originally a Horse Stable in 1897

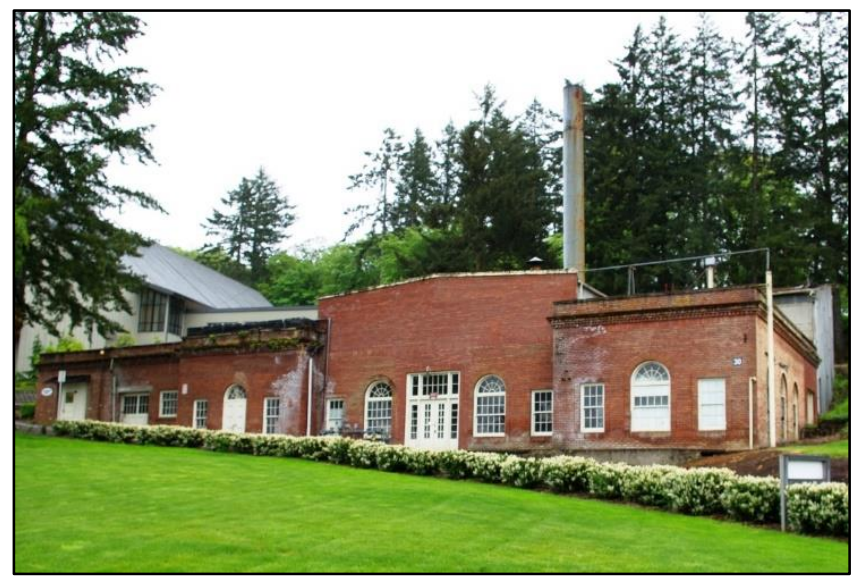

Note. Photo credit: M.O. Stevens

The tuberculosis hospital built several more buildings during their fifty-year tenure on the property, several of which are still in use by Corban University. One of the hospital's earliest building projects was the engine room and the dairy barn built in 1912 (Oregon Health and Sciences University, 2005)The dairy barn was necessary for care of the large herd of cows the hospital managed to meet the dairy needs of both patients and employees living on the property. Eventually the hospital developed sixty acres of garden plots to supply the residential population with food and to raise their own feed for the cow herd (Willamette Heritage Center, 2012). When Corban occupied the property, the dairy barn was utilized for storage until 2017 when it was remodeled into a student maker space (Figure 4.3). 


\section{Figure 4.3}

1912 Milk Barn and Engine Room Turned Current Day Maker Space
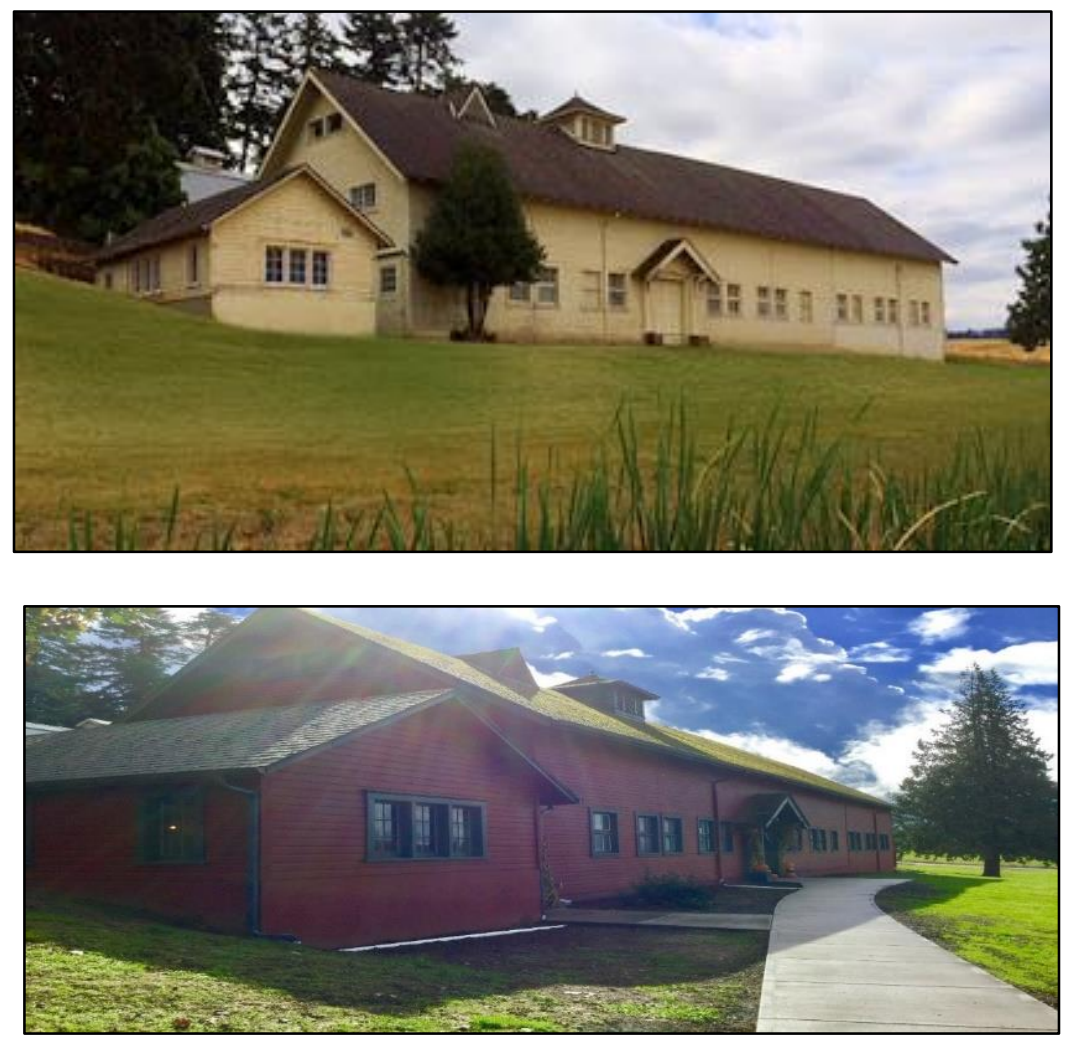

Note. Upper panel photo credit: S. Hunt; Lower panel photo credit: Corban University website Between 1910 and 1925, five residential pavilions were built as dormitories for tuberculosis patients. Open-air sleeping pavilions were one of the best practices of the day for treating tuberculosis (Willamette Heritage Center, 2012). Figure 4.4 shows one of the medical pavilions with a long row of beds opposite a wall of windows to let in fresh air. Four of the five pavilions at the tuberculosis hospital were razed by 1957, but Pavilion C, built in 1923 was retained (Oregon Health and Sciences University, 2005) and is still in use on Corban's campus today (Figure 4.5). In 2005 Corban University’s Pavilion, the home of the campus Student Center including the Common Grounds coffee 
shop, the commuter lounge, and classrooms, was remodeled, and serves as a central hub of student activity on Corban's campus.

Figure 4.4

An Open-Air Sleeping Pavilion for the Patients of the Tuberculosis Hospital, 1920

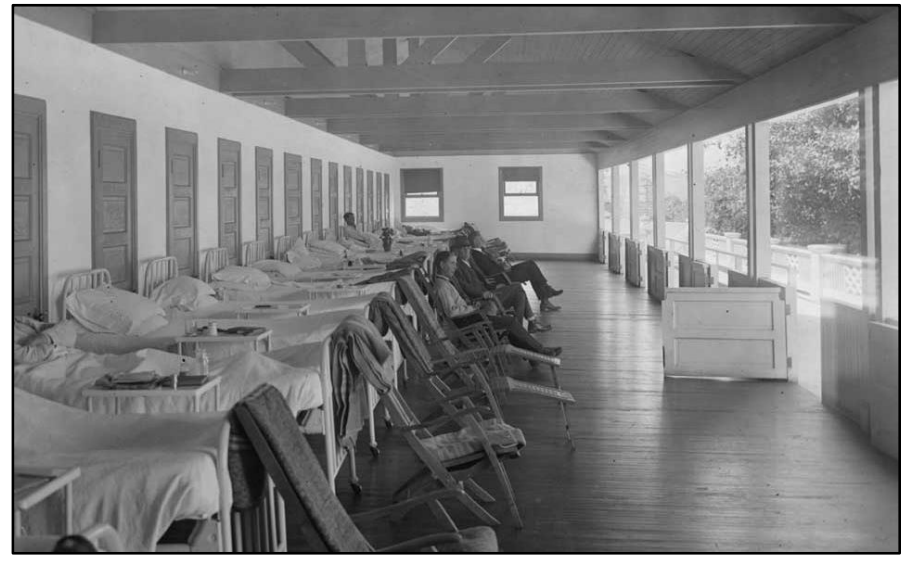

Note. Photo credit: OHSU Digital Collections

\section{Figure 4.5}

Corban University's Pavilion Built in 1923, Photo from 2020

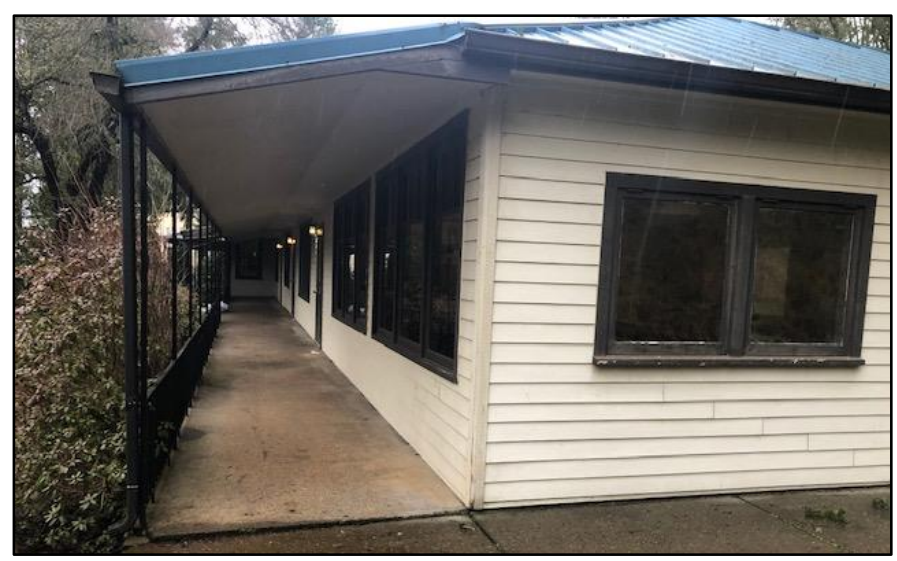

Note. Photo credit: E. Edwards 
In 1932 the tuberculosis hospital completed construction on a multi-story medical facility (Oregon Health and Sciences University, 2005) which later became the university’s Academic Center housing faculty offices, classrooms, the library, and the campus bookstore (Figure 4.6).

\section{Figure 4.6}

1932 Tuberculosis Hospital, Currently Primary Academic Center of Corban's Campus
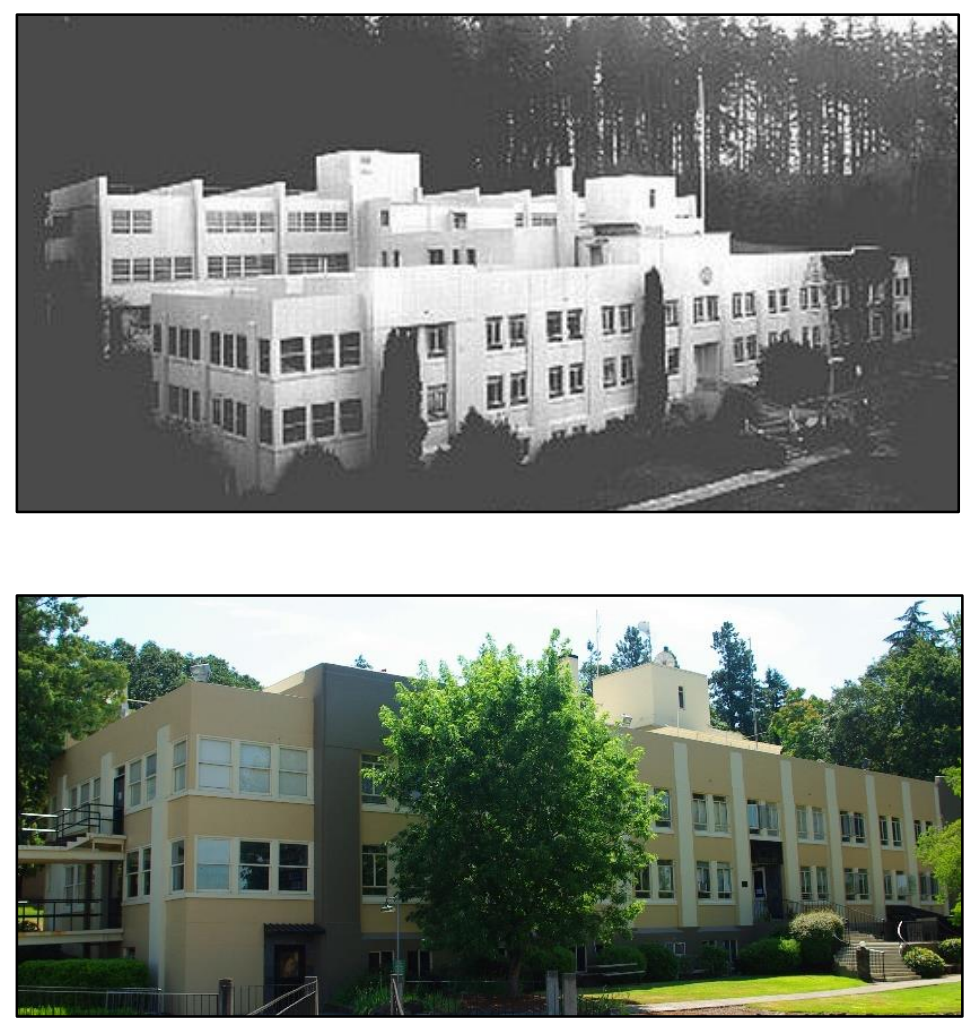

Note. Upper panel photo credit: Oregon Historic Photograph Collections; Lower panel photo credit: M.O. Stevens

In 1934 a Nurses Home housing 40 nursing staff was built out of brick reclaimed from the Oregon State Capitol building fire (Oregon Health and Sciences University, 2005). This building remains on Corban's campus as the oldest residence hall, holding 55 
male residents and named Farrar Hall (Figure 4.7), after the Reverend Herbert Farrar, Corban University's first president (GoogleMaps: Corban University Campus Map, n.d.).

The last remaining campus building constructed for the Tuberculosis Hospital was a dormitory to house male and female employees in 1953 (Oregon Health and Sciences University, 2005), which now serves the campus as the all-female Aagard Residence Hall (Figure 4.8) and the sister hall to Farrar, collectively known as "Fraagard" due to their location as the only residence halls at the bottom of the campus hill.

\section{Figure 4.7}

Farrar Hall is the Oldest Residence Hall on Corban's Campus, Built in 1934

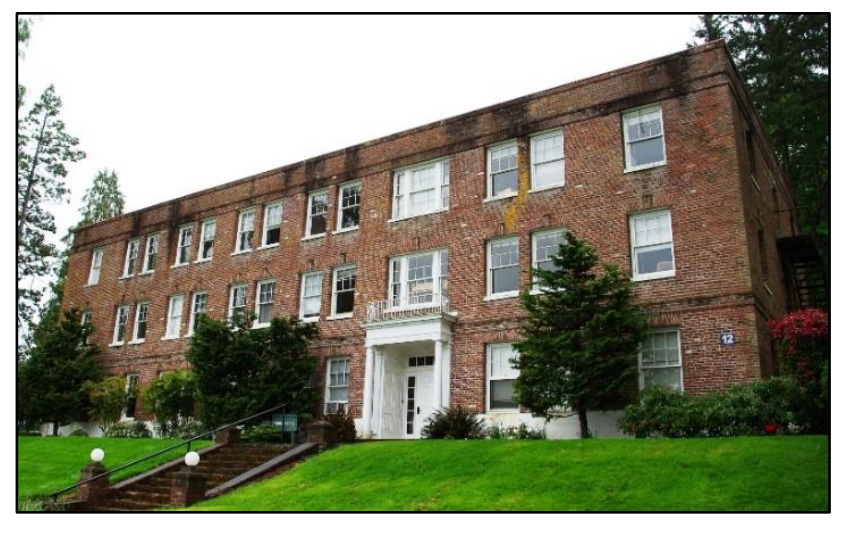

Note. Photo credit: M.O. Stevens 


\section{Figure 4.8}

Aagard Hall: TB Hospital's Last Construction Project (1953) remaining at Corban Univ.

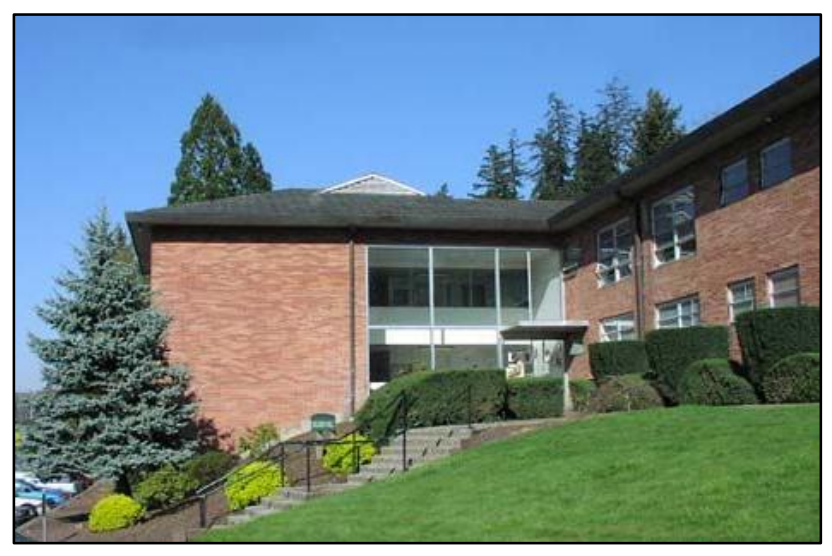

Note. Photo credit: Corban University website

While both previous property occupants were educational in mission as well as residential, they clearly were not built with the intention of housing a modern-day university. From the study's observation and interview data, it was clear that some structural elements of the buildings as well as their locations created barriers to the formation of student community. Despite those identified challenges, however, the buildings have also provided creative opportunities that have resulted in key elements of the unique identity and culture of Corban University's campus.

\section{Theme 1: Campus Topography}

The theme of campus topography emerged as the clearest descriptor of participant's experiences of or with the designed, built, or natural components of the campus. The most prominent topological campus elements which had the greatest influence on the participants' views of students' sense of belonging were clustered within three subthemes: hillside campus, wayfinding and pathways, and building location. 


\section{Hillside Campus}

Corban University has 220 acres of property built into a forested hillside in a rural region of Salem, Oregon (Corban University: Facts and Distinctions, n.d., para 11). During my field observations, the most commonly utilized language regarding campus navigation was "up" or "down," which due to the hillside, was a geographically accurate direction for every destination on Corban's campus. As seen in the topographic map in Figure 4.9, the steepest part of the hill is the side where the majority of the campus buildings are located.

\section{Figure 4.9}

Topographic Map Demonstrating the Hillside Incline on Corban University's Campus

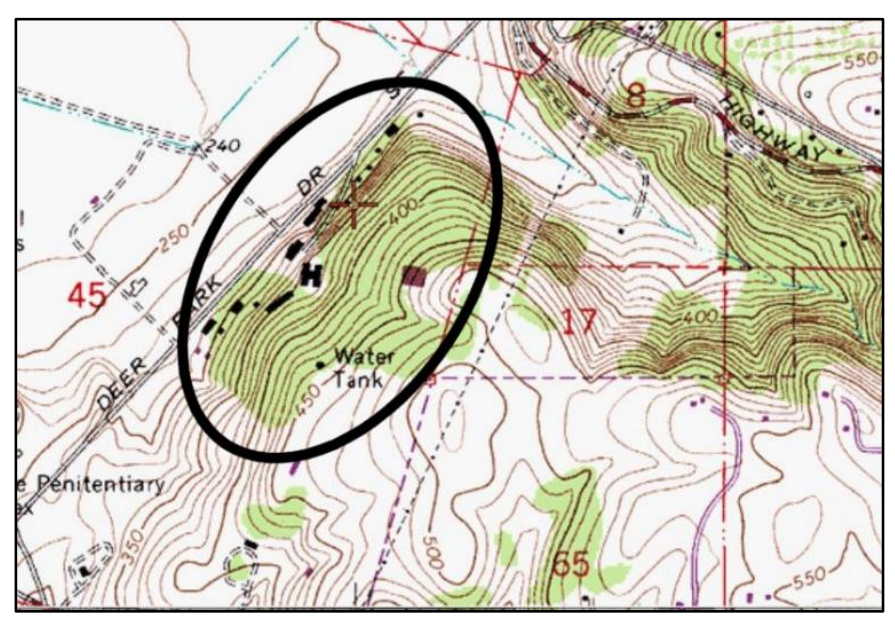

The topographic map shows the lowest part of campus aligning with Deer Park Drive, which is at an altitude of approximately 280 feet. As demonstrated on the map, the majority of the campus buildings (small black marks) exist within the lower level of the hill but have over 100 feet of elevation gain within a short distance, seen where the lines are closer together. By the time the highest building on campus is reached, the Jeffer's 
Sports Center (the university gym), another 50 feet of elevation is gained, totaling nearly 200 feet of elevation from the bottom to the top of campus.

Figure 4.10

Satellite Map Showing Forest Density on Corban University’s Campus

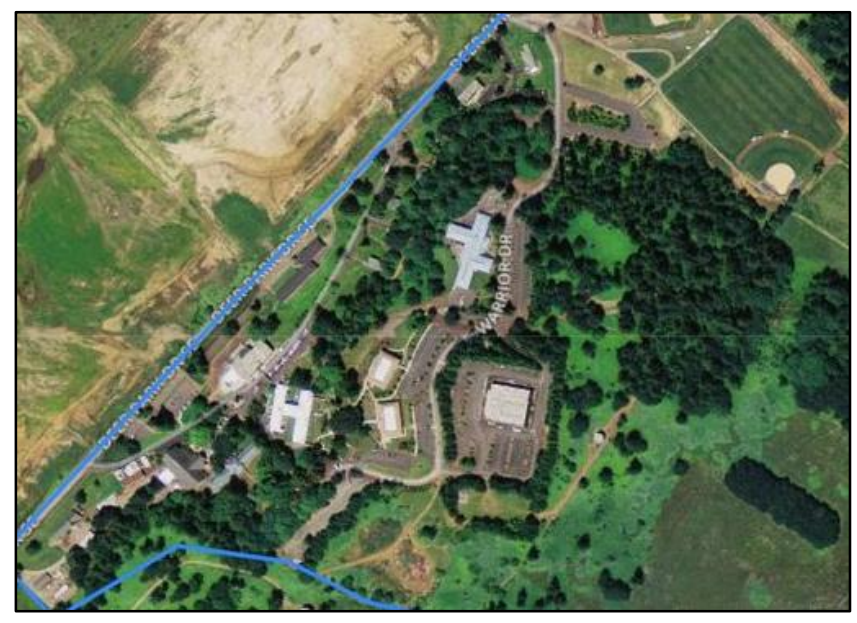

Because the hill is also heavily forested (as seen in Figure 4.10) and with such a significant incline (as seen in Figure 4.9), access to campus buildings was not usually attained by simply walking straight up or down the hill from any given point. Rather, the campus topography required pathways to horizontally traverse the side of the hill allowing for a more gradual ascent. With nearly 200 feet of elevation to get from the buildings on the western edge of campus at the bottom of the hill to the buildings on the eastern edge of campus at the top of the hill, roads, sidewalks, and pathways were built to navigate the incline gradually enough to support walkability.

The university campus map (Figure 4.11) shows the many roads and walkways that traverse the side of the hill to the north and south with horizontal switchbacks to avoid forested areas, creating a more gradual ascent. Figure 4.11 also shows the campus 
nature trails, some of which providing shortcuts if a person was willing and able to navigate natural terrain on a relatively steep incline. The campus map is referenced throughout the data, and a larger format for easier viewing is included as Appendix F.

\section{Figure 4.11}

\section{Corban University Campus Map with Legend}

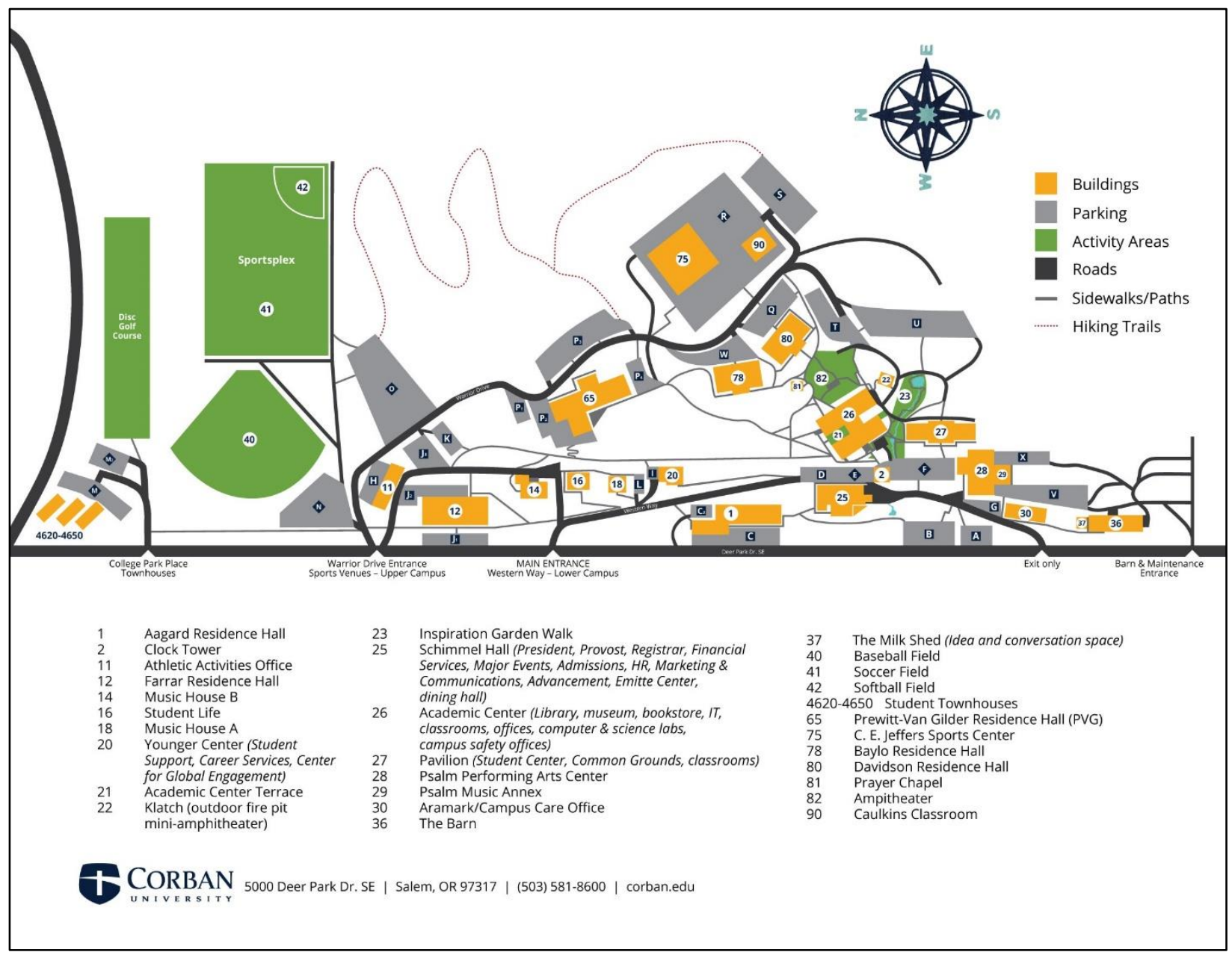

Oliver (employee) defined the campus topography as broken into "altitudinal tiers" and stated that each of the primary classroom buildings is on a different tier "so if you're a student, on a [typical] Monday of classes you could have a class at each tier." 
Another employee, Lukas, said that students commonly make jokes about skipping class when a class is held in a building at the very top of the hill. "They say it pretty jokingly, but...it $i$ s all the way up there" he said. As a professor, he has a vested interest in students' class attendance. "I hate to see when they assign me [to teach in] in that building up there [Caulkins Hall, see Figure 4.11, building 90]. I have to walk up the hill, and students have to walk up the hill after being in class at the bottom...then we'll have to go back down again."

When asking a student named Joy to consider something on the campus she might change in order to enhance the student community, she talked about how the hillside influenced the social reputations of the residence halls. Her first year at Corban she was assigned to live in Aagard Hall (see Figure 4.11, building 1), one of the two residence halls at the bottom of the hill, and she was afraid to go to the residence halls located at the top of the hill "because they all seemed so cool." But when her roommate in Aagard was hired as a Resident Assistant in one of the upper residence halls the following year, she decided to move with her. "But I'll still go down [to visit]...I just wish other people knew how awesome the Fraagard community is [the combined name of the two residence halls at the bottom of the hill, Farrar (Figure 4.11, building 12) and Aagard] because they're definitely overlooked." When asked if she thinks she would feel the same way if she had never lived in Fraagard, she was quick to reply, "absolutely not, because I probably would have never gotten it." Several of the students interviewed shared Joy's view regarding the reputation of the residence halls at the bottom of the hill. When discussing the centrality of the residence hall locations, Grace was comparing the benefits 
of the Prewitt-Van Gilder (PVG) residence hall (see Figure 4.11, building 65) to the Balyo/Davidson Halls (see Figure 4.11, buildings 78 and 80, respectively), indicating that while PVG is a popular residence hall, compared to Balyo/Davidson “it's not central on campus...but it is more central than Fraagard.” As Kevin, a Farrar resident, expressed it, "Fraagard has been the butt of the jokes for a long time because we live in the rickety old buildings at the bottom of the hill." It was quickly apparent that student perceptions of Farrar and Aagard Halls were generally not very positive, with the building locations at the bottom of the campus hill contributing to the negative views.

Another student named Dan said that if he had the power to change anything on campus, he would relocate Caulkins Hall, the classroom building located at the top of the hill. "I don't know where I'd put it" he said, "but definitely not at the top of the hill...it's a long walk." Dan went on to describe the campus joke that all students develop "Corban calves" from walking uphill so often in any given day. Throughout the course of the interviews, several participants referenced the campus joke of "Corban calves" alluding to how strong their legs were getting from walking the campus. As the interviewer, I was impressed by how a potentially negative topographical campus element had been reframed as a unique part of the student experience and even turned into something worth bragging rights.

\section{Wayfinding}

On a densely forested university campus built on a hillside, it can be assumed that a students' ability to locate resources and services becomes a greater challenge than navigating a topographically flat, wide-open campus. Banning's (1996) outline of campus 
wayfinding principles describes a critical institutional process for the retention of students which begins with their first impression while on a campus. Simple navigational tools such as up-to-date campus maps and strategically placed signs can make a significant difference in a students' decision to attend the university, as well as influence their overall educational experience (Strange \& Banning, 2015). Observation of campus wayfinding along with interview data demonstrated these important elements of the built campus environment.

During a campus observation, I had been given a campus map to determine the best place to park my car and then walk to one of the residence hall facilities. On the map, which I later learned was out of date and not as accurate as the current map seen in Figure 4.11, the residence hall appeared to be just behind an office building I had previously visited, so I decided to park near that building (see Figure 4.11, building 16, the Student Life House) and walk to the hall (see Figure 4.11, building 65, Prewitt-Van Gilder Residence Hall). Prior to this field study, I had purposely not studied the campus topography and had only previously been to campus for short visits in specific buildings. My goal during field study was to experience the campus through the lens of a visitor without much prior familiarization.

Upon parking, and while looking at the map, I turned to look in the direction of the residence hall and discovered a steep, forested embankment in front of me, with no sight of the residence hall that had seemed so close on paper. No sidewalks appeared to lead in even the general direction of where the map showed the residence hall to be; in fact, the only sidewalk I could see appeared to lead far to the south, when the direction I 
needed to go was east. Utterly befuddled at how to reach my destination, I entered the nearby office building and asked an employee how to walk to the residence hall. They kindly attempted to hold back their laughter when I told them I had intentionally parked outside of their office because it appeared on the map to be close to the Prewitt-Van Guilder (PVG) residence hall I was planning to observe. They informed me that there was, indeed, a path from their building to the residence hall, but it was a nature trail through the forest that climbed nearly straight up the hillside. My alternative was to follow the long sidewalk to the south, which would indeed take me quite a distance out of my way before it switched back to head north and would eventually end at my destination. Considering my shoe choice of heels, I opted for the sidewalk and after a brisk 10-minute walk to the south and then to the north around the perimeter of a small forest, I reached the residence hall that had appeared on the map as only slightly east. The pathways and nature trails I learned about on that day were a point of pride for some Corban students, however, as several participants made references to the impact pathways had on their social decisions, as well as on their feeling of connectedness to the university. Joy said that when she came to campus early for student leadership training this year, she had lots of time to explore. And even though she had already spent a year on Corban's campus, she discovered new off-road trails that she now takes frequently and reports that using these trails "makes Corban [locations] feel more connected to each other, in ways I never noticed before.” Along with Joy's greater sense of connectedness that she discovered from the campus trails, another student named Chris discussed how he enjoyed the views on the trails which made them good places to go for walks to think 
and reflect. From an efficiency perspective, Chris reported that not all the trails actually provided short cuts to campus locations, but instead they served as a more peaceful way to reach a destination.

Campus signs are a significant component of wayfinding for more reasons than just directing people how to reach their destination. Signs also communicate an intended use or a perception of a space. In a few locations on Corban's campus, there was a gap between what was printed on a sign and how participants referred to or seemed to perceive the space. The most prominent example occurred with both employee as well as student participants.

During my first few days of interviews, references would be made to how Corban University didn't have a Student Center that served as a centralized gathering space for all students. Based on field observations, I assumed the campus coffee shop and the commuter lounge below it were the closest the campus had to fulfilling that need, but no one referred to them as anything but the coffee shop and commuter lounge. Approximately half-way through my interview schedule, I met with Oliver (employee), who not only referred to the campus student center, but informed me that he supervised the space. I told him I wasn't aware the campus had a student center and asked where it was located. He said, "in the Pavilion" to which I responded, "what's the Pavilion?" Recognizing my confusion, he then said, "it's the coffee shop." I followed up by asking him: "if you were to use the title "Student Center" to students, would they know where that is?" Oliver responded "no, probably not. It's not the way it's used. It's really just the coffee shop." My campus observations to that point had not included an intentional look 
at campus wayfinding, so this part of the conversation piqued my interest. Following Oliver's interview, I went to the staircase leading up to the front entrance of the Pavilion (see Figure 4.11, building 27) building, which houses the coffee shop and the commuter center. There was a sign, clearly communicating that the Pavilion houses both a Student Center and classrooms as well as the coffee shop (see Figure 4.12).

The day after interviewing Oliver and learning about the campus Student Center, I interviewed another employee, Nancy, who is also an alumna of Corban. When asked if the current campus buildings promote an institutional commitment to student community building, she said,

I think we do the best with what we've got, and I think it's carried us far. However, do I think there can be improvements with buildings \& rooms we have? Yes. The coffee shop can use some huge updates. And I think we need just a Student Center on campus_-we're so far behind other universities. There's literally just no space for anyone to hang out, whether you're a commuter or oncampus student. They just need space: maybe that means a large cafe-I don't know, because cafes are definitely good because there's coffee $\&$ you'll find people there, even faculty \& staff. From what I've noticed, meetings happen in the coffee shop or in our dining hall. So yes, I would love to see funds or more resources put toward that, but I think we could do a better job.

I told Nancy I had only recently learned that the name of the building that housed the coffee shop was The Pavilion. "But it's not only called the Pavilion" I said. "On the sign, it says 
there is also a Student Center there." To which Nancy replied, "Nice! I never noticed or heard of that."

Figure 4.12

The Pavilion Sign Identifies the Student Center and Classrooms

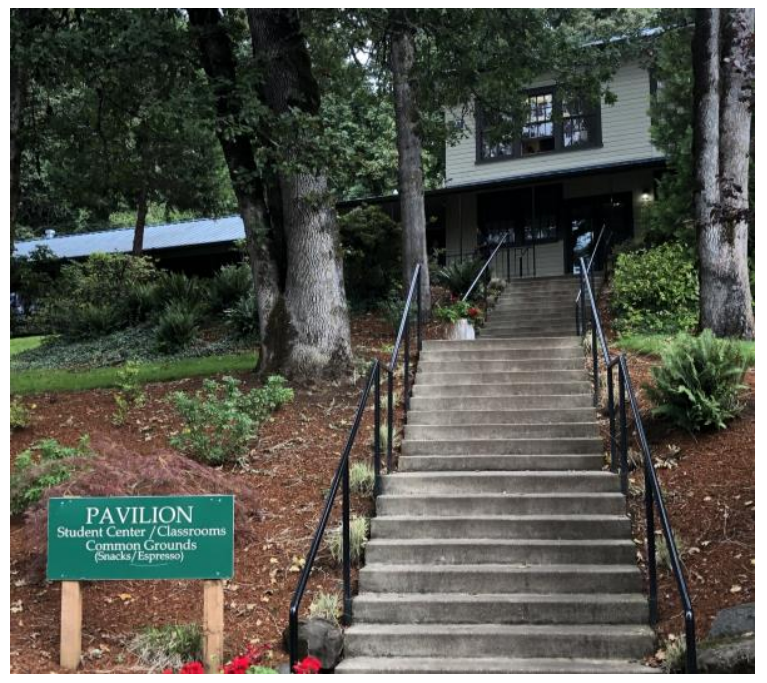

Heidi was similarly surprised when I identified the campus coffee shop as "Common Grounds," the official title listed on maps and signage. She asked "Common Grounds?" And then said:

I never heard anyone in my life call it Common Grounds. Like Aramark is the “Travis Memorial Dining Hall.” Last year as a freshman I was like, "Hey, you guys going to the Travis Memorial Dining Hall?" they were like, "Aramark?" Aramark is written here. So, "Travis Memorial” no more, and I just adopted "Aramark."

While signs that hold official institutional names may be helpful for visitor wayfinding, in that they match the campus map and can direct people to acquire the services they 
need, study participants confirmed that members of the university community often utilitize their own colloquial titles for spaces, regardless of official institutional space names.

\section{Building Location}

The location of buildings on Corban's campus came through the data as a contributor to the choices students made regarding where they elected to spend time and which activities they engaged in. Building location also appeared in the data as a deterrent to meeting some institutional goals. Due to the campus topography on the forested hillside, buildings were spread both across the hillside horizontally and up and down the hillside vertically. As referenced earlier, some buildings were at the top of the hill, while some were at the bottom, and the thick forest which made for beautiful views also dictated building locations.

The coffee shop was identified by several participants as a place where community is fostered, but when asked if the location of the building was central for easy access, the responses were varied. Eric attributed the coffee shop's popularity to its location on campus: "It's a really nice central location on campus, so it's easy to say "let's meet up at the coffee shop," or if I have a free hour to go in and find a couch and talk to someone there." Lukas (employee) disagreed about the centrality of the coffee shop location and expressed that it was especially not convenient for anyone living in the residence halls. "If you put something closer [to the Academic Center Building], there's three dorms that it's much closer to, and actually in a proximity where they would 
populate it, and other people might journey to it." He held the view that a more centralized location for the coffee shop would result in higher use by more students.

A phrase commonly heard throughout interviews was that the campus had no true center. When I would ask participants where the center of campus was, I received different answers nearly every time. Some had an aspirational view of a campus center based on what they had seen at other campuses, envisioning a large, flat green space; more like a campus quad. Others saw it as a central corridor, like a main artery leading up and down the center of the hill connecting all buildings. After campus observation and analysis of the data, my conclusion is that due to the forested hillside topography, neither a flat outdoor quad nor a central corridor can exist at Corban University. Oliver (employee) articulated his feelings of what the Corban community misses experientially due to the lack of a central quad:

When I go to other institutions, one of my favorite things on those flat, midwestern institutions, or even some here in the Pacific Northwest, is the outdoor community space. Oftentimes I see students playing football or throwing a frisbee or just walking around. But with the way our campus is designed, there is not that space available. When you look at your typical quad, their administrative buildings and their classrooms are right in that space. It's not necessarily that we can walk out the door and have that here, let's face it - we're on a hill. You can put on your mountain boots and get up there a bit. Nancy (employee) viewed the current campus center as the main artery pathway of campus, and asserted its location existed near the central Academic Center: "Just to the 
left of the Academic Center, there's a long path between the Academic Center and PruittVanGuilder [residence hall], and everything just kind of goes up directly from the Academic Center. We would call that central." Despite the varied opinions, a central campus location that most participants seemed to agree on was surrounding the Academic Center (Figure 4.11, building 26).

Based solely on building proximity, the most campus buildings were clustered in a diagonal path headed up the front of the hill from the southwest to the northeast (see Figure 4.13). And while this may have been a primary artery connecting the majority of the campus buildings, the topography did not allow for one straight sidewalk heading through the center between those buildings. The environmental reality this campus faces is a web of sidewalks, roads, stairs, and walkway overpasses weaving their way from the bottom of the hillside to the top.

Figure 4.13

\section{Campus Map with Central Building Cluster Circled in Blue}

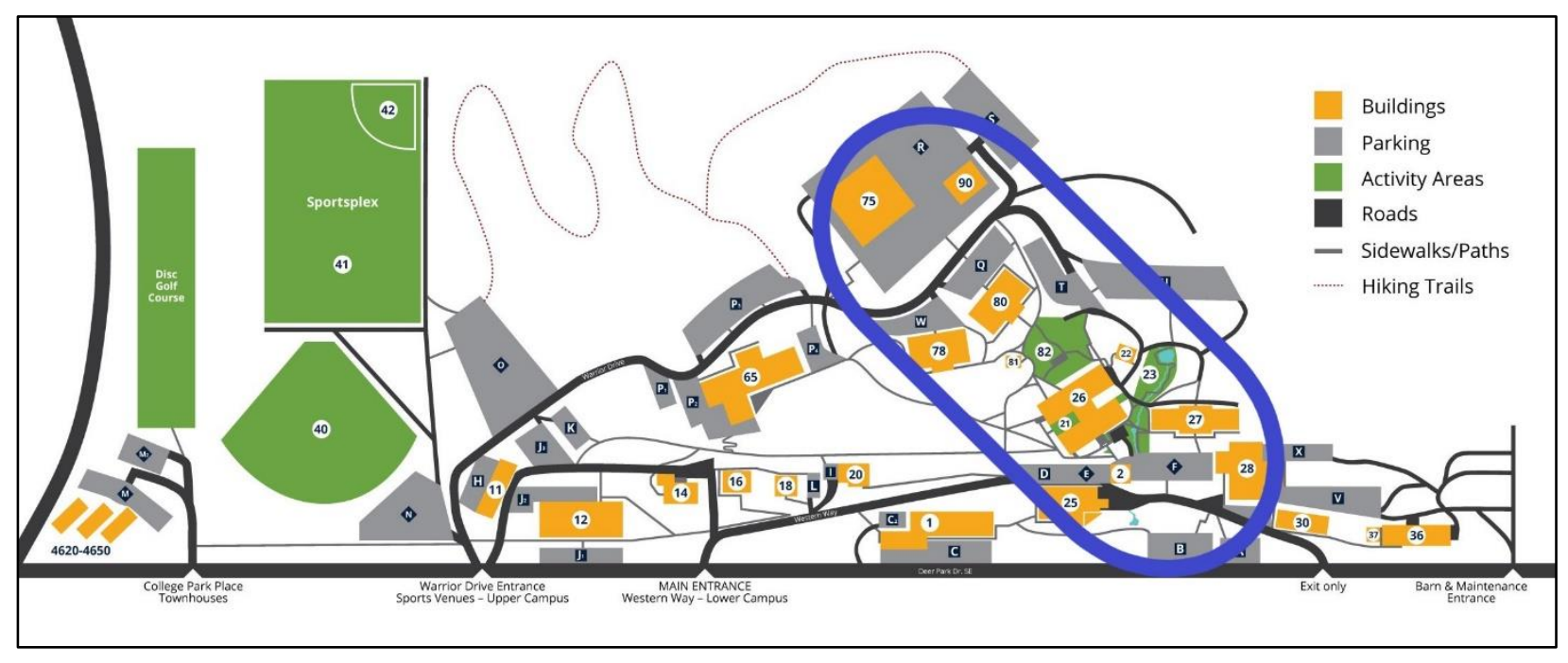


When analyzing building location through this proxemic lens, I found that the majority of the buildings in this central corridor met the needs of the general population of the student body. Three of the four classroom buildings were present: Academic Center (Figure 4.13, building 26), Pavilion (Figure 4.13, building 27), and Caulkins (Figure 4.13, building 90), along with Schimmel Hall (Figure 4.13, building 25) which housed the majority of the student service offices and the dining hall, two of the five campus residence halls, and student community spaces including the Psalm Performing Arts Center (Figure 4.13, building 28), the Coffee Shop and Commuter Center (Figure 4.13, both in building 27), the Klatch (Figure 4.13, building 22) and the Sports Center (Figure 4.13, building 75). The PVG residence hall (Figure 4.13, building 65) is located at a higher altitude on the hill and has a sidewalk which led directly into the central corridor without direct access to the lower buildings on the north end, so socially it fit within the central corridor, just in a somewhat less convenient location. Chris, a Davidson Hall (Figure 4.13, building 80) resident, confirmed this analysis:

As Davidson residents, we think we're the best-placed dorm to get to places because it's right up there [near] the classrooms. Whereas PVG is a little far, Fraagard is a little far, but it's not that difficult for Davidson and Balyo. I think it's probably one of the more accessible dorms because...PV/AC [Pavilion and Academic Center] are really the two main places you go, or Caulkins, which is above by the gym. Those are the three classroom buildings where [students are] walking back and forth. So, then you're going to walk by Davidson, too. 
Eric was the only student who identified an area as a campus center, primarily due to the locations residential students spend time when outside of their residence halls. He said: The center of campus really does feel like it's between here [the Psalm Center], the coffee shop, and the dining hall, because that's where every one of the dorm communities, outside of when they're in their dorms, spend the majority of their time on campus.

Given these topographical and structural realities, it was plausible that a student could meet all their academic and social needs functioning only within the central building corridor of the campus (as shown in Figure 4.13).

Unfortunately for the residents who live in the two remaining residence halls, Farrar and Aagard (Figure 4.13, buildings 12 and 1, respectively), their location outside of the central building corridor contributed to the negative stigma about those who live at the bottom of the hill. As Kevin previously noted, they were already disadvantaged due to their buildings being the oldest on campus, original to the property before Corban acquired it. The three residence halls at the top were all significantly newer construction, with many more amenities and modern designs. The structural layouts of the upper residence halls were designed with student community building in mind, and with infrastructure and policies guided by those designs. The halls at the bottom of the hill were held captive to the limitations of the building designs of 1934 and 1953, respectively. These pre-existing conditions created a forced divide on Corban's campus that was evident from field observations and participant interviews. 
Further, this topographical division could contribute negatively to the institutions' current efforts to attract more students to the Younger Center (Figure 4.13, building 20) as it shifts the facility into a more student-centered space. Having served as an academic resource center where students only came if they needed support and housing offices for international student services, the institution was attempting to create more of a Student Center within the space in the hope of attracting more students to spend time casually in the Younger Center for a wider breadth of reasons. The building was relatively new and boasted very modern space and facilities, which seemed to me as an observer, like the sort of space students would be eager to spend time in. However, as Oliver (employee) told me: "The idea is there to give students a space, and even one of our better or newer spaces, to interact in. But also, it's a destination as opposed to a pathway [to another location]."

Other buildings students identified as having a location that detered them from use are The Barn (Figure 4.13, building 36), and the Sports Center (Figure 4.13, building 75). The Barn was a newly opened maker space that was renovated from a former livestock barn into a beautiful space where students could express creativity in a variety of forms. The only problem was its location, as it has the double-burden of being at the bottom of the hill and on the outer perimeter of campus. It borders the edge of campus with a field of cows on the other side of the property line. When discussing The Barn with an employee on campus, a student overheard us and added "Oh yeah - The Barn. I love to go there, but it's so far away." I heard similar sentiments about the Sports Center, which was perched on the very top of the hill. Lukas (employee) theorized that students 
who lived in the residence halls at the top of the hill most likely frequent the gym and utilize the exercise equipment there more frequently than those who live below.

Another element related to building location that appeared in the data was which functions existed within which buildings. It wasn't so much about the geographic location of the building itself, but rather what combination of functional spaces each building housed. Joy said:

I love when I have classes in PV [Pavilion], because there's a lot of classes here, and I see a lot of people I'm already in class with, and students from other classrooms... and then there's also a coffee shop and the commuter lounge, it's all in one spot. There's a place where we can be social, and just catch up quickly. I like how the library is connected to more classrooms, and to the mailroom and bookstore and everything.

The building designs, both the functional spaces within them, as well as their architectural structure were reported to influence students' sense of connection to their community and overall sense of belonging.

\section{Theme 2: Campus Infrastructure}

Every university has their unique policies and organizational systems which reflect their institutional mission and values. For a church-related university such as Corban, many policies and priorities reflect the theological commitment as shown in the university's mission and value statements. For such institutions, the campus culture is shaped by an agreement upon entering the institution — whether as student or employeethat this shared theological commitment will guide an externalized adherence to these 
organizational systems. These shared commitments then, influence everything within the culture from student conduct to administrative decision-making and prioritization.

A theme emerged in the data collected at Corban University demonstrating how such cultural elements of their institutional infrastructure influenced the built campus environment and students' use of space. Policies on gender-specific residence halls and lobbies with limited hours of co-ed use influenced student access as well as student perception of which campus spaces they could engage in community. As an institution with limited resources, prioritization of those resources—-both fiscal and employee's time - came through in the data as having an impact on student and employees' perceptions of Corban's commitment to fostering a vibrant student community. Messaging from the university also emerged as an area of influence on how students perceived campus spaces and utilized them. And the last subtheme of the institutional infrastructure was simply the layout of furniture within shared student spaces. The types of furniture and the placement of the furniture both come through the data as playing a significant role in how students engaged in community within common spaces.

\section{Institutional Policies}

University policies ranging from hours of building access to residency requirements to co-ed residence hall lobby visitation played a significant role in students' use of campus space. A creative policy to encourage corporate spiritual engagement in community was reflected in the institutional decision to close the campus coffee shop and the dining hall during the three hours per week of chapel programming. This policy was particularly interesting as Corban does not mandate chapel attendance for students, as 
many CCCU-member institutions do. During a field observation I went to the coffee shop while chapel was in session and observed how the space was divided so the lounge area was available, but the section where food and beverages were sold was gated off. A large crowd of students were lined up next to the gate, waiting to make a purchase when the gate opened.

Other institutional policies such as a residency requirement for all students (unless they live within a commutable distance with family) during their first three years promoted an institutional value of the residential experience. No limitations on students having cars on campus as well as providing free parking communicates institutional support for students to leave campus as desired. One employee wondered if this policy encourages students toward finding their third place in one of the downtown Salem coffee shops where she frequently sees Corban students (approximately 6 miles away), rather than finding that place on campus.

Gender policies regarding residence halls were reported as a significant contributor to the social dynamics in the residence halls. Two of the five campus residence halls are single-gender occupancy and have limited co-ed visitation hours for their common lobby spaces. The other three residence halls have co-ed occupancy with co-ed lobbies open to all students twenty-four hours per day. These policies influence where students spend their time together, as well as their perceptions of and attitudes toward specific residence halls. As Oliver (employee) expressed:

All of Farrar - the whole building is men, and in Aagard the whole building is women. Whereas the PVG lobby and the Balyo/Davidson buildings have both 
genders, and it probably makes it easier for our students to hang out. It's more inviting to come to a space that it's already gender inclusive.

Joy also expressed the experiential difference between the two single-gender residence halls and the others: "for Aagard and Farrar, since they aren't co-ed dorms, [the social life of the lobbies is] just...different." According to Chris, however, for Aagard and Farrar residents, there are still many other places for them to socialize outside of their lobbies with limited visitation hours.

As previously mentioned, some buildings are destinations, while others are locations a student may stop as they walk past. Lukas (employee) hypothesized that the residence hall visitation policies do have an influence on the social dynamics of the co-ed residence halls: "Because it is a co-ed dorm, I think some people might journey there for the purpose of socialization" he said.

\section{Resource Allocation}

Employee participants referenced that Corban, like other similar small institutions, often has limited resources such as budget, personnel, or technology. As an enrollment-dependent institution, small enrollment can equate a small operating budget, as well as a small employee base to educate the student population. It was reported that at Corban, employees often play a variety of roles and perform a variety of tasks beyond what their job description dictates. Faculty don't have the luxury of only teaching select courses within their academic specialty, and administrators have staff teams consisting of generalists skilled at performing a breadth of tasks. Budget limitations result in continual re-prioritization of the greatest need. Personnel are often spread thin, which can limit 
creative problem-solving or initiative. New ideas often come from passionate employees, and in an atmosphere of limited resource, a collective lack of energy can minimize creative thinking.

While those challenges may be realities for Corban, the Student Life department, who works most closely to shape the student experience, places high value on creativity, innovation, and curiosity. Despite obvious financial and personnel limitations, it was clear that the development of Corban's student community was being pushed to the top of the resource prioritization funnel. A student leader named Fiona told me about the physical changes in the dining hall she experienced when she returned to campus after summer break. She said the walls and pillars had previously been painted bright colors, which she assumed was to create a fun and lively atmosphere, but in her opinion the colors "were just distracting and weird." Over the summer they had been repainted in neutral colors, which Fiona reported felt much more "toned down," which she expressed felt more appropriate for an eating area.

I interviewed Fiona in the lobby of the residence hall where she works as a Resident Assistant, and while there, she pointed out how the lobby furniture is not the same as it had been the previous academic year. Oliver (employee) explained that the Residence Life staff had hired a local interior designer to help them "make the lobbies feel more homey." He said, "students have their spaces in their rooms, but we want to get them out into the community so they feel like [the residence hall lobby is] a space they would want to be." The Area Coordinators who provide oversight to each residence hall were tasked with auditing all lobby furniture and then partnered with the interior designer 
over the summer to relocate the lobby furniture between halls to provide a freshness and revitalization to each lobby without purchasing new furniture. According to Fiona, it made a positive difference to students when they returned from the summer and saw fresh furniture in their lobbies and different art on the lobby walls. One lobby had a large whiteboard attached to the wall with the question "What was the best part of your summer?" and Fiona reported that the board itself was drawing community as students were enjoying writing and reading what others wrote. "Things like that change...really made a difference" she said.

While residence hall lobby furniture refreshing was an institutional resource allocation that impacted campus residents' impressions of community-building spaces, even more significant resources had been prioritized for the construction and renovation of two spaces made newly available to all Corban students. In 2017 an outdoor open-air, covered pergola consisting of concrete block seating surrounding a fireplace was constructed and named "The Klatch." The plaque on a front pillar defined The Klatch as "a place for conversation and coffee" and is dedicated to an employee who served the institution for 30 year with a "passion for the great outdoors" (Figure 4.14).

The structure is located in the functional center of campus, between the largest academic building and the Pavilion containing the coffee shop and commuter center. Its location is framed within a forested corridor which climbs the hillside in the center of the campus, connected by landscaped trails, benches, ponds, and bridges (Figure 4.15). Not only does this green corridor on campus demonstrate the institution's commitment to maximizing the natural elements surrounding their campus buildings, but to place a 
student community-centered structure in one of the most central and naturally beautiful locations on campus demonstrates a prioritization of student community.

Figure 4.14

The Klatch is an Outdoor Gathering Space with a Fireplace for Student Use
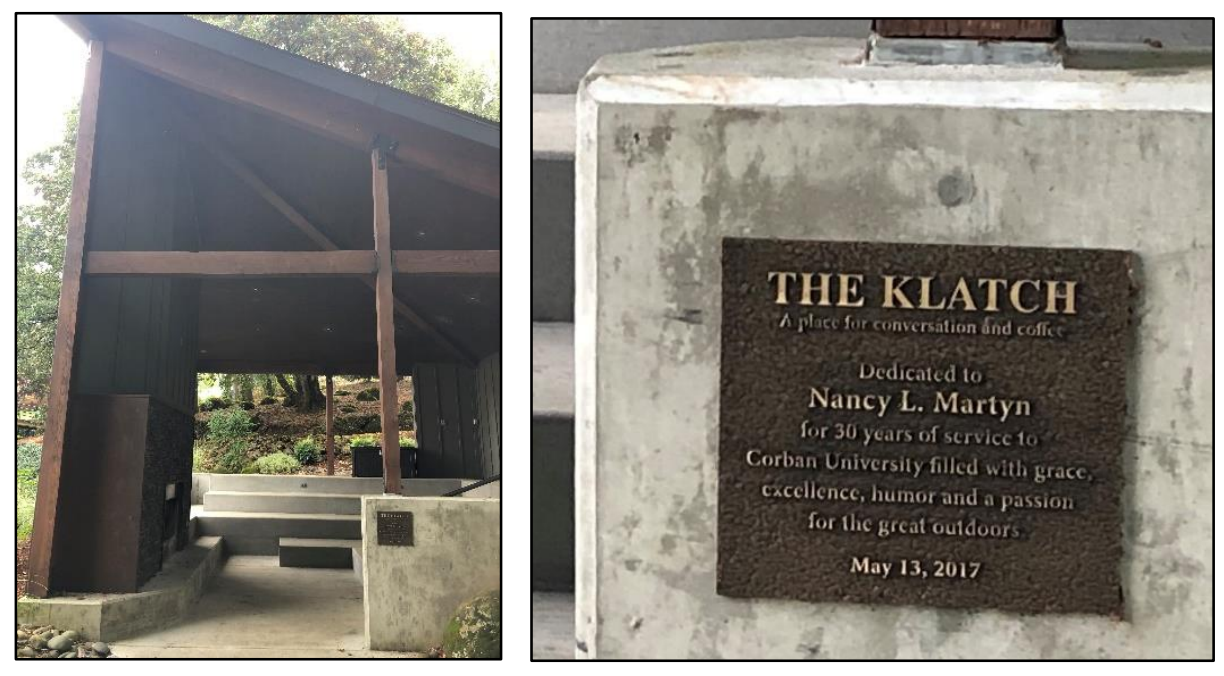

Note. Photo credit: K. Stave

Several students referenced spending time in the Klatch for solitude, or in groups.

Dan discussed how popular it is during the university's monthly "Sabbath Chapel" programs, which he described as a dedicated time for the student body to focus on solitude, rest, and prayer. "The Klatch tends to be a public place for people to pray and meditate during that hour" he said. Eric referenced it as a place where small groups meet or special events take place. He and Isla also identified it a common location for students to hang hammocks, a popular pastime for many Corban students. Both Grace and Ben referenced how much they enjoy it when their faculty held class sessions in the Klatch, and both expressed how they wished it would happen more frequently. Dan has had several personally meaningful moments in the Klatch. He described how the space holds 
a special feeling "especially at night when the winds are coming in and the fire gets rolling... it's such a beautiful place for students to gather around." Grace added that she has realized the Pacific Northwest rain is an inhibitor to the Klatch getting as much use as it could. Several participants discussed the weather as a deterrent for utilizing the outdoor spaces on their beautiful campus as much as they'd like.

\section{Figure 4.15}

\section{Landscaping on Corban's Campus Accentuates the Natural Existing Green Space}

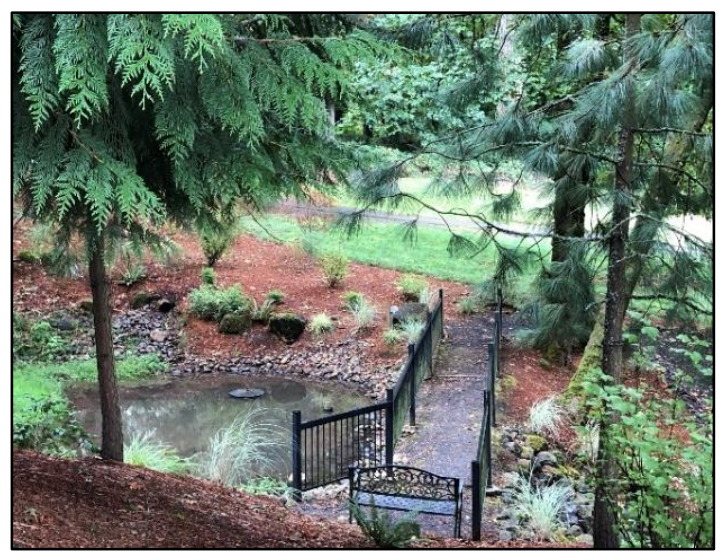

Note. Photo credit: K. Stave

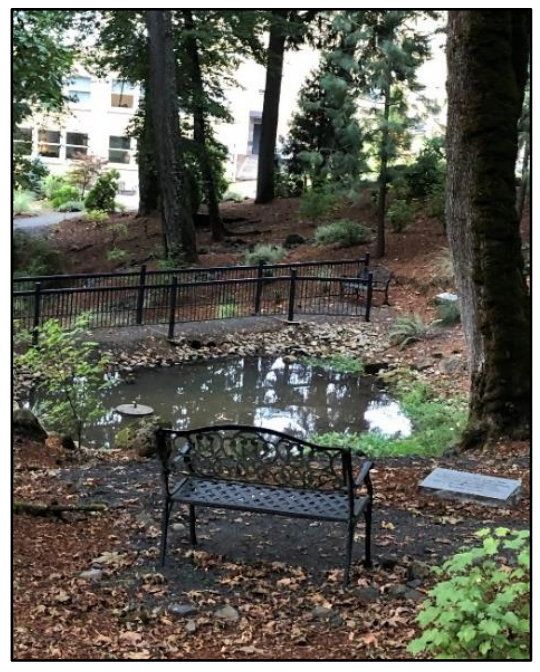

Note. Photo credit: K. Stave 
Another sign of Corban's student-centered prioritization of resources is through the recent renovation of one of the campuses' oldest buildings: The Barn (See Figure 4.3). With a desire to increase students' curiosity and creativity, the Corban Student Life staff received approval to renovate the property's original livestock barn, later utilized for university storage, into a student-centered maker space. The Barn offers students opportunities to "cultivate their curiosity" within four unique spaces: a design lab for classes, events, and open table hours, a gallery for art shows displaying the work of students, employees, and local guests, a woodshop where students can learn and practice woodworking, and the milkshed which houses gatherings for "discussing ideas, brainstorming, exploring, examining, questioning, thinking, and wondering" (Corban University: The Barn, n.d.2 para.2).

While these recent projects demonstrate an institutional prioritization of studentcentered spaces to enhance campus community building, Oliver (employee) articulated the ongoing challenges the institution faces and the continued commitment of resources necessary for further student investment.

You have to dedicate time for your staff to help improve these spaces. The lobbies in the residence halls, for instance, the furniture arrangement and the art are examples of [the Dean of Students] and his team saying, "I'm going to dedicate my staff's time to make this happen." And the student center design; I oversee that space. This is me saying to one of my staff members (who I think has an eye for those sorts of things) "will you make time investing into making the space look different?" So, a year ago, that space didn't look as nice as it looks now. I'm not 
saying it looks amazing...but it's been improved. It's a matter of dedicating resources towards it. But there's a lot of financial barriers and building design barriers. And even [barriers regarding the] time that we could dedicate towards thinking creatively to change some of our spaces, [those] are keeping us from creating good community spaces.

While these are realistic barriers at Corban, the data shows evidence of a pattern of resource prioritization for student community spaces, demonstrating an institutional commitment to the value of a strong student community.

\section{Institutional Communication}

When considering institutional communication, the data reflected a differentiation regarding how the university is communicating (or not communicating) their value of fostering a strong student community. There was a distinction made within the employee participant group between institutional communication that demonstrated the universitywide value of student community (which demonstrates a philosophy) versus institutional communication for the purpose of promoting the use of campus space (which demonstrates a tangible commitment to guide students toward spaces intended for community). All employees in the study articulated the belief that the university holds the collective value of fostering student community as a high priority, and as such, efforts are made to communicate that value. The data identified an expressed need by the employees for the institution to communicate this value through both direct articulation of this value, as well as through active promotion of space use. 
How the institution directly communicated its commitment to a strong student community was reported to occur in several ways. According to the employee participants, students are made aware of the university's commitment to student community when members of the institutional administration speak publicly about their value of the student community, when they engage relationally with students, and when they take action demonstrating their prioritization of student community. Lukas (employee) discussed the consistent rhetoric he has heard from the upper administration to students affirming their commitment to students engaging in healthy community through the venues of "chapel, email, speeches, t shirts and mottos." He further discussed how student-centered the university's mission and values statements are, and how frequently he hears reference to them in community gatherings where administrators are speaking. He has also noticed how often speakers invited to campus will present specifically on topics that demonstrate a value of student community, which he attributes to university decision-makers selecting specific speakers for that purpose. Nancy (employee) reported that she believed students knew the university cared about their collective student experience since the institutional culture included a prioritization of personal care and respect between all members of the campus community. She articulated the level of relational connectivity between students and employees when she said:

If a student goes to their RA [with a concern], the RA goes up the line. And because lots of our upper management have personal connections to students, they don't have to go far. Information moves so quickly that we know when to address 
things. I think people feel a sense of belonging when they know they are heard about things - about the little things.

According to Nancy, when students feel like their voice is heard by important decision-makers on campus, they believe the institution cares about the student community.

Institutional decisions and action taken by the administration was another way employees felt assured that students were aware that the university prioritizes their experience. One employee named Maggie said that she assumed students feel satisfied, safe, and included on campus because of how frequently there are student-focused space renovations or classroom innovations reflecting the institution's value of the students' campus experience. Maggie, Oliver, and Nancy (employees) identified the institutional decision to transform the Younger Center-the campus' most new and modern building - from a predominantly administrative office building into a more studentcentric space was an important message to students that they are valued. "The idea," Oliver said, "is to give students a space, and even one of our better or newer spaces, to interact in. This is a sign of the university trying to do some things [to communicate their value of student community.]" Maggie sees the in-process changes to the Younger Center as a step toward modeling to students that student-centered institutional ideas can come to fruition. She gave the example of the fulfillment of smaller proposals like the creation of a lockable mother's room for commuter students to help build confidence in the student body that the university is recognizing their needs and values them, despite times of limitations and budget constraints. Maggie explains: 
I think one thing that's been hard for our administration, as well as the whole student body, is budgeting issues and constraints. For instance, there's plans to be able to have huge renovations on our fields for athletics; there's plans that have been communicated to the student body about increasing our agriculture program and our agribusiness program, there's plans...to be able to expand our athletic complex, and to...have lights on our field. So, I feel there is a desire [by the administration] to be able to accomplish some of those things, but I feel like sometimes we're saying, "yes, we're going to do these things" and then, "oh, wait, no, actually, we're not able to do that."

According to Maggie, any time the institution makes a visible change to a space benefitting the students, that decision communicates the institutional value of fostering a strong student community, subsequently increasing students' belief that the university cares about their campus experience.

While Oliver affirmed his perception of the benefits of university administration communicating their institutional commitment to the student community through direct messaging, personal relationships with students, and through student-centered space changes, he also expressed a belief that the institution can do better at communicating this value through the direct marketing of student spaces. He reported that the university doesn't often overtly promote the intended use of a space, which can leave students to wonder about it, or worse, miss opportunities for building community within it. For example, "I don't think people really know what the Klatch is," he said, "unless someone tells them that this is what the Klatch is for. I think that's a big marketing gap for people 
to know that those spaces are available for them." Lukas (employee) had similar sentiments about the promotional work the university still must do. "I think the university does a lot to gather students for different occasions...expressing their commitment to the community through events...to gather them [students] together" he said. "But I do think the spaces are an afterthought...there's a lot about gathering people, but I don't think that there's much about creating the spaces." He also discussed how places of social connection on campus, like the PVG residence hall lobby, aren't promoted as such. When asked how he thinks non-PVG residents become aware of social activities happening in the PVG lobby, he reported an assumption that students learn word-of-mouth through their peers, or from coming to an event there once and seeing a lively community having fun, which prompts them to want to come back.

From the perspectives of the student participants, the form of institutional communication that influenced their sense of belonging the most came through personal relationships with staff and faculty members. Kevin, Joy, Eric, and Isla affirmed that personal connections to employees provided the experience of feeling valued and heard from the university. Isla said that when becoming a student leader, interacting with members of the Student Life staff on a consistent basis helped her see the bigger picture of the university, which then provided more insights and connections to the people in smaller community around her. Kevin said he was confident that the administration cared about community and the holistic development of students because "I sat through three weeks of [student leader] training before the school year started, and I was really hearing how much they care about the students. So that makes it really easy to see." Eric 
discussed how being personally mentored by a staff member provided him significant meaning and connection to the university community. Personal communication through time spent with staff and faculty was reported to play a significant role in students' sense of belonging to the institution.

\section{Furniture Layout}

The data unanimously demonstrated that the placement and layout of furniture within a space had an influence on how students engaged socially in community. While the technical terminology of sociofugal furniture design (facing away from others) and sociopetal furniture design (facing toward others) was never discussed, the same furniture layout concepts were key components to every student participants' experience of feeling a sense of belonging within the Corban community. The primary campus locations where furniture layout was reported to have the greatest influence on students' engagement were also the same locations that emerged from the data as having the largest influence on students sense of belonging within the Corban community: the residence hall lobbies, the dining hall, and the campus coffee shop.

Residence hall lobbies were a frequently reported location where furniture layout variations influenced students' connections to peers within their community. Joy discussed how a long table in her residence hall lobby provided her the opportunity to connect with people while doing their homework in the same space. "Spending time with people but getting my work done at the same time-just the way that I am personally, I love having people near me even when we're not talking. It just makes me happy." Several of the residence hall lobbies are loosely divided into sections where the furniture 
allows people to be engaging in different activities while still interacting. Chris credited the strong community within his residence hall to this multi-purpose furniture layout in the lobby. He said the space "allows for separation but also connection" through combinations of activities within spaces like a semi-private movie room with no door, so non-movie watchers can interact with those watching movies, or a ping pong table near a study area, so someone studying can interact with those playing ping pong. "It's separate enough to get your work done, but [close enough to] also interact." Grace also mentioned how the variety of tables and soft furniture in the lobbies "allows for small groups as well as big groups" to gather.

Surprisingly, three of the four employee participants referenced their perception of the importance of the residence hall furniture layout based on what they heard from students, or from what they experienced when they were students at Corban. Nancy, a current employee and recent alumna, remembered a variety of activities taking place in the PVG lobby when she was a student due to its large size and amenities. "I remember a lot of girls baking in the kitchen... someone was always playing pool or ping pong...it's also sectioned off by furniture, so there could be $8-10$ small groups hanging out all at once." Oliver discussed how the furniture layout directly contributes to the multifunctional use of the Balyo residence hall lobby. "There's a fireplace there...[with] nice, comfortable couches... that kind of form a room around the fireplace. And then there are round tables on the other side of that where folks sit to study." Lukas has heard the international students he works with discuss how frequently they prepare meals together in the PVG residence hall kitchen, even if they live in other buildings, because 
the PVG kitchen opens into part of the lobby where people can gather. He also discussed his understanding of students' perceived benefits the variety of furniture and amenities: If you saw people sitting on the couches, you could join them. But if you didn't know those people... or [it] didn't feel right, you could go over and start to play pool, if that wasn't being utilized. You can say hi to somebody who's maybe over studying at a table there...someone might be cooking. There seems to be options to engage.

Due to the twenty-four-hour accessibility of three of the five residence hall lobbies, the data indicated that the furniture in those spaces is highly utilized by students and offers a wide variety of flexibility for the spaces, resulting in high levels of activities and use.

The dining hall was the second-most commonly identified location where furniture layout was mentioned as having an influence on students' social engagement. From field observation in the space, I observed the main seating area of the dining hall to be relatively open with a variety of seating arrangements spread throughout. As Joy identified, "it's very open...so it's easy to just see people \& say "Hi! How was your day?"' Heidi had the realization during our interview that the types of conversations occurring in the dining hall during meals are significantly influenced by the types of tables where people chose to sit. She explained the variety of seating options and how they influenced the way students engaged:

In the main dining hall, specifically, there are higher tables towards the back that if you want to be alone, you can have a private conversation with one person. There are booths if you want to sit in a family-style setting with people...or [sit 
with] a certain set of people, a smaller amount of people. There are tables toward the window, where [you sit] if you want to have a really open conversation with people... where you can just start talking to anybody.

Chris affirmed Heidi's notion that people chose which furniture to sit on based on the types of conversations they want to have. He said "most of the time you're sitting at a [long] table and interacting with the people next to you. There are booths...that are more for if you just have one person you want to hang out with." Ben reported that the wide range of seating in the dining hall allows for a wide variety of people to interact with one another:

The environment fosters conversation because there is such a wide variety of people there, it reinforces the importance of community. Because you can contribute to a conversation, you feel valued and you know you aren't isolated. You are always welcomed to share a meal as long as you are actively seeking out new relationships.

The data from these student participants demonstrates the social benefits resulting from furniture variety within a dining hall space which allows for both the cultivation of oneon-one relationships as well as opportunities to meet new people in larger-group settings. This social versatility appears to be linked directly to furniture variety and arrangement within the space.

The last identified location most frequently referenced by students as having the greatest influence on their connection to the campus community was the coffee shop. The majority of my campus interviews were held in the coffee shop, providing significant 
time for observation of the space. There is also a variety of furniture there, with the addition of soft couches and chairs along with regular height tables, high-top tables, and a counter with stools. While the space is predominantly open, it is semi-divided into sections which gives the feeling of different rooms. Annie discussed how the room divisions allow the different sections to feel more private and permit more intimate conversation that other students can't hear. While many students reported they would expand the coffee shop if they were able to make changes, Annie said she wouldn't want it much bigger than it is currently. "I wouldn't necessarily want it to be much bigger than it is...its [size is] the reason why a lot of people choose a small Christian University in the first place. It's a defined space." Dan also discussed how he appreciated the semidivided layout of the coffee shop and how the furniture variation contributes to different activities:

Given the fact that everybody's a little bit separated...we were able to have somewhat of a sense of privacy, but still be in an open setting. Definitely a lot of flexibility. If you want to do homework, you can do it in one of these desks. If you just want to talk with a group, the couches are great. It feels like that physical layout definitely adds to the students' [positive] attitude toward the [coffee] shop. Eric commented that his favorite thing about spending time in the coffee shop is the soft furniture which makes the space "feel more like a living room area where people can hang out and do homework or just talk about how their day's been doing." He even admitted to falling asleep on the couches a few times, and witnessing other students doing the same. Annie also agreed that the variety of seating options contributed to 
students' social choices by providing hard and soft furniture in both public or more private settings, which appeals to students choosing what fits their mood on a given day. “... and coffee helps," she added.

Within this given community-building space, students utilized a variety of furniture types and layouts to guide their social interactions. When a variety of furniture types are provided by the institution within a community space, it contributes to positive social connections between students and their peers, strengthening their sense of belonging within the university community.

\section{Theme 3: Social Dynamics of Space}

The last prominent theme emerging from the study's data was the unexpected social influencers of the development of student community at Corban University. A unique location where social patterns were discovered to emerge was on the pathways and sidewalks of Corban's campus. The data uncovered patterned use of sidewalks that even the participants were surprised to find themselves identifying. Affinity groups were discovered as a consistently identified outcome of time spent in specific campus locations. From students who appeared to live in their residence hall lobbies to the international students who shared meals in a meeting room within the cafeteria to commuter students and their lack of access to the third places of residential students, the result of the data was evident: space shapes social affinities. Campus traditions were also demonstrated to be largely place-based at Corban. The identity of a building and how students experience personal belonging within it was often attributed to the legacy and reputation of traditional events drawing the community together. Lastly, residence hall 
lobbies rose to the top of the data pool as the most prominent campus locations for students to consistently engage in "pure sociability" (Oldenburg \& Brissett, 1982, p. 270) on Corban's campus. These assertions will be discussed in the upcoming section.

\section{Buildings and Pathways as Social Spaces}

As previously discussed, the concept of a building's location being in route to other buildings was perceived as providing greater access to that space, as students have multiple reasons to pass by. When contrasted to a building located at the edge of a campus area, student participants reported that they believe students would generally only visit that location if it was their singular purpose, leading participants to believe less people overall would visit these "destination" building locations. Pathways designed to run past multiple buildings provide more exposure to those buildings and more opportunity for students to experience them. This was a point of discussion particularly centered around the new identity the institution is working to give the Younger Center (see Figure 4.11, building 20), as the space continues to be redesigned to include more student-centered services.

On Corban's campus, pathways also influence which students go visit the very popular Prewitt-Van Gilder Hall (PVG) residence hall lobby (Figure 4.11, building 65). A resident of PVG named Fiona discussed how her hall's lobby has the reputation on campus as being a social, lively place for all students to gather-even those who aren't residents of the building. The data supported that claim, showing that residence hall lobbies were the most frequently identified campus third places by study participants, and of the five residence hall lobbies, the PVG lobby was named most consistently the 
location for students to gather in community. As a co-ed residence hall whose lobby is open to all students twenty-four-hours per day, it is one of the most highly accessible social locations on campus. However, the building's campus location detracts from students' ability to engage in community as frequently as they might if it was not located geographically at the end of a primary campus pathway. The sidewalk connecting to the central artery of campus ends at PVG, with a dense forest stretching beyond. Fiona articulated the problem clearly:

You wouldn't know [what is going on] if you aren't by PVG, since PVG is on the edge of the residence halls and most people don't necessarily walk by. But if you were to walk by, you could see what's going on [because of the large bank of windows in the lobby doors]. If people were bored one night and didn't live in PVG, they could say "hey_let's go see what's going on at PVG" and walk up here, look in the windows and decide if they want to knock and come in or keep going."

Fiona went on to articulate how she assumed students might visit the PVG lobby more frequently if the building's location was in route to other locations, rather than a destination where the sidewalk ends. When discussing residence hall access with Chris, he began reflecting on the length of time it takes to walk from the upper residence halls on the top of the hill to the halls at the bottom of the hill, which led him to consider the routes he and his friends take when going to and from any of the campus buildings.

If there were five people, one from each dorm, all leaving PV [Pavilion] 101 which is the farthest [classroom to the south, see Figure 4.11, building 27], 
Davidson [Figure 4.11, building 80] would split off first [to go up the hill]. Aagard [Figure 4.11, building 1] would split off to go down the hill, down the main stairway, and then PVG, Farrar, and Balyo [Figure 4.11, buildings 65, 12, and 78 respectively] would [come to a fork and have] three separate pathways. He went on to tell me about how, in his experience, students utilize the multiplicity of sidewalks to intentionally cultivate or minimize their social interactions.

If you want to talk to someone from PVG a little longer, you walk up that [sidewalk] and go up. But if you don't really want to [continue the conversation], you cut off [at the fork] and separate. Or a lot of times there will be people standing at the fork because they want to finish the conversations they're having...but they're not going to walk with the other person...to PVG - it's too far.

After nearly 10 minutes of discussing the social dynamics of the Corban pathways, Chris mused, "it's very strange to talk about this...it's kind of natural to do it [but not to talk about it]." Articulating how he used campus pathways for the first time was very energizing for Chris, and exciting for me as the interviewer to see the proverbial light bulb go on regarding how he and his community are influenced by the ways they navigate campus pathways.

\section{Affinity Groups Formed through Campus Spaces}

One of the determinant factors for how students make decisions about where to go and which paths to take is based on their peer relationships. The data demonstrated that 
the built campus environment had an influence on who students connected with and contributed to the development of affinity groups.

One of the most prominent affinity groups identified on Corban's campus was the collective social identity of each residence hall. Since all student participants held residency status and had lived on campus for a minimum of 2 semesters, each one had some level of experience with residential affinities. Nearly all of them spoke to how their broader sense of belonging within the Corban community was connected to a campus residence hall community.

Joy discussed how living in Aagard, a quieter women's hall, allowed her an emotionally safe environment to slowly explore the community at her own pace during her freshman year. Admittedly, she didn't make very many friends first semester and decided to join the "FBI: Fraagard Bureau of Improvement" second semester, resulting in an increase of friendships. She reported:

Since I was making more friends in Farrar, I would feel more comfortable to hang out in Aramark [the dining hall] with them. And then from there, things got so much better for me because I was socializing with a bunch of interesting people...it was like a domino effect: "oh, I feel a part of Fraagard now," and then “oh, I feel a part of these different groups," and "wow—look at that!" it escalates to "I feel a part of Corban as a whole."

The social affinity Joy found in a residence hall leadership team was her connection to meeting more people in the dining hall, contributing to her sense of belonging to the broader institution. Kevin discussed how within each residence hall group, there's a sense 
of strong community and hall identity. "For the most part, in my dorm, all the guys really get along well, we have a blast." Fiona talked about her sense of belonging stemming from a connection to her residential community because of the significant amount of time spent with the same people there. "This is my home. [And the lobby] is where I have fun, where I come to unload and where I am able to just hang out and not worry about things, even things in my room." These students found their social identity as members of the affinity groups connected to their respective residence hall communities.

Those residence hall affinities are exemplified in the campus dining hall, which students refer to as "Aramark," the name of the food service provider. The most frequently referenced location for the identification of various affinity groups in the data was the dining hall. Kevin discussed how every year there has been a silently identified "Farrar table," and he described how it wasn't only Farrar, but every residence hall group has their own tables. "Everyone loves intermingling. So, it's not exclusive. But, generally speaking, it seems like there's like a template [for where each group sits]." Heidi knew the template well:

There are certain areas where the athletes sit, and it's typically toward the end of tables closest to the TV side of the main dining hall. And then you have people who are...more political, like the nerds and gamers who are in a different complete dining hall, and...then certain dorm communities have places where they sit so, Farrar is more likely to sit in the lowest back long table. Aagardian's are more likely to sit in the tables closer to the windows or in the booths, and then Balyo \& Davidson for the longest time ever, this sounds kind of mean, I guess, 
but has ruled the highest top table. And then international students are in a small [meeting room] area, that's typically where they spend the majority of their time. Andrew recognized how the social separations in the cafeteria had the potential to sound divisive within the student body, but from his perspective, it wasn't. "You have a sense of camaraderie with your own dorm, but you're also able to appreciate people from other dorms." Heidi also discussed the flexibility within this unspoken system. "Although there are these strange separations, it's not enforced. Anyone can sit anywhere, anytime; we just keep gravitating toward [the same] areas. If someone sits at the Balyo/Davidson high table, nothing would happen. People wouldn't be upset about it." While Heidi and other students believed the unspoken affinity group seating assignments weren't exclusive and were open to anyone, Ben disagreed. As a student who doesn't feel like he has one specific group to belong to, he discussed the importance of speaking on behalf of his peers who haven't found a shared affinity in the dining hall seating system, and how, for those people, being in the dining hall can feel isolating.

Another group isolated from the dining hall affinities is the commuter population, who, unless they purchase a commuter meal plan, are not permitted to be in the dining hall. And while they are missing the social dynamics present in the dining hall, they have a designated space in a room beneath the coffee shop allocated for them. Dan referred to this space as a lounge for commuters to hang out and relax between classes, and a place they can store their belongings in lockers. Due to its proximity at the base of the stairs to the coffee shop, I asked Annie if students view the commuter lounge as an extension of the coffee shop, or if it is a protected space reserved for the use of commuter students 
only. Annie affirmed that non-commuters generally don't sit there, and that the campus views the space as having a separate identify from the coffee shop.

During field observations I was in the commuter lounge at the end of a chapel hour when the coffee shop upstairs was closed and would be opening shortly. I noticed how many more students were sitting in the commuter lounge than I had seen during previous observations - they seemed to be everywhere, on tables and on the floor. This gave me reason to doubt that the student body truly saw the space as protected solely for the affinity group of commuters, or at least maybe only when it was convenient to do so.

The data which emerged around affinity groups at Corban demonstrated a connection for most groups to a specific campus space. Residents of Aagard and Farrar Halls feel a strong part of the "Fraagard" group, giving them a sense of connection to their halls and a shared identity known within the larger university community. Residents of the other residence halls reported feeling the same sense of social connection within their space and a similar social identity stemming from it. The dining hall supported those affinities through the silent assignment of affinity group seating, while simultaneously creating an isolating experience for those who don't already feel a sense of belonging to an identified group. The commuter lounge serves as a dedicated location for social connection among commuter students who don't have that same level of social engagement on campus as the residential students.

\section{Campus Traditions Shaped by Campus Spaces}

According to Lukas (employee), students at Corban also create affinities around activities. He said he has heard students report, 
"[my affinity group could be] the disc golf club that I found, or my sports team, or my hall, or the group that goes and serves the homeless every Friday." And so, [community] is maybe less directed by the university and more found, discovered, selected, or created by the students around affinity.

This connection of student affinity development and activity leads to another key data point of influence on the social dynamic within campus spaces: student activities and traditions. Formal and informal campus activities alike appeared in the data to have a connection to students' sense of belonging within the campus community, and some activities which have continued year after year have become campus traditions.

Several students mentioned the social connection they've developed with other students through informal, unstructured recreational activities like hanging hammocks or playing outdoor basketball. Isla discussed how "hammocking" was a community-building activity for many Corban students, and Eric and Grace agreed. With a campus as forested as Corban's, students with hammocks have many options for locations to swing, and it was reported to be a very popular social activity. Joy talked about how the outdoor basketball court near Farrar Hall will draw students from all over campus to play. She said Farrar's location as the furthest residence hall from the campus' central corridor was not a deterrent for students, as they would come from across campus to play together at the only outdoor basketball court on campus.

A more structured ongoing activity reported in the data which brought students together within a space was campus worship nights, planned or impromptu. These were reported to have the flexibility to occur anywhere, but common locations referenced were 
the Klatch, the Performing Arts Center (or the chapel building, as students refer to it), and the Amphitheater. As members of a Christian community, Dan, Isla, and Heidi all referenced the appreciation they had for connecting with their peers through worship events. While Eric agreed that worship events held meaning, he specifically identified the broader chapel program as an ongoing, place-based activity where his participation with peers contributes significantly to his sense of belonging on Corban's campus.

Some of the most renowned campus traditions were connected directly to the residence halls that annually host them. Aside from the outdoor basketball court, another activity that was reported to draw students to come down the hill to Farrar Hall was to watch Farrar residents engage in one of Corban's longest-standing annual traditions: The Pumpkin Smash. Here, Farrar residents wrestled on a mat filled with smashed pumpkins and the winner received the honor of being named the Smash King. Similarly, the male residents of Balyo and Davidson Halls competed annually in the Lumberjack Games with events such as log jousting and tug-of-war. The female residents of Balyo and Davidson had an annual competition of their own which included events such as challenging each other to a showdown, barrel-racing and other events at The Rodeo. Other long-standing residence hall-based campus traditions were the Mr. VG pageant hosted by the PVG community, and the annual Aagard Basement Bash with pumpkin-painting, trick-ortreating, and harvest games (Corban University: Residence Life, n.d.). Since each of these campus traditions are open to the entire community to either watch or engage in, Eric told me that these campus traditions are what bring people to the residence halls. And since they are spread out throughout the academic year, each one becomes something to 
anticipate and as Lukas (employee) articulated it, "creates rhythms of commonality and people being together."

The most surprising (and entertaining) campus tradition mentioned by Heidi, Joy, and Kevin were the cafeteria games. These games were not only unwritten, but several happen silently with no words ever spoken. The Corban student body had created a silent system of games occurring only within the cafeteria, and reportedly, everyone knew what to do. Kevin discussed how participating in cafeteria games made him feel known. For example, in the napkin game, one person would make eye contact with another person across the room while placing the corner of a napkin on their tongue. This informs the one being challenged that they must do the same. As soon as they do, it's a race to see who can eat the napkin the fastest without their hands. Kevin said having someone challenge him to the napkin game "makes me feel like I'm being drawn in...like people are trying to interact and involve me." Joy discussed a much louder game where someone stands up and shouts a word, usually pronouncing it wrong intentionally, and someone else has to spell it as quickly as possible. These games, along with the conversations and group fellowship that happens in the dining hall all hold deep meaning for Joy. "I genuinely believe the relationships I've made in Aramark are the reason I feel so bound to Corban," she said. Heidi referred to Aramark as a "playground" because of all of the games people play there. She added more detail to the napkin game telling me that sometimes it'll be one on one, but other times it can be five on five. And there will be a standing ovation around the entire dining hall for the winner. She talked about less obvious games like gently hitting someone in a crowd and trying to not let them figure 
out who did it, or tossing a wadded napkin on someone's plate without them noticing, or two people competing to see who can fold a paper napkin the fastest. For Heidi, these games:

...reaffirm that this is the right place to be. It just makes me so happy. It also makes me feel privileged at the same time that this is something I get to have, that the majority of the people cannot have, no matter how highly rated their university is.

I asked all participants who discussed the cafeteria games if they believed Corban students would ever play these games in any location outside of the cafeteria, or even outside of campus. They all affirmed that the activity is tied to the location, as it is linked to the culture of the cafeteria and wouldn't be understood or appreciated in any other environment. But for these students who described the cafeteria games, they do understand and have a deep appreciation for how their sense of belonging to the Corban campus has been strengthened through participation in these games.

\section{Residence Hall Lobbies as Social Spaces}

The residence hall lobbies came through prominently in the data as a significant location for the development of student community, resulting in the highest number of participants linking their sense of belonging to time spent with peers in residence hall lobbies. Interestingly, this dynamic was consistent across all five residence hall areas, despite differing social reputations, building locations, and building designs. Chris discussed how the physical ways each residence hall lobby is structured influenced how students engaged socially within them. 
Every lobby is very different, so that's very interesting. Davidson feels very open \& secluded, but Balyo is very separated by the floors, so there's no connections there. PVG is just one big mess, so there's not a lot of room for studying... [it's more about] having fun, it's really loud all the time. Farrar and Aagard are just their own little thing, because they're all male or all female, so those are separate. While the three residence hall lobbies with 24 hour co-ed access, PVG, Davidson, and Balyo, attract the largest number of students, those who have lived in the single-gender older buildings of Aagard and Farrar communicated different types of benefits to the community developed in their buildings, despite limited co-ed access in their lobbies. Heidi discussed how the building structure of Aagard allows for small group or private social interactions, as it has multiple smaller lobbies, some of which can be reserved. "Aagard has a second-floor lobby, a third-floor lobby... and a basement that can be reserved that people typically...go in with the purpose of homework or hanging out with a specific friend or boyfriend." She also mentioned that the main lobby on the first floor cannot be reserved, so is open to all female residents 24 hours per day and permits male students during limited hours.

When student participants were asked where their campus third place might be, the majority identified the residence hall lobbies as the locations they most consistently socialized. Many would ask if a residence hall lobby could qualify as a third place since, according to Banning et al.'s 2010 data, it is a part of a students' residence, which Banning designates as the first place for college students. During student interviews, I provided the student participants with the literature's definition of a third place, but also 
encouraged them to think broadly about their community-based experiences and the locations they occurred within. Most students were asked to identify two campus locations they utilize as a third place, and for the majority of them, a residence hall lobby was one of their two responses.

Chris described the relationships he's developed with peers in his residence hall lobby as "sacred and intimate." He said, "spending time in the Davidson lobby helps [me] strengthen the bond [I have] with fellow residents." Isla reported feeling more connected to the PVG residential community than the overall Corban community and having ore PVG pride than Corban pride. She said, "living in the residence halls can feel like living with family - this is how to build a family on campus." Annie lived in a socially wellconnected residence hall, and then moved to the campus-owned townhouses for a year. While she appreciated having less rules and gaining some independence through living in that space, she moved back to the residence halls this year because she missed living in community. She referred to the social life of the residence hall lobbies as "natural community." When discussing living in the townhouses, she identified that she missed "having that space where you just run into people... with the townhouses you have to be much more intentional... when walking down to do laundry, I'm not going to run into residents in the lobby doing homework." The distinction Annie made between campus residences contributed to my understanding of campus third places.

Residence hall lobbies can meet the literature's definition of a campus third place, as the students' room can fulfill the classification of a first place. Whereas in a townhouse or apartment-style campus residence, there isn't as often a central lobby to congregate in, 
and if there were, students may not need to leave their space as frequently as those in the residence halls do to have their needs met. According to Lukas (employee), students will most likely seek a third place that is easy to access, an assessment which aligns with the data identifying residence hall lobbies as the dominant location residential students identify as their third place. He said this:

Corban has a real lack of third places that are open-some of those spaces close and lock, and because everything on this campus is really spread out...you don't want to walk across campus with the hope of something being open, or people being in it [when they may not be, so] you probably stick to what's around where you live.

Several student participants affirmed the distance between buildings as a barrier for seeking out locations to socialize, as well as the additional dynamics of the work of hillclimbing and the frequent Pacific Northwest rain. Ben is a student who came to Corban from a geographic region with minimal rainfall, and he referenced how difficult the transition has been living in the rainy climate of the Pacific Northwest. But he also discussed feeling what many other students expressed as a result of spending time socializing with peers in a space designated for the purpose of socializing: he felt a sense of personal value by merely contributing to a good discussion. For Ben, as well as for many of his peers, this is what motivates them to go to the place where their respective community of friends spend time together and join them in active conversation. 


\section{Campus Coffee Shop as Social Space}

The campus coffee shop is one such location that students reported traveling to in search of social connection with peers. However, based on the third place literature, I was surprised that Corban's coffee shop did not show up in the data as the dominant campus location that the majority of the students engage in community. While it did receive many mentions as a place students do spend time, there wasn't the same level of enthusiasm expressed about what happened within it, when compared to how students discussed the dynamics in the residence hall lobbies or the dining hall. While the social dynamics in those locations appeared to be linked with larger groups and activities (homework, games, movies, etc.), the coffee shop appeared in the data as a location for individuals or small groups to do quiet, calm things. Independent studying was frequently reported to occur there, along with one-on-one coffee dates and meetings. Dan is a student who has felt significantly connected to the Corban community due to time spent in the coffee shop:

I've had great moments here in the coffee shop that have really shaped my identity as to who I am, and where I belong on campus. And it's definitely strengthened my fellowship with other people, other students; the coffee shop's really been one of those places where I can just feel at home and be able to be a part of it.

Eric expressed a similar sentiment: "separate communities intersect in the coffee shop which helps me feel connected to the Corban community." One of the identified "separate communities" that several participants mentioned were the commuter students. 
Due to the proximity of the commuter lounge located beneath the coffee shop with an open stairwell connecting the two spaces, some students have the perception that the coffee shop is primarily a campus place for commuters. Ben said, "The coffee shop is mostly [occupied by] commuters - my friends and I don't spend a lot of time there." Kevin also identified a deterrent to spending time in the coffee shop is its limited space. He referenced how simply entering the space can be difficult as the stairwell bottlenecks when it's crowded, and it can also be difficult at times to find a seat. During my field observations I experienced what Kevin was referencing when I entered the coffee shop during a busy time and couldn't find an available table.

Having a larger gathering space similar to the coffee shop was articulated as a desire by students and employees alike. Based on the data, it appears that students desire a larger space with more options to engage in community around activities. Kevin referenced a large state university in his hometown where he has spent time with friends in the student union building.

There's bowling alleys and restaurants and plenty of nice places [to hang out]. My friends who attend [that university] spend a lot of time there. There's nothing like that here. There's no space that's just meant to be a common area for people who live on or off campus.

Kevin identified that Corban's campus was lacking a large, activity-based space where students gather to spend time together, and he presumed that students would connect more frequently if such a space were available. 
According to Oliver (employee), the current design of the coffee shop is an improvement over what it had been. He said it used to be only a 10x10 space, so they did renovations to expand and connected it to the commuter lounge below. Despite the improvements, he said the building structure itself is a limiter to additional work being done. "We can still do some [more] work to it, perhaps. But there's a bill attached to that," he said. When asked if he saw students using the coffee shop as their third place on campus, Oliver was skeptical. "They may identify their particular residence hall lobby?" he guessed. "They might identify the dining hall? I don't know if they would identify the coffee shop as much.” Despite my anticipation that the only coffee shop on a small university campus would most likely be identified as the students' third place for socialization, the data collected at Corban University demonstrated that this cannot be an assumed conclusion.

\section{Interconnection of Themes}

As seen within the data, many of the emergent themes and subthemes overlapped and connected with one another. Campus topography is very connected to the social dynamics within the built environment because the degree to which student use the space is influenced by the physical parameters and limitations of the building itself. The historic location of the buildings on the property influence the decision-making of where to prioritize resources when connecting spaces with walkways or building new facilities. Further, buildings constructed nearly a century ago can not only be difficult to maintain, but more difficult to renovate, which can leave the institution no choice but to meet their educational goals as effectively as they are able, given the limitations the buildings 
provide. Similarly, where buildings are located influences where pathways are built, which has been found to have an influence on students' social interactions and sense of connectivity to the campus. Likewise, the campus infrastructure surrounding policies impacts the use of campus spaces and therefore the social dynamics occurring within them. These themes are deeply interwoven into one another, and each have been identified as playing a significant role in how students engage within campus spaces and experience a personal sense of belonging to the institution. 


\section{CHAPTER 5: DISCUSSION AND IMPLICATIONS}

As seen in Chapter 4, this exploratory case study produced three dominant themes that emerged from the data as key ecological influences in the support or hinderance of students' sense of belonging at a small, residential, private institution. Analysis of the data themes produced five key findings that answered the two research questions of the study (see Table 5.1). The study's key findings were: the impact of campus topography on student engagement, the social importance of campus pathways, the effect of location on building use, the influence of place-based campus traditions on students' sense of belonging, and the correlation between sense of belonging and campus third places.

\section{Table 5.1}

Intersections of the Study's Research Questions, Data Themes, and Key Findings

\begin{tabular}{|c|c|c|}
\hline \multirow{4}{*}{$\begin{array}{l}\text { RQ1: } \\
\text { What are students' experiences of } \\
\text { community-focused built campus } \\
\text { spaces as those spaces pertain to } \\
\text { students' sense of belonging at a } \\
\text { small, rural, residential institution? }\end{array}$} & \multirow{3}{*}{$\begin{array}{l}\text { Data Theme 1: } \\
\text { Campus } \\
\text { Topography }\end{array}$} & $\begin{array}{c}\text { Finding 1: the impact of campus } \\
\text { topography on student } \\
\text { engagement }\end{array}$ \\
\hline & & $\begin{array}{l}\text { Finding 2: the social importance } \\
\text { of campus pathways }\end{array}$ \\
\hline & & $\begin{array}{c}\text { Finding 3: the effect of location } \\
\text { on building use }\end{array}$ \\
\hline & $\begin{array}{c}\text { Data Theme 3: } \\
\text { Social Design of } \\
\text { Space } \\
\end{array}$ & $\begin{array}{c}\text { Finding 5: the correlation } \\
\text { between sense of belonging and } \\
\text { campus third places }\end{array}$ \\
\hline \multirow{4}{*}{$\begin{array}{c}\text { RQ2: } \\
\text { To what extent do small, rural } \\
\text { residential campuses intentionally } \\
\text { design or emphasize community- } \\
\text { centered third places within their } \\
\text { built space? }\end{array}$} & \multirow{2}{*}{$\begin{array}{l}\text { Data Theme 2: } \\
\text { Campus } \\
\text { Infrastructure }\end{array}$} & $\begin{array}{c}\text { Finding 3: the effect of location } \\
\text { on building use }\end{array}$ \\
\hline & & $\begin{array}{l}\text { Finding 4: the influence of } \\
\text { place-based campus traditions on } \\
\text { students' sense of belonging }\end{array}$ \\
\hline & \multirow{2}{*}{$\begin{array}{l}\text { Data Theme 3: } \\
\text { Social Design of } \\
\text { Space }\end{array}$} & $\begin{array}{l}\text { Finding 2: the social importance } \\
\text { of campus pathways }\end{array}$ \\
\hline & & $\begin{array}{l}\text { Finding 4: the influence of } \\
\text { place-based campus traditions on } \\
\text { students' sense of belonging }\end{array}$ \\
\hline
\end{tabular}


This chapter summarizes these key findings and outlines subsequent implications for practice, theory and research, as well as the limitations of the study.

\section{Discussion of Key Findings}

The study's themes, which informed the study's five key findings, are summarized to show how they answered each of the study's two research questions. The first theme of campus topography considered the ecological components of the university property: how the natural or built elements of the campus environment influenced student's social engagement. The social context of the built campus environment has been demonstrated in the literature to have a significant influence on students' psychological sense of belonging and their perceptions of mattering, both of which are significant contributors to student attrition and retention (Manning \& Kuh, 2005; Strayhorn, 2012; Strange \& Banning, 2015). Viewing the data through this lens highlighted the influence of a campuses' geographic location on student engagement (Finding 1). Similarly, this ecological view also brought to light the social impact of campus pathways (Finding 2), and how students' use of buildings and the services they offer is affected by the location of the buildings (Finding 3). These findings each contribute to answering the study's first research question, which is: "What are students" experiences of community-focused built campus spaces as those spaces pertain to students' sense of belonging at a small, rural, residential institution?"

The second theme which emerged from the data highlighted the connection between institutional infrastructure and student space use. Campus policies, 
communication strategies, and institutional resource allocation each contributed to how students engaged socially within campus spaces and further, shaped student perceptions around the university's commitment to the development of a vibrant student community. The designated purposes of specifically located buildings and how those purposes were promoted within the student body was reported as impacting students' use of the space and their perceptions of the building's function and personal relevance (Finding 3). Further, the institutional prioritization and communication of place-based programs and traditions were linked to student and employee views on the university's value of fostering a strong student community (Finding 4). These findings provided answers to the study's second research question, which is: "To what extent do small, rural residential campuses intentionally design or emphasize community-centered third places within their built space?"

The third data theme looked closely at the social influence of space design, and the structural aspects of social spaces on campus which contributed to a strong student community. Through this theme, the social influence of the types of campus pathways and routes they provided were identified as a contributor to student engagement (Finding 2). When campus environments were designed to foster activity engagement, those spaces played a significant role in students' sense of belonging to the institution (Finding 4). Within the context of this third data theme, both of these key findings contributed to the answer of the study's second research question. Lastly, the campus locations identified as third places for residential students were found to have a positive influence 
on students' sense of belonging (Finding 5), contributing to the answer of the study's first research question.

\section{Finding 1: Campus Topography}

The geographic features of a campus property were found to influence students' decisions regarding which activities they chose to engage, in which locations, and with whom they chose to socialize. Due to Corban University's geographic location on a hillside, participants reported that navigating campus provided challenges because reaching nearly every location involved walking up or down the hill. This data is important to consider as universities assess the building locations of classrooms, residences, and student-centered offices within the unique topography specific to their campus. At Corban, the gymnasium and student fitness center are in a building at the top of the hill, a location reported to be less-frequently accessed by students because of the amount of physical effort required to reach it. While the activities occurring in this area may provide substantial opportunities for peer engagement, the location of the facility appeared to be a deterrent for some students to engage socially there.

How students perceive their ability or interest in navigating the topographical features of the campus will influence where they choose to spend their time and how they engage in the life of the campus. This is worth consideration due to its connection to the college student development literature which has shown that students who are more involved in the community life of the campus report higher levels of satisfaction about their overall educational experience, feel more connected to the university community, 
and are more successful academically (Astin, 1984; Pascarella \& Terenzini, 2005; Schlossberg, 1989).

\section{Finding 2: Pathways}

Campus pathways and sidewalk patterns surfaced in the data as a unique contributor to a social dynamic worth consideration. Students in the Corban study reported a higher likelihood of impromptu social encounters within facilities located along a path than in buildings at the end of a route. One of the most social residence hall lobbies with twenty-four-hour access was predicted by study participants to potentially have an even higher level of student engagement if the sidewalk leading to it didn't end at the building, making it an intentional destination site only. Further, the data demonstrated that a higher number of campus pathways (both formal pathways (sidewalks) and informal pathways (trails)) contributed positively to students' perception of the connectivity of campus and its navigability, as well as to students' social interactions while utilizing the pathways. This user-centered approach to the design of campus pathways creates greater opportunities for student intersections, which leads to more social contact, which can generate more relational vitality and a desire to invest more deeply in the campus community (Kenney, et al. 2005).

\section{Finding 3: Building Locations}

Related to campus topography and pathways, student-centered building locations also came through in the data as a key contributor to student space use and social engagement. Corban University's campus was found to have a central building corridor (See Figure 4.13) that included the majority of the primary student-use spaces, resulting 
in reduced use and an occasional negative perception of the buildings located outside of that corridor. The Barn (See Figure 4.11, building 36) is a prime example of a newly designed creative maker space promoted heavily for student use, but since its opening in 2017, has been limited in functionality due in part to its remote location. While on campus I also heard reports of an intentional in-process shift of building functionality through the re-purposing of the Younger Center (See Figure 4.11, building 20) into a lively student hub with several resource services for students, particularly for international students. Due to its campus location outside of the central building core, the study's data demonstrates that the student-use goals of the Younger Center have the potential of facing a similar outcome as The Barn. Both buildings provide unique opportunities for social engagement which could attract a variety of students with differing interests. These spaces could support the development of a wider range of social affinity groups on campus, which is highly supported by the literature on student mattering (Friedmann, 2005; Hurtado, 2012; Schlossberg, 1989,), and could contribute toward the university's goals of fostering a stronger student community. This demonstrates that despite an institutions' attempts to make positive student-centered changes, students have a higher likelihood of missing the socially developmental opportunities the university is endeavoring to provide if student-focused buildings are not located in prime student-use areas of the campus. The study's data show that creating student-centered spaces within highly trafficked campus locations is a key component of fostering a vibrant student community. 


\section{Finding 4: Place-Based Campus Traditions}

One of the ways the second research question was answered at Corban University was through the institution's demonstration of their collective value of student community building through university-sponsored events and student-centered traditions. The campus-wide events described most often were consistent in their frequency of occurrence as well as were place-based, in that they were linked to a specific location. One event was the weekly chapel program located in the Psalm Center, and the other was the campus-wide annual activities hosted by each respective residence hall community. The experiential reports from participants about these events aligned with the literature stating that institutional traditions play a significant role in a student's perception of their ability to belong within the campus community (Manning \& Kuh, 2005). Residential students at Corban knew they had the opportunity to contribute their involvement by hosting an activity for the entire campus, as well as to participate when other residence halls hosted their annual events. For the students who chose to attend chapel, they articulated a sense of emotional connection to their peers who regularly gathered in the same location, a space designated for community worship. The chapel program also served as a weekly manifestation of the institution's mission and expressed values of a community promoting worship. Similarly, the traditional annual residence hall events represent the institution's commitment to "build a vibrant Christian community that promotes...creative expression, and activities reflecting God's character" (Corban University: Mission and values, n.d., para.1). 
Fulfilling the university's mission and values through student engagement has been long-since demonstrated in the literature as a contributor to student success and retention (Astin, 1984; Pascarella \& Terenzini, 2005; Schlossberg, 1989). These types of programs and institutional traditions not only provide students the sense that they are contributing to the furtherance of a rich campus community, but allow them to gain a deeper understanding of the institutional mission and their role in the legacy of the university, which contributes to their sense of institutional belonging (Cheng, 2004; Magolda, 2001; Manning \& Kuh, 2005; Schlossberg, 1989 ). Further, time spent within affinity groups engaged in place-based activities can create an assigned cultural identity for a physical campus space, thereby connecting meaning to the location because of the memories created there (Friedmann, 2005; Leach, 2005). This key finding in the data demonstrated the connection between place-based student engagement and students' sense of belonging to the institution.

\section{Finding 5: Sense of Belonging in Campus Third Places}

Campus spaces designed for students to engage socially play an important role in the development of healthy communities on a college campus, as they provide students a safe haven to interact and relax outside of their home or work environment (Butts, Beltramini, Bourassa, Connelly, Meyer, Mitchell, Smith, \& Willis, 2012). When correlating residential students' sense of belonging with their identified third place, the most frequently mentioned campus locations were the students' residence hall lobbies, and by extension, the dining hall. Previous research studies asking university students to identify their third place concluded that coffee shops were the dominantly selected 
locations, with the majority located off campus (Banning, Clemons, McKelfresh \& Gibbs, 2010; Waxman, Clemons, Banning, \& McKelfresh, 2007). However, these studies were done at large, public institutions with no participant parameters for residency status, and with no intention to assess students' sense of belonging to the institution. While the Corban University coffee shop fit Oldenburg's (1989) description of a third place, the majority of my student participants reported that it did not contribute to their sense of belonging as significantly as the residence hall lobbies and the dining hall. Therefore, for small, residential institutions who place a missional value on the development of a strong student community, simply identifying campus locations that meet third place criteria is not enough for assessing an environmental impact on students' sense of belonging.

The data also demonstrated that by nature of membership in a residential community, there is an affinity established in that all residents of the same living area have shared experiences specific to residing together. At Corban, residential identity is a significant definer of affinity groups. The belonging literature stresses the importance of universities creating intentional social niches where students can develop a sense of community based on a common affinity (Hurtado, 2012), and it was reported that Corban has done that effectively within each of their residential buildings. This residential social niche extends beyond the residence hall lobby and reaches into the dining hall, since all residential students are on a meal plan, and eating is a recurring necessity. Students reported that they would frequently leave the residence halls together to go to meals and then sit together with members of their residential community at their living area's unofficially designated table in the dining hall. At Corban, the "Aramark" dining hall 
experience was reported to not only support the necessities of food selection and consumption, but its design was also reported to support a socially engaged meal experience. The dining hall "regulars" (those who have meal plans), have also created an unofficial tradition of games embedded within the culture of the place. While these games are not institutionally sponsored or even structured with written rules, student participants identified these games as a part of the culture of the dining hall that contributed to their feelings of connection to the university as a whole. This data aligns with the previously stated literature regarding the significant role institutional place-based traditions play in contributing to a student's perception of their ability to belong within the campus community (Manning \& Kuh, 2005).

\section{Implications for Theory}

The result of this study's identification of third place locations on small, private, residential university campuses adds another dimension to Seamon's $(1979,2015)$ psychological characteristics of home, which Oldenburg (1989) built upon with third place descriptors. The Corban study develops this correlation between home and third place a step further, identifying third place characteristics that are also critical to the establishment of a residential students' sense of belonging to their institution. The data shows that locations meeting third place criteria must also provide students the ability to participate in a variety of activities within their affinity groups to create an ecological connection between the place and their sense of belonging to the institution. Table 5.2 compares each of Seamon's five descriptors of the home environment to Oldenburg's aligning third place qualities as well as to characteristics of the residential students' 
campus third places that contribute to their sense of belonging, as described on Corban's campus.

Table 5.2

Comparison of Home, Neighborhood Third Places, Campus Third Places

\begin{tabular}{|l|l|l|}
\hline $\begin{array}{l}\text { Characteristics of } \\
\text { Home } \\
\text { (Seamon, 1979, 2015) }\end{array}$ & $\begin{array}{l}\text { Characteristics of } \\
\text { Third Places } \\
\text { (Oldenburg, 1989; } \\
\text { Waxman 2006) }\end{array}$ & $\begin{array}{l}\text { Characteristics of } \\
\text { Residential Students' } \\
\text { Identified Third Places } \\
\text { Contributing to Sense of } \\
\text { Belonging }\end{array}$ \\
\hline $\begin{array}{l}\text { Sense of rootedness, } \\
\text { connecting person to } \\
\text { place }\end{array}$ & $\begin{array}{l}\text { Consistent presence of } \\
\text { regulars; opportunity to } \\
\text { linger }\end{array}$ & $\begin{array}{l}\text { Time spent "hanging out" } \\
\text { with peers in residential } \\
\text { affinity group engaging in } \\
\text { activities such as playing } \\
\text { pool, socializing, studying } \\
\text { together; collective } \\
\text { participation in campus } \\
\text { traditions }\end{array}$ \\
\hline $\begin{array}{l}\text { Sense of ownership that } \\
\text { increases with familiarity }\end{array}$ & $\begin{array}{l}\text { Regulars get special } \\
\text { privileges like reserved } \\
\text { seating or the ability to go } \\
\text { behind the counter to } \\
\text { retrieve something, } \\
\text { providing increased } \\
\text { familiarity and perceived } \\
\text { ownership }\end{array}$ & $\begin{array}{l}\text { Residents of each residence } \\
\text { hall have permanent } \\
\text { admission access to their } \\
\text { lobby and the right to } \\
\text { determine which non- } \\
\text { residents enter to participate } \\
\text { in community building } \\
\text { occurring there; } \\
\text { membership in a residential } \\
\text { community provides a table } \\
\text { designation with instant } \\
\text { community for meals in the } \\
\text { dining hall }\end{array}$ \\
\hline $\begin{array}{l}\text { Social or emotional } \\
\text { renewal in a personalized } \\
\text { place; relief from } \\
\text { external responsibilities }\end{array}$ & $\begin{array}{l}\text { Bringing people together in } \\
\text { a common location for no } \\
\text { reason but to socialize; } \\
\text { relief from external } \\
\text { responsibilities }\end{array}$ & $\begin{array}{l}\text { Neither the residence hall } \\
\text { lobby nor the dining hall } \\
\text { have assigned } \\
\text { responsibilities for most } \\
\text { students, allowing for a } \\
\text { feeling of letting go of life } \\
\text { demands, allowing them to } \\
\text { be present with their peers } \\
\text { enjoying time together }\end{array}$ \\
\hline
\end{tabular}




\begin{tabular}{|l|l|l|}
\hline $\begin{array}{l}\text { Freedom of self- } \\
\text { expression }\end{array}$ & $\begin{array}{l}\text { No criteria for admission; a } \\
\text { social expectation exists } \\
\text { for diversity of expression }\end{array}$ & $\begin{array}{l}\text { Residential students have } \\
\text { opportunity to personalize } \\
\text { their residence hall lobbies } \\
\text { to fit their activities by } \\
\text { arranging furniture; they can } \\
\text { personalize their dining hall } \\
\text { experience through their } \\
\text { designated residential } \\
\text { seating areas; in both places, } \\
\text { affinity groups can start } \\
\text { their own traditions }\end{array}$ \\
\hline $\begin{array}{l}\text { Relational sense of } \\
\text { warmth }\end{array}$ & $\begin{array}{l}\text { Friendliness and hospitality } \\
\text { from staff toward regulars; } \\
\text { a sense of mutual concern } \\
\text { and support between } \\
\text { regulars and staff }\end{array}$ & $\begin{array}{l}\text { At many small residential } \\
\text { institutions, especially } \\
\text { CCCU member schools, } \\
\text { relational warmth is a } \\
\text { reflection of the institution's } \\
\text { value of fostering a strong } \\
\text { student community and } \\
\text { often extends between } \\
\text { employees and students }\end{array}$ \\
\hline
\end{tabular}

While the third place literature aligns these social qualities of home with the characteristics of environments such as bars, cafes, or diners, the Corban data describes similar characteristics of campus third places reported to contribute to students' sense of belonging within a residential university context. The two key characteristics of the campus locations reported to have the strongest contribution to students' sense of belonging were spaces linking students to a larger affinity group (in this case, a collective residence hall identity), and spaces with a functional, sociopetal design allowing for furniture arrangements supporting a variety of activities occurring within the space. This addition to the theory of third place also answers the first research question seeking to determine students' experiences of community-focused built campus spaces as those spaces pertain to students' sense of belonging at a small, rural, residential institution. 


\section{Implications for Practice}

Previous research considering third place identification on a university campus has only occurred at large, public institutions, and did not seek to link students' time spent in the identified third place to their sense of belonging to their institution. This study built on these previous studies, but scaled it to small, residential universities who place institutional priority on the development of student community. While the study site was also selected specifically due to its rural location and its institutional membership in the Council for Christian Colleges and Universities, those additional components did not limit the applicability of data for campuses not matching those specific criteria. Therefore, this study's data is transferable to small, residential, private university campuses who articulate a missional commitment to fostering a vibrant campus community. The most prominent findings with transferable implications for practice are campus topography's impact on student engagement, the social influence of campus pathways, and the connection between student involvement in campus activities and their sense of belonging to the institution.

Beyond merely the built campus environment, campus topography influences students' social engagements and is worth considering for institutions who place a high value on fostering a vibrant student community. At Corban University, a campus built on a hillside impacted students' interest levels for accessing campus resources as well as their social choices. The hillside topography precluded the development of a campus quad and therefore the ability for large groups of students to engage together outdoors in a singular open space, but resulted instead in smaller groups of students utilizing outdoor 
niches for smaller community building and utilizing the forested nature of the campus to hang hammocks and to explore walking trails. Campus topography impacts the ways students engage socially, so capitalizing creatively on the natural geographical resources of a campus will influence the student community. Institutions can promote outdoor community engagement specifically connected to their campus topography by loaning hammocks or slackline webbing in a forested campus or setting up hammock stands and other outdoor seating areas on flat, non-forested campuses. In regions with mild weather, the creation of a large outdoor amphitheater space where campus activities are held can become a campus space associated with strong student engagement. And on campuses with buildings spread far apart, programs that loan bicycles, scooters, or Segways can increase social connectivity.

Campus pathways and sidewalk patterns were reported in the data as a unique contributor to a social dynamic meriting further consideration by institutional leadership and campus planners. While constructing new sidewalks or relocating buildings along their route may require an unattainable allocation of resource, universities can audit the locations of student-centered services, resources, and hangouts and consider relocating them into facilities in high student access areas or along pathways in route to other student points of interest. Pathways can also be viewed more expansively than simply concrete sidewalks, with consideration given to areas of campus where trails or gravel paths may be installed to provide greater connectivity between student-centered points of interest. To enhance students' social engagement, universities could also study the patterns of student pathway use and install seating areas at highly-trafficked sidewalk 
forks or other areas where students consistently congregate along a path. Further, consideration of the residential density metrics of a university campus (Kenney, et al., 2005) can assist campus planners in creating a more walkable campus, increasing opportunities for students' social interactions.

Finally, further consideration of campus activities and annual traditions as well as the spaces hosting the events will provide a significant social benefit to the student community. While many campuses do host annual events which have evolved into tradition over time, it is critical not to underestimate the value of the tradition on the enhancement of the student community. Marketing of these traditions is a significant way to not only build enthusiasm within the student body, but also creates an ongoing reminder of the bigger institutional values that the events promote. Institutions should be bold to memorialize their unique campus traditions in permanent ways that not only showcases them to students and campus guests, but also invites students into a rich legacy of campus tradition. Less formalized campus events and quieter traditions also hold significant value among students and can be encouraged by creating a variety of adaptable student spaces where these activities can be hosted. Sociopetal space designs with wide open spaces and flexible furniture options are critical for university campuses with an institutional commitment to the development of a robust student community.

\section{Institutional Recommendations}

Corban University was selected as the study site due to the many ways its campus met the unique criteria supporting an exploration of the study's research questions. Further, as an institutional member of the Council of Christian Colleges and Universities 
(CCCU), Corban was the selected study site due to the similarities in mission and infrastructure which would allow for transferrable institutional recommendations for other CCCU member schools. Therefore, while the recommendations that follow were developed during the study on Corban University's campus, they are broad enough for consideration on other CCCU member campuses.

\section{Chapel Infrastructure}

Despite participation in the chapel program at Corban University being optional for students and employees, it clearly served as a weekly reflection of the institution's mission and expressed values as a vibrant faith community. During each of the three hours per week that chapel occurred, the institution further expressed its missional commitment to corporate spiritual growth by closing several student-centered spaces including the coffee shop and the library. However, during my campus observations I witnessed a significant number of students crowding the commuter center and waiting outside the coffee shop gate for it to re-open after chapel ended, which caused me to wonder if closing student community areas during a non-required consistently-occurring community event sent a mixed message to students. Investing in a strong chapel program three times per week sends a message of missional commitment, and not mandating attendance sends a message permitting student choice for how they choose to invest in community. However, closing student community spaces during non-mandated event hours seems to send a contradictory message communicating an institutional prioritization of one student community gathering space over others. If authentic student 
community is desired, it is critical to align institutional policies and practices to communicate a consistent message regarding the importance of community development.

\section{Residence Hall Inequities}

University administrators may also take note of areas where individual findings from this study might intersect within a single area on campus, creating the potential for increased social impact on the development or detriment of one particular part of the campus community. An example from the Corban study was the negative reputation among students regarding two of the oldest buildings on campus, the Farrar and Aagard Residence Halls (jointly referred to as "Fraagard"). Student perceptions of these buildings were reported to be shaped by each of the themes identified in this study, all jointly contributing to a clear difference in levels of social engagement within these living areas from what was occurring within the other campus residence halls.

Campus topography played a role in the negative reputation of Farrar and Aagard, as their locations at the bottom of the hill were often referenced as being far away from the other more centralized student-centered spaces. This distance contributed to a perception that the students living in Fraagard had less interest in peer socialization and even enjoyed the isolation the building locations provided. Pathway routes also contributed, as they ended at each residence hall resulting in students rarely stopping for socialization on their way somewhere else but only going there if Farrar or Aagard was their intended destination. Since the buildings were located outside the central building corridor with limited proximity to other student-centered buildings, the campus plan itself contributed to a perception of isolation. 
Further, the campus infrastructure had a strong role to play in negative social assumptions about the halls, as the policies regulating student use for Farrar and Aagard were significantly more limited than the other residence halls. While the other three residence halls had lobbies with twenty-four hour access for male and female students, Farrar is an all-male residence and women were only permitted in the building during specific hours, with the same policy for the all-female Aagard Hall with male students only permitted during designated times. Since residence hall lobbies were reported as a primary campus location for third place socialization, the restrictive building policies of Fraagard contributed to furthering their residents' social disadvantage.

However, the one reported social advantage of Fraagard was their strong tradition of annual campus-wide events. During student interviews I heard multiple reports of the Farrar "Pumpkin Smash" event, one of the campuses' longest-standing and most popular student activities. Aagard's "Basement Bash" was also mentioned, although not with the same level of enthusiasm and honor as the Farrar event. These reports affirmed the mattering literature's emphasis on participation in university-wide activities and how the culture of a community can be shaped by campus tradition (Astin, 1984; Tinto, 2001; Manning \& Kuh, 2005) as much as it may also be shaped by its topography, pathways, and location. An evaluation of points of inequity between residence halls, including assessment of key social contributors (such as building location, pathways, and policies) is recommended with the goal of leveling the social playing field between residence hall communities. 


\section{Commuter Life Program}

Lastly, this study brought to light the residentially-centric nature of Corban University's student community. While the residence hall lobbies are technically open for anyone to spend time, they are very focused on the residential population. Further, the dining hall serves as an extension of the residence hall, where all residential students are on meal plans and engage together in a largely social meal experience which excludes commuter students. The residential students at Corban have two expansive campus areas for the development of community that each create exclusivity toward commuter students, and yet the only dedicated space for the commuter population is wide open and can be accessed by anyone. The creation of an enclosed, central, committed space for commuter students as well as the development of a commuter assistant programmirrored after a resident assistant program—can provide the message to commuters that they are valued, and that the institution is intentionally investing in efforts to integrate them into the campus community.

\section{Limitations and Further Research}

While the findings of this study have answered its stated research questions, they also highlighted the study's limitations and created new questions to be answered by further research. A few considerations for further investigation are suggested here.

This study was limited to the campus of one small, private, faith-based institution of higher education in the Pacific Northwest and focused on the experiences of residential students within that environment. While the findings are transferrable to institutions comparable in size and mission, further research is needed to understand commuter 
students' experiences of third places and their subsequent sense of belonging on similar campuses. This additional analysis would provide valuable data regarding a broader range of student perceptions regarding the influence of their campus environments on the student body's social integration and institutional sense of belonging.

Additionally, the third place studies at large public institutions (Banning, Clemens, McKelfresh, \& Gibbs, 2010 and Waxman, Clemons, Banning, \& McKelfresh, 2007) could be furthered by considering the connection between identified third places and students' sense of belonging within those larger environments. The current data could be narrowed to the smaller percentage of students who identified their third places as existing on campus, and then students' perceptions of those identified campus third places could be further explored to assess if there is a connection between their experiences within those locations and their institutional sense of belonging.

Prior to data collection and analysis, this study did not consider the influence of building location on an institution's efforts toward fostering a vibrant student community. Further campus planning research could be considered to explore how building location influences students' use of buildings based on proximity to other student-centered locations, and to look for a connection between those patterns of building use and students' institutional sense of belonging.

Due to the natural connection of the third place literature in urban planning and development, another rich area for research could be a comparison study of a university's residence hall community as a small neighborhood. Consideration of social and ecological constructs such as walkability, human scale, and third place could be analyzed 
within a university's residence hall to consider how particular urban planning metrics for fostering community in a neighborhood might inform the design, infrastructure, and furniture layout of a campuses' residential spaces and how those metrics contribute to the enrichment of a robust student community.

\section{Conclusion}

This exploratory case study on a small, rural, residential, private university campus has added to the previous work of Oldenburg (1997), Waxman, Clemons, Banning, and McKelfresh (2007), and Banning, Clemons, McKelfresh and Gibbs (2010), introducing the impact of student-centered third places on university campuses. While their research laid a foundational rationale for institutions to consider the social importance of prioritizing campus third places, my study extended their model by linking students' sense of belonging to the development of campus community within campus third places. Unlike Banning et al.'s studies, my research found that the campus coffee shop was not the top-identified third place for residential students, but rather their residence hall lobbies, and by extension, the campus dining hall. For residential students to cultivate a strong sense of institutional belonging within these campus third places, the location itself should foster a natural affinity connection between students as well as promote social interaction and encourage activity engagement through flexible sociopetal interior design. Further, in order for these campus third places to effectively contribute to a robust student community, building location, surrounding pathways, and the broader campus topography should each be considered as they play an often-unidentified role in the development of strong peer connections. 
This study demonstrates a strong link between the designation and design of campus third places and students' sense of belonging to the institution, which has previously not been connected on university campuses. Due to the previouslysubstantiated contribution of sense of belonging to student engagement, academic success, and student retention, this study serves as further impetus for residential institutions of higher education to give greater consideration to the built campus environment and particularly, third place locations designed for the purpose of student socialization. Social spaces contribute to or detract from a students' sense of belonging to the institution. When viewed through an ecological lens, the entire campus can be considered a social space ready for campus decision-makers to enhance the student experience, while also demonstrating their commitment to a vibrant, connected student community. 


\section{REFERENCES}

Altman, I. (1970). Territorial behavior in humans: An analysis of the concept. In L. A. Pastalan \& D. H. Carson (Eds.), Spatial behavior of older people (pp. 1-24), Ann Arbor, MI: University of Michigan-Wayne State University Press.

Altman, I. (1975). The environment and social behavior: Privacy, personal space, territory, and crowding. Monterey, CA: Brooks/Cole.

Arthur, P., \& Passini, R. (1992). Wayfinding: People, signs, and architecture. New York: McGraw-Hill Book Company.

Astin, A. W. (1984). Student involvement: A developmental theory for higher education. Journal of College Student Personnel, 25(4), 297-308.

Azusa Pacific University (n.d.). Four cornerstones. Retrieved from: https://www.apu.edu/about/cornerstones/

Banning, J. H. (1978). Campus ecology: A perspective for student affairs. Washington, DC: National Association of Student Personnel Administrators. Retrieved from www.campusecologist.org/files/Monograph.pdf.

Banning, J. H., \& Cunard, M. (1986). Environment supports student development. ACU-I Bulletin, 54(1), 8-10.

Banning, J. H., \& Bryner, C.E. (2001). A framework for organizing the scholarship of campus ecology. Journal of Student Affairs, 10, 9-20.

Banning, J. H., Clemons, S., McKelfresh, D., \& Waxman, L. (2006). Designing the third place: A concept for campus auxiliaries. Journal of the National Association of College Auxiliary Services, 6(3), 46-50. 
Banning, J. H., Clemons, S., McKelfresh, D., \& Gibbs, R. W. (2010). Special places for students: Third place and restorative place. College Student Journal, 44(4), 906912.

Banning, J. H. (2016). Campus ecology and university affairs: History, applications and a future: A scholarly personal narrative. Arvada, CO: Terra Cotta Publishing.

Baumeister, R. F., \& Leary, M. R. (1995). The need to belong: Desire for interpersonal attachments as a fundamental human motivation. Psychological Bulletin, 117(3), 497-529.

Beaulieu, C. (2004). Intercultural study of personal space: A case study. Journal of Applied Social Psychology, 34(4), 794-805.

Bell, P., Greene, T., Fisher, J., \& Baum, A. (1996). Environmental psychology. Fort Worth, TX: Harcourt Brace College Publishers.

Bell, V. (1999). Performativity and belonging. Thousand Oaks, CA: Sage Publications, Inc.

Benne, R. (2001). Quality with soul: How six premier colleges and universities keep faith with their religious traditions. Grand Rapids, MI: Wm. B. Eerdmans Publishing.

Blocher, D. H. (1978). Campus learning environments and the ecology of student development. In J. H. Banning (Ed.), Campus ecology: A perspective for student affairs (pp. 19-26). Cincinnati, OH: National Association of Student Personnel Administrators.

Boyer, E. L., \& Carnegie Foundation for the Advancement of Teaching. (1987). College: The undergraduate experience in America. New York, NY: Harper \& Row. 
Boyer, E.L., (1990). Campus life: In search of community. A special report of the Carnegie foundation for the advancement of teaching. Princeton, NJ: Princeton University Press.

Butts, P., Beltramini, E., Bourassa, M., Connelly, P., Meyer, R., Mitchell, S., Smith, J., \& Willis, TJ., (2012). The college union idea (2nd ed.). Stanford, CA: The Association of College Unions International.

Cheng, D. X. (2004). Students' sense of campus community: What it means, and what to do about it. Journal of Student Affairs Research and Practice, 41(2).

Chism, N., \& Bickford, D. (Eds.) (2002). The importance of physical space in creating supportive learning environments. New Directions in Teaching and Learning, 92. San Francisco: Jossey-Bass.

Chism, N. (2006). Challenging traditional assumptions and rethinking learning spaces. In D. Oblinger (Ed.), Learning spaces (pp. 2.1 - 2.12). Boulder, CO: Educause.

Chon, K., \& Maier, T. A. (2009). Welcome to hospitality: An introduction. Delmar Cengage Learning, Inc.

College Data (n.d.). Retrieved from http://www.collegedata.com.

Council for Christian Colleges \& Universities (n.d.). Retrieved from http://www.cccu.org/

Corban University (n.d.). Mission and Values. Retrieved from: https://www.corban.edu/about/mission-and-values/

Corban University (n.d.). Our History. Retrieved from: https://www.corban.edu/about/history/ 
Corban University (n.d.). The Barn. Retrieved from: https://www.corban.edu/studentlife/the-barn/

Corban University (n.d.). Residence Life. Retrieved from: https://www.corban.edu/student-life/residence-life

Council for Christian Colleges \& Universities (2017). Annual Report. Retrieved from https://www.cccu.org/wp-content/uploads/2018/01/2017-AnnualReport_WEB_pages.pdf

Council for Christian Colleges \& Universities (2018). Annual Report. Retrieved from https://www.cccu.org/wp-content/uploads/2018/12/2018-Annual-Report_web.pdf

Creswell, J. W., \& Creswell, J. D. (2018). Research design: qualitative, quantitative, and mixed methods approaches (Fifth edition.). Thousand Oaks, CA: Sage Publications, Inc.

Dober, R. (1992). Campus design. New York, NY: J. Wiley \& Sons.

Dovey, K. (2005). The silent complicity of architecture. In J. Hillier \& E. Rookskby (Eds.), Habitus: A sense of place (pp. 283-296). Aldershot: Ashgate Publishing.

Edginton, B. (2010). Architecture as therapy: A case study in the phenomenology of design. Journal of Design History, 23(1), 83-97.

Edwards, B. (2014). University architecture. Abingdon, England: Taylor \& Francis.

Fink, J. E. (2014). Flourishing: Exploring predictors of mental health within the college environment. Journal of American College Health, 62(6), 380-388. 
Frank, L. D., Sallis, J. F., Saelens, B. E., Leary, L., Cain, K., Conway, T. L., \& Hess, P. M. (2010). The development of a walkability index: Application to the neighborhood quality of life study. British Journal of Sports Medicine, 44(13).

Fontana, A., \& Frey, J. (2005). The interview: From neutral stance to political involvement. In N. K. Denzin \& Y. S. Lincoln (Eds.), The sage handbook of qualitative research ( $3^{\text {rd }}$ ed., pp. 695-727). Thousand Oaks, CA: Sage Publications, Inc.

Friedmann, J. (2005). Place-making as project? Habitus and migration in transnational cities. In J. Hillier \& E. Rooksby (Eds.), Habitus: A sense of place (pp. 315-333). Aldershot: Ashgate Publishing.

Gonzalez, G. M. (1989). Understanding the campus community: An ecological paradigm. New Directions for Student Services, Winter(48), 17-26.

Glanzer, P. L., Carpenter, J. A., \& Lantinga, N. (2011). Looking for God in the university: examining trends in Christian higher education. Higher Education, $61(6), 721-755$.

Glaser, B. G. (2016). Open coding descriptions. The Grounded Theory Review, 15(2), 108-110.

Glesne, C., \& Peshkin, A. (1992). Becoming qualitative researchers: An introduction. New York, NY: Longman.

GoogleMaps (n.d.). Corban University campus map. Retrieved from: https://www.google.com/maps/d/u/0/viewer?ll=44.883713266661225\%2C122.95836748836058\&z=17\&mid=1b6XijQukk4qwhLebCodYQxxXxmwtylTj 
Guba, E. G. (Ed.). (1990). The paradigm dialog. Thousand Oaks, CA: Sage Publications, Inc.

Hall, E. T. (1966). The hidden dimension: Man's use of space in public and private. London, UK: Bodley Head.

Hall, E.T., Birdwhistell, R.L., Bock, B., Bohannan, P., Diebold, A.R., Durbin, M., Edmonson, M.S., Fischer, J.L., Hymes, D., Kimball, S.T., La Barre, W., Lynch, F. McClellan, J.E., Marshall, D.S., Milner, G.B., Sarles, H.B., Trager, G.L., \& Vayda, A.P. (1968). Proxemics. Current anthropology, 9(2/3), 83-108.

Hall, E. T. (1971). Proxemics and design. Design and environment. 2, 24-25.

Hausmann, L. R. M., Schofield, J. W., \& Woods, R. L. (2007). Sense of belonging as a predictor of intentions to persist among African American and white first-year college students. Research in Higher Education, 48(7), 803-839.

Hightower, B. (2017). We shape our buildings (episode transcript) [Architecture blog]. Retrieved from: https://www.hi.works/ep01-transcript/

Hurtado, S. (2012). Forward. In T. Strayhorn, College students' sense of belonging: A key to educational success for all students. (pp. ix-x). New York, NY: Routledge. Jamieson, P., Fisher, K., Gilding, T., Taylor, P.G., \& Trevitt, A.C.F. (2000). Place and space in the design of new learning environments. Higher Education Research and Development, 19(2), 221-237.

JISC e-Learning Programme. (2006). Designing spaces for effective learning: A guide to 21st century learning space design. Bristol, UK: Higher Education Funding Council for England (HEFCE). 
John Brown University (n.d.). Mission, vision, values. Retrieved from: https://www.jbu.edu/president/mission-vision-values/

Jorgensen, D. L. (2015). Participant observation, in emerging trends in the social and behavioral sciences (pp. 1-15). London: Sage Publications, Inc.

Kenney, D., Dumont, R., \& Kenney, G. (2005). Mission and place: Strengthening learning and community through campus design. American Council on Education. Westport, CT: Praeger Publishers.

Kolb, A., \& Kolb, D. A. (2012). Kolb's learning styles. In N. M. Seel (Ed.), Encyclopedia of the sciences of learning (pp. 1698-1703). Boston, MA: Springer.

Kuh, G. D., Schuh, J. H., \& Whitt, E. J. (1991). Involving colleges: Successful approaches to fostering student learning and development outside the classroom. San Francisco, CA: Jossey-Bass.

Kuh, G., Kinzie J., Schuh, J., \& Whitt, E. (2005). Student success in college: Creating conditions that matter. San Francisco, CA: Jossey-Bass.

Leach, N. (2005). Belonging: Towards a theory of identification with space. In J. Hillier \& E. Rooksby (Eds.), Habitus: A sense of place (pp. 297-311). Aldershot: Ashgate Publishing.

LeCompte, M., \& Preissle, J. (1993). Ethnography and qualitative design in educational research (2nd ed.). San Diego, CA: Academic Press.

Leslie, L. L., \& Brinkman, P. T. (1988). The economic value of higher education. American Council on Education/Macmillan series on higher education. New York, NY: Macmillan Publishing. 
Magolda, P. M. (2001). What our rituals tell us about community on campus. About Campus, 5(6), 2.

Mallon, D. J. (2015). Making their place: Identifying the transformation of college space to student place, a study of individual student placemaking (Doctoral dissertation). Available from ProQuest database. (AAT 3728037).

Manning, K., \& Kuh, G. (2005). Promoting student success: Making place matter to student success (Occasional Paper No. 13). Bloomington, Indiana: Indiana University Center for Postsecondary Research.

Marten, G.G. (2001). Human ecology: Basic concepts for sustainable development. Sterling, VA: Earthscan Publications Ltd.

Maxwell, D. M. (2016). Student union transformation: A case study on creating purposeful space. Bloomington, IN: Indiana University.

Maxwell, J. A. (2013). Qualitative research design: An interactive approach (3rd ed.). Thousand Oaks, CA: Sage Publications, Inc.

McMillan, D. W., \& Chavis, D. M. (1986). Sense of community: A definition and theory. Journal of Community Psychology, 14(1), 6-23.

Meagher, B. R., \& Marsh, K. L. (2017). Seeking the safety of sociofugal space: Environmental design preferences following social ostracism. Journal of Experimental Social Psychology, 68, 192-199.

Merriam, S. B., \& Tisdell, E. J. (2016). Qualitative research: A guide to design and implementation (4th ed.). San Francisco, CA: Jossey-Bass. 
Miles, M. B., Huberman, A. M., \& Saldana, J. (2014). Qualitative data analysis: A methods sourcebook (3rd ed.). Thousand Oaks, CA: SAGE Publications.

Miller, T., Bender, B., \& Schuh, J. (2005). Promoting reasonable expectations: Aligning student and institutional views of the college experience. San Francisco, CA: Jossey-Bass/National Association of Student Personnel Administrators.

Moos, R. H. (1979). Evaluating educational environments: Procedures, measures, findings, and policy implications. San Francisco, CA: Jossey-Bass.

Oblinger, D. (2006). Learning how to see. In D. Oblinger (Ed.) Learning spaces. Boulder, CO: Educause. Retrieved from http://www.educause.edu/learningspaces. Oldenburg, R., \& Brissett, D. (1982). The third place. Qualitative Sociology, 5(4), 265284.

Oldenburg, R. (1989). The great good place: Cafes, coffee shops, bookstores, bars, hair salons, and other hangouts at the heart of a community. Philadelphia, PA: Da Capo Press.

Oldenburg, R. (1997). Making college a great place to talk. In G. Keller (Ed.), The best of planning for higher education: An anthology of articles from the premier journal in higher education planning (pp. 90-94). Ann Arbor, MI: Society for College and University Planning.

Oldenburg, R. (1997). Our vanishing “third places.” Planning Commissioners' Journal, 25(1), 6-10.

Oregon Health and Sciences University (2005, February - April). Housing the victims of the great white plague: The Oregon state tuberculosis hospital. Historical 
Collections and Archives, Oregon Health and Sciences University, Portland, OR, United States. Retrieved from: https://www.ohsu.edu/historical-collectionsarchives/housing-victims-great-white-plague-oregon-state-tuberculosis

Palmer, P. J., Zajonc, A., \& Scribner, M. (2010). The heart of higher education: A call to renewal. New York, NY: John Wiley \& Sons.

Pascarella, E. T., \& Terenzini, P. T. (2005). How college affects students. vol. 2: A third decade of research. San Francisco, CA: Jossey-Bass.

Putnam, R. D. (2000). Bowling alone: The collapse and revival of American community. New York: Simon \& Schuster.

Raisman, N. (2008). The power of retention. University Business. Retrieved from https://www.universitybusiness.com/article/power-retention

Rapoport, A. (1990). The meaning of the built environment: A nonverbal communication approach. AZ: University of Arizona Press.

Ratcliffe, M., Burd, C., Holder, K., \& Fields, A. (2016). Defining rural at the U.S. census bureau. ACSGEO-1. Washington, DC: U.S. Census Bureau.

Reeve, J.R., \& Kassabaum, D. G. (1997). A sense of place master plan: Linking mission and place. APPA Proceedings 1997, 219-228.

Reif, Z. (2014). Building community through physical space. (Doctoral dissertation). Retrieved from https://ttu-ir.tdl.org/handle/2346/60605.

Renn, K.A., \& Patton, L.D. (2010). Campus ecology and environments. In J. H. Schuh, S. R. Jones, \& S. R. Harper (Eds.), Student services: A handbook for the profession (pp. 260-275). Hoboken, NJ: John Wiley \& Sons. 
Robbins, P. R., \& Tanck, R. H. (1995). University students' preferred choices for social support. Journal of Social Psychology, 135(6), 775-776.

Rosenbaum, M. S. (2006). Exploring the social supportive role of third places in consumers' lives. Journal of Service Research, 9(1), 59-72.

Rosenberg, M., \& McCullough, B. C. (1981). Mattering: Inferred significance and mental health among adolescents. Research in Community \& Mental Health, 2, 163-182.

Saldaña, J. (2016). The coding manual for qualitative researchers (3rd ed.). London: Sage Publications, Inc.

Santasiero, E. (2002). The third place: Essential for campuses and for communities. The Lawler Review, 1, 0-13.

Schlossberg, N. K. (1989). Marginality and mattering: Key issues in building community. New Directions for Student Services, 1989(48), 5-15.

Schlossberg, N.K., Lassalle, A.D., \& Golec, R.R. (1990). The mattering scales for adult students in postsecondary education. American Council on Education. College Park, MD: University of Maryland.

Schmitz, A. (Ed.) (2012). A primer on communication studies. Retrieved from https://2012books.lardbucket.org/books/a-primer-on-communication-studies/s04nonverbal-communication.html

Schramm, W. (1971). Notes on case studies of instructional media projects. Working paper, the Academy for Educational Development, Washington, DC.

Scott-Webber, L. (2004). Environmental behavior research and the design of learning spaces. Ann Arbor, MI: Society for College and University Planning. 
Scott-Webber, L. (2017). Challenge: 4000 years of behavioral conditioning define the designs of face-to-face classrooms, next generation learning environments. In N. Alias \& J. Luaran, (Eds.), Student-driven learning strategies for the $21^{\text {st }}$ century classroom (pp. 10-25). Hershey, PA: IGI Global.

Scott-Webber, L., Konyndyk, R., French, R., \& French, J. (2018). Significant results: Space makes a difference increasing student academic engagement levels. (Report). European Scientific Journal, 14(16), 61.

Seamon, D. (1979). A geography of the lifeworld: Movement, rest and encounter ( $1^{\text {st }}$ ed.). London: Croon Helm.

Seamon, D. (2015). A geography of the lifeworld: Movement, rest and encounter $\left(2^{\text {nd }}\right.$ ed.). NY: Routledge.

Seidman, I. (2013). Interviewing as qualitative research: A guide for researchers in the social sciences (4th ed.). New York, NY: Teachers College Press.

Sensbach, W. (1997). Restoring the values of campus architecture. In G. Keller (Ed.), The best of planning for higher education: An anthology of articles from the premier journal in higher education planning (pp. 80-89). Ann Arbor, MI: Society for College and University Planning.

Smith, G. A. (1992). Education and the environment: Learning to live with limits. SUNY Press.

Spitzberg, I. J., \& Thorndike, V. V. (1992). Creating community on college campuses: Beyond the cultural politics of enjoyment. NY: SUNY Press. 
Stage, F. K., Muller, P., Kinzie, J., \& Simmons, A. (1998). Creating learning centered classrooms. What does learning theory have to say? ASHE-ERIC higher education report, 26(4).

Strange, C. C., \& Banning, J. H. (2001). Educating by design: Creating campus learning environments that work. San Francisco, CA: Jossey-Bass.

Strange, C. C., \& Banning, J. H. (2015). Designing for learning: Creating campus learning environments for student success ( 2 nd ed.). San Francisco, CA: JosseyBass.

Strayhorn, T. (2012). College students' sense of belonging: A key to educational success for all students. New York, NY: Routledge.

Taub, D. J. (1998). Building community on campus: Student affairs professionals as group workers. The Journal for Specialists in Group Work, 23(4), 411-427.

Temple, P. (2007). Learning spaces for the 21st century. Retrieved from https://www.researchgate.net/profile/Paul_Temple2/publication/237472897_Lear ning_spaces_for_the_21st_century_A_review_of_the_literature/links/02e7e 52ce7 883a7ed3000000/Learning-spaces-for-the-21st-century-A-review-of-theliterature.pdf

Temple, P. (2008). Learning spaces in higher education: An under-researched topic. London Review of Education, 6(3), 229-241.

Temple, Paul. (2009). From space to place: university performance and its built environment. Higher Education Policy, 22(2), 209-223. 
Tierney, W. G. (1993). Building communities of difference: Higher education in the twenty-first century. Greenwood Publishing Group.

Tinto, V. (2001). Rethinking the first year of college. Higher Education Monograph Series. Syracuse, NY: Syracuse University.

Tinto, V. (2003). Learning better together: The impact of learning communities on student success. Higher Education Monograph Series. NY: Syracuse University.

Tracy, K. (1995). Action-implicative discourse analysis. Journal of Language and Social Psychology, 14(1-2), 195-215.

Tracy, S. J. (2012). Qualitative research methods: Collecting evidence, crafting analysis, communicating impact. New York, NY: J. Wiley \& Sons.

U.S. Department of Education (n.d.). College Scorecard, Find Schools/Size. Retrieved from: https://collegescorecard.ed.gov/

US News and World Report (2019). Azusa Pacific University. Retrieved from: https://www.usnews.com/best-colleges/azusa-pacific-university-1117

US News and World Report (2019). Wheaton College. Retrieved from: https://www.usnews.com/best-colleges/wheaton-college-1781

US News and World Report (2019). John Brown University. Retrieved from: https://www.usnews.com/best-colleges/john-brown-university-1100

Vandegrift, A. (2012). Oregon led the fight against TB with the first state hospital. Salem, OR: Willamette Heritage Center.

Vischer, J. C. (2008). Towards a user-centred theory of the built environment. Building Research \& Information, 36(3), 231-240. 
Walsh, W. B. (1973). Theories of person-environment interaction: Implications for the college student. Iowa City, Iowa: American College Testing Program.

Walsh, W. B. (1978). Person/environment interaction. In J. H. Banning (Ed.), Campus ecology: A perspective for student affairs (pp. 7-18). OH: National Association of Student Personnel Administrators.

Warren, C. (2001). Qualitative interviewing. In Gubrium, J.F. \& Holstein, J.A. (Eds.), Handbook of interview research: Context and method (pp. 83-101). Thousand Oaks, CA: Sage Publications.

Waxman, L. (2006). The coffee shop: Social and physical factors influencing place attachment. Journal of Interior Design, 31(3), 35-53.

Waxman, L., Clemons, S., Banning, J., \& McKelfresh, D. (2007). The library as place: Providing students with opportunities for socialization, relaxation, and restoration. New Library World, 108(9/10), 424-434.

Wheaton College (n.d.). The value of a Wheaton education. Retrieved from: https://www.wheaton.edu/academics/the-value-of-a-wheaton-education/

Yin, R, K. (2018). Case study research and applications: Design and methods (6 ${ }^{\text {th }}$ ed.). Thousand Oaks, CA: Sage Publications. 


\section{APPENDIX A: PARTICIPANT EMAIL INVITATIONS}

\section{A1: Student Participant Email}

\section{DATE}

\section{Dear [INSERT FIRST NAME],}

My name is Kim Stave and I am currently a doctoral student at Portland State University collecting data for my dissertation research on your campus. I am conducting an exploratory study to assess if campus buildings/spaces are important for developing campus community, and more specifically, if you have a location(s) on your campus that you feel contributes positively to your personal sense of belonging at [INSERT UNIVERSITY NAME].

After spending many years working in Student Affairs at Christian Universities, I have developed some great contacts in your Student Life department who recommended your name as a student who might have some interest and insights to offer my study!

If you choose to participate, involvement in the study will include the following:

- Reading and signing an informational consent form explaining the study and your role in it, along which you will be provided opportunity to ask questions

- Scheduling and participating in a 1-hour in-person audio-recorded interview with the researcher to occur on your campus

Successful completion of the above-mentioned involvement will result in compensation of a $\$ 20$ gift card to a coffee shop on your campus.

If possible, please reply within 5 business days of the date of this email informing me if you have interest in participating in this study.

I appreciate your consideration of participation in my research!

Sincerely,

Kim Stave, Doctoral Student

Portland State University

College of Education 


\section{A2: Employee Participant Email}

\section{DATE}

\section{Dear [INSERT FIRST NAME],}

My name is Kim Stave and I am currently a doctoral student at Portland State University collecting data for my dissertation research on your campus. I am conducting an exploratory study to assess if campus buildings/spaces are important for developing campus community and learn which location(s) on your campus students feel contributes positively to their personal sense of belonging at [INSERT UNIVERSITY NAME]. Specifically, for you as an employee, I am seeking to hear your perceptions of how the institution demonstrates its stated value of student community through built campus space.

After spending many years working in Student Affairs at Christian Universities, I have developed some great contacts in your Student Life department who recommended your name as a colleague who engages with students in community-building spaces and who might have some interest and insights to offer my study.

If you choose to participate, involvement in the study will include the following:

- Reading and signing an informational consent form explaining the study and your role in it, along which you will be provided opportunity to ask questions

- Scheduling and participating in a 1-hour in-person audio-recorded interview with the researcher to occur on your campus

Successful completion of the above-mentioned involvement will result in compensation of a $\$ 20$ gift card to a coffee shop on your campus.

If possible, please reply within 5 business days of the date of this email informing me if you have interest in participating in this study. I appreciate your consideration of participation in my research!

Sincerely, Kim Stave, Doctoral Student Portland State University College of Education 


\section{APPENDIX B: CONSENT TO PARTICIPATE IN RESEARCH}

Project Title: In Search of a Third Place on Campus: An Exploration of the Effects of Built Space on Students' Sense of Belonging

Researcher: $\quad$ Kim Stave, College of Education

Portland State University

Researcher Contact: kstave@pdx.edu / 863.414.0945

You are being asked to take part in a research study. The box below highlights key information about this research for you to consider when making a decision whether or not to participate. Carefully review the information provided on this form. Please ask questions about any of the information you do not understand before you decide to participate.

Key Information for You to Consider

Voluntary Consent. You are being asked to volunteer for a research study. It is up to you whether you choose to participate or not. There is no penalty if you choose not to participate or discontinue participation.

Purpose. The purpose of this research is to explore if college students at a small, rural, residential university have a location on campus they perceive contributes positively to their sense of belonging at their institution, and to determine if built campus environments are important for supporting an institutional commitment to a vibrant student community.

Duration. It is expected that your participation will last no more than one hour.

Procedures and Activities. You will be asked to meet with the researcher and answer interview questions regarding your experience of particular spaces on campus.

Risks. Some of the minimal foreseeable risks or discomforts of your participation include potentially telling the researcher about behaviors you have witnessed within particular campus spaces. However, all personally-identifying information will be removed from the study during the interview transcription process. If you are identifiable in any photograph utilized by the researcher, your express permission will be requested prior to the photograph being used for the study.

Benefits. Some of the benefits that may be expected include: No direct benefits, but the researcher hopes to gain new understandings of how students experience the physical spaces on their campus and hopes this research can be transferrable to other similar universities to demonstrate the importance of including intentionally-designed community-building spaces on campus.

Alternatives. As an alternative to participation, you could: Participation is voluntary and the only alternative is to not participate. 


\section{What happens to the information collected?}

Information collected for this research will be used toward the fulfillment of the researcher's doctoral dissertation, with the intention of future publishing the study.

\section{How will my privacy and data confidentiality be protected?}

We will take measures to protect your privacy including removing all personallyidentifying information and assigning pseudonyms to each participant. If participants are identifiable in photographs, those photographs will not be published in the final student without direct participant permission. Despite taking steps to protect your privacy, I can never fully guarantee that your privacy will be protected.

Individuals and organizations that conduct or monitor this research may be permitted access to inspect research records. This may include private information. These individuals and organizations include the Institutional Review Board that reviewed this research and potentially members of the researcher's dissertation committee.

\section{What if I want to stop participating in this research?}

Your participation is voluntary. You do not have to take part in this study, but if you do, you may stop at any time. You have the right to choose not to participate in any study activity or completely withdraw from participation at any point without penalty or loss of benefits to which you are otherwise entitled. Your decision whether or not to participate will not affect your relationship with the researcher or Portland State University.

\section{Will I be paid for participating in this research?}

Compensation of a $\$ 20$ gift card to a campus coffee shop will be provided to all participants upon completion of participation.

\section{Who can answer my questions about this research?}

If you have questions, concerns, or have experienced a research related injury, contact:

The Researcher: OR The Research Advisor:

Kim Stave Dr. Karen Haley

863.414.0945 $\quad 503.725 .8270$

kstave@pdx.edu_ khaley@pdx.edu

\section{Who can I speak to about my rights as a research participant?}

The Portland State University Institutional Review Board ("IRB") is overseeing this research. The IRB is a group of people who independently review research studies to ensure the rights and welfare of participants are protected. The Office of Research Integrity is the office at Portland State University that supports the IRB. 
If you have questions about your rights, or wish to speak with someone other than the researcher or research advisor, you may contact:

Office of Research Integrity

PO Box 751

Portland, OR 97207-0751

Phone: (503) 725-5484

Toll Free: 1 (877) 480-4400

Email: hsrrc@pdx.edu

\section{Consent Statement}

I have had the opportunity to read and consider the information in this form. I have asked any questions necessary to make a decision about my participation. I understand that I can ask additional questions throughout my participation.

By signing below, I understand that I am volunteering to participate in this research. I understand that I am not waiving any legal rights. I have been provided with a copy of this consent form. I understand that if my ability to consent for myself changes, either I or my legal representative may be asked to provide consent prior to me continuing in the study.

I consent to participate in this study.

\section{Name of Adult Participant} Signature of Adult Participant Date

Researcher Signature (to be completed at time of informed consent) I have explained the research to the participant and answered all of his/her questions. I believe that he/she understands the information described in this consent form and freely consents to participate. 


\section{APPENDIX C: PARTICIPANT INTERVIEW QUESTIONS}

\section{C1: Student Interview Protocol}

The interview will begin with the researcher introducing the study (including the purpose and research questions), providing definitions of key concepts (third place, community, sense of belonging), a review of the interview format (categories of questions, interview time frame, number of participants), a broad overview of the methodology (how remaining data is collected through employee interviews \& campus observations, transcription with pseudonyms assigned, identifying photos used only with permission, timeline for study completion), and an invitation for participant questions.

\section{Part I: Demographic/Background Information}

1. Please state your first \& last name, major, class standing, Christian Affiliation/Denomination (if any).

2. Which campus residence do you live in?

3. How many semesters have you lived in campus housing prior to this one?

4. Can you sum up in 1 sentence why you chose to attend [UNIVERSITY NAME]?

5. What has been the most meaningful part of your overall college experience here so far?

\section{Part II: Experience with Built Campus Space}

6. Tell me about the space on campus you most frequently hang out with groups of students?

Prompts as needed:

a. What physical qualities in the space make it attractive/comfortable to you?

b. Are there social dynamics present in the space that make it more attractive/comfortable to you? (e.g. certain people are there/aren't there; types of conversations that typically occur, etc.?)

c. How frequently do you go there?

d. Is there a specific time of day you tend to go more consistently?

e. How much time do you typically spend there?

f. What are the activities you engage in the most consistently there?

g. Who is there? Mostly the same people, or does it vary?

$\mathrm{h}$. Is the location open/available for any student at the university to be there, or is the space accessible (either literally or perceived) as being available to specific students? (e.g. a residence hall lounge for residents only or an athletics lounge for athletes only, etc.)

7. Do you have any other spaces on campus that you frequently hang out with groups? If so, tell me about them. 


\section{Part III: Perception of the Influence of the Space}

Following the discussion of specific space/s on campus, the researcher will explain that the questions will now transition to the participant's perception of the influence the space may have on them. After each question is read, the definition of each corresponding concept (third place and sense of belonging, respectively) will be read to refresh the participant's memory.

8. Tell me about the ways the space/s meets the descriptions of a third place to you?

9. Do you think there are ways the space/s contributes to you feeling more connected to the larger university community? If so, describe how.

10. Similarly, are there ways you think the space/s contributes to your personal sense of belonging to the university community? Please describe.

11. If the identified space/s does not help you feel connected/or contribute to a sense of belonging, what could change about the space to help it accomplish those things?

12. Is there anything else on this topic that you'd like to tell me?

\section{C2: Employee Interview Protocol}

The interview will begin with the researcher introducing the study (including the purpose and research questions), providing definitions of key concepts (third place, community, sense of belonging), a review of the interview format (categories of questions, interview time frame, number of participants), a broad overview of the methodology (how remaining data is collected through student interviews \& campus observations, transcription with pseudonyms assigned, identifying photos used only with permission, timeline for study completion), and an invitation for participant questions.

\section{Part I: Demographic/Background Information}

1. First \& last name, position title, department, length of time in position/at institution

2. Positional relationship to building student community

3. Relationship to/involvement with spaces where students spend time on campus

\section{Part II: Experience with Built Campus Space}

4. Tell me about the locations on campus you see students frequently "hanging out" socially?

Prompts as needed:

a. What are the physical qualities of the space? What do you think makes it attractive/comfortable to students? (e.g. comfortable furniture/layout; music; seating arrangement, etc.)?

b. Are there specific times of day students tend to go more there more consistently?

c. Do you have a sense of how much time students typically spend when they go?

d. What are the activities students engage in the most consistently there?

e. How is the space promoted by the university (Who is it for? What is the messaging around its use)? 
f. How is the space perceived by students? (Is it seen as open/available for any student at the university to be there, or is it perceived as being available only to specific students? e.g. a residence hall lounge for residents only or an athletics lounge for athletes only, etc.)

5. Are there other spaces like this on campus? If so, please tell me about them.

Prior to the next question being read, the definition of third place will be read to refresh the participant's memory.

6. In what ways do you perceive the space/s you described meets the description of a third place for students?

\section{Part III: Perception of the Institutions Values}

7. Tell me about the institution's stance on/value of student community?

a. How were you made aware of this stance/value?

8. If there is an institutional commitment to student community building, do you believe the built spaces on your campus promote that commitment/value?

a. How/Why?

b. Why not?

9. Are you aware of the institutional administration's personal views on and/or commitments to fostering student community on campus?

a. If so, how are you aware of this? How do you know if it is valued?

b. In your opinion, do students know this is an institutional value? If so, how?

10. Is there anything else on this topic that you'd like to tell me? 


\section{APPENDIX D: PRE- AND POST- INTERVIEW FIELDNOTE FRAMEWORK}

\section{D1: Pre-Interview Fieldnote Observation Structure}

Prior to participant interviews, a campus map will be reviewed and general observations will be made of built spaces on campus the researcher anticipates as a space which could promote community building among students. Observations will occur during perceived high-student access times. Field notes and photographs will be utilized for documentation. The following framework will be utilized in each space:

\section{LOCATION D1a: (repeat for multiple locations)}

- Time of day/day of week

- Total time spent in space

- Type (purpose, name, etc.) of facility housing the space, if any

- Location Identifier on Campus Map

- General location on campus:

- Located along a high foot traffic-area, or more remote location on campus?

- Combined in facility with other high-use amenities that appears to attract students?

- External \& Internal way-finding signage:

- Easily identifiable \& navigable?

- Identified purpose of space (if any)

- Number of students currently within space

- What are the general activities happening within the space?

○ Does the space have posted hours? If so, what are they? 


\section{D2: Post-Interview Fieldnote Observation Structure}

Following participant interviews, the researcher will observe the location(s) identified by participants as meeting the criteria for a third place on campus, if possible, at the specified time(s) the participant identified as being there most consistently.

Beyond the following criteria utilized in the pre-interview observations, the researcher will note tangible validation of participant reports regarding the space and any potential impact on users.

\section{LOCATION D2a: (repeat for multiple locations)}

○ Time of day/day of week

- Total time spent in space

- Type (purpose, name, etc.) of facility housing the space, if any

- Location Identifier on Campus Map

- General location on campus:

- Located along a high foot traffic-area, or more remote location on campus?

- Combined in facility with other high-use amenities that appears to attract students?

- External \& Internal way-finding signage:

- Easily identifiable \& navigable?

$\circ \quad$ Identified purpose of space (if any)

- Number of students currently within space

- What are the general activities happening within the space?

- Does the space have posted hours? If so, what are they? 


\section{APPENDIX E: ANTICIPATED PROVISIONAL CODES}

Appendix E contains an outline for the first stage of the study's data coding process, which is the creation of data categories, or provisional codes (Saldana, 2016). These codes are generated from the study's conceptual framework and research questions, literature related to the study, and the researcher's prior knowledge and experience on the topics of the study. The provisional codes are organized within the context of the study's conceptual framework (campus ecology), theoretical frameworks (third place and sense of belonging), and site category (institutions with value of student community; namely the Council for Christian Colleges and Universities).

\section{Campus Ecology}

- Influence - macro

- Influence - micro

- Transactional relationship (space-on-person/person-on-space)

- Feeling supported by space

- Space design - general

- Sociofugal (designed to inhibit social interactions)

- Sociopetal (designed to enhance social interactions)

- Classroom design

- Living area design

- Community space design

- Natural Space/Nature

- Built Space/Physical

- Accommodations/accessibility

- Social Space

- Personal bubble

- Designed for learning

\section{Sense of Belonging}

- Spatial stories/memories of spaces

- Personalization of space

- Sense of place/“my place”/ownership

- Safe space - emotional

- Safe space - physical

- Learning in community

- Living in community

- Acceptance/inclusion

- Acceptance/inclusion - minorities

- Validation 
- Mattering

- Belonging

- Common affinity space

- Cultural identity

- Shared purpose

- Good fit

- Friendships

- Campus involvement - high

- Campus involvement - low

- Campus tradition

- University mission/values

- Community-building activities

\section{Third Place}

- Community-building gathering spaces

- Coffee/coffee shop

- Conversation

- Social engagement

- Sense of home

- Loyalty

- Friends like family

- Consistent clientele/regulars

- Lingering/long time spent

- Rootedness

- Favorite seat

- Emotional renewal

- Celebration/joy

- Self-expression

- Mutual respect/trust

- Hospitality

- Ordinary - physical space

- Ordinary - people

- Human scale/intimate space

- Accessible by foot

- Comfortable furniture

- Third place - off campus

- Third place - on campus 


\section{$\mathrm{CCCU}$}

- Community related to Christian theology

- Community related to institutional value

- Community as defining characteristic

- Relational campus culture 


\section{APPENDIX F: CORBAN UNIVERSITY CAMPUS MAP}

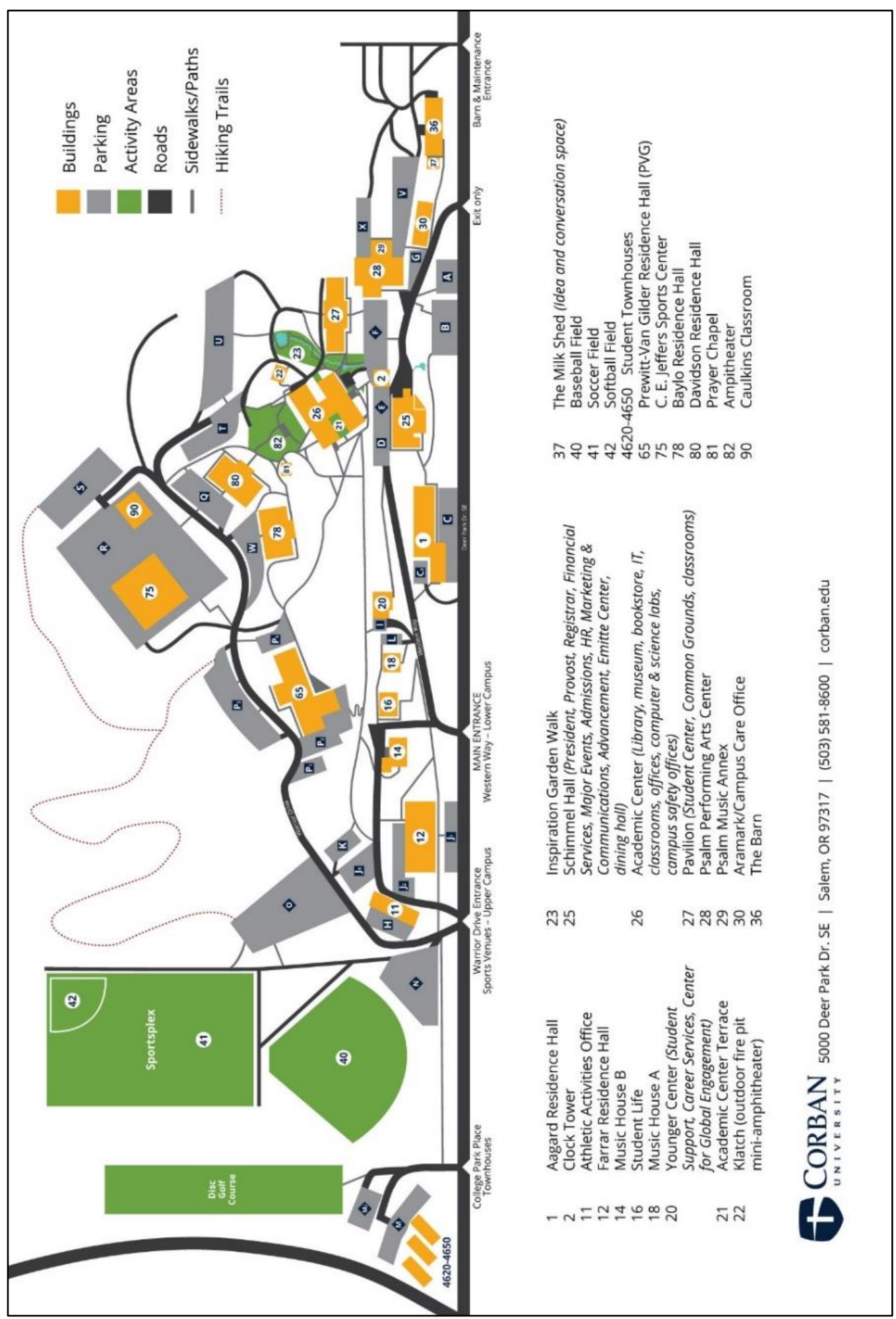

